\title{
Waste Treatment Plant Support Program: Summaries of Reports Produced During Fiscal Years 1999-2010
}

GH Beeman

August 2010

\section{Pacific Northwest}

NATIONAL LABORATORY

Proudly Operated by Battelle Since 1965 


\title{
DISCLAIMER
}

This report was prepared as an account of work sponsored by an agency of the United States Government. Neither the United States Government nor any agency thereof, nor Battelle Memorial Institute, nor any of their employees, makes any warranty, express or implied, or assumes any legal liability or responsibility for the accuracy, completeness, or usefulness of any information, apparatus, product, or process disclosed, or represents that its use would not infringe privately owned rights. Reference herein to any specific commercial product, process, or service by trade name, trademark, manufacturer, or otherwise does not necessarily constitute or imply its endorsement, recommendation, or favoring by the United States Government or any agency thereof, or Battelle Memorial Institute. The views and opinions of authors expressed herein do not necessarily state or reflect those of the United States Government or any agency thereof.

\author{
PACIFIC NORTHWEST NATIONAL LABORATORY \\ operated by \\ BATTELLE \\ for the \\ UNITED STATES DEPARTMENT OF ENERGY \\ under Contract DE-AC05-76RL01830
}

Printed in the United States of America
Available to DOE and DOE contractors from the Office of Scientific and Technical Information,
P.O. Box 62, Oak Ridge, TN 37831-0062;
ph: (865) 576-8401
fax: $(865)$ 576-5728
email: reports@adonis.osti.gov

\begin{abstract}
Available to the public from the National Technical Information Service, U.S. Department of Commerce, 5285 Port Royal Rd., Springfield, VA 22161 ph: (800) 553-6847 fax: $(703) 605-6900$ email: orders@ntis.fedworld.gov online ordering: http://www.ntis.gov/ordering.htm
\end{abstract}

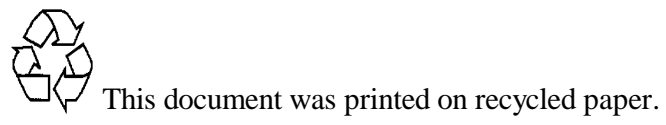





\title{
Waste Treatment Plant Support Program: Summaries of Reports Produced During Fiscal Years 1999-2010
}

\author{
GH Beeman
}

August 2010

Prepared for

the U.S. Department of Energy

under Contract DE-AC05-76RL01830

Pacific Northwest National Laboratory

Richland, Washington 99352 

PNNL-19648

\section{Foreword}

The Waste Treatment Plant (WTP) being built on the U.S. Department of Energy (DOE) Hanford Site will be the largest radioactive waste treatment plant in the world. Bechtel National Inc. (BNI) is responsible for the design, construction and commissioning of the WTP. The Pacific Northwest National Laboratory (PNNL) has provided significant research and testing support to the WTP. This report provides a summary of reports developed initially under PNNL's "1831" use agreement and later PNNL's "1830" prime contract with DOE in support of the WTP.

In March 2001, PNNL under its "1831" use agreement entered into a contract with BNI to support their research and testing activities. However, PNNL support to the WTP predates BNI involvement. Prior to March 2001, PNNL supported British Nuclear Fuels Ltd. in its role as overall designer and constructor. In February 2007, execution of PNNL's support to the WTP was moved under its "1830" prime contract with DOE.

Documents numbered "PNWD-XXXX" were issued under PNNL's "1831" use agreement. Documents numbered "PNNL-XXXX" were issued under PNNL's "1830" prime contract with DOE. The documents are sorted by fiscal year and categorized as follows:

- Characterization

- HLW (High Level Waste)

- Material Characterization

- Pretreatment

- Simulant Development

- Vitrification

- Waste Form Qualification.

This report is intended to provide a compendium of reports issued by PNWD/PNNL in support of the Waste Treatment Plant. Copies of all reports can be obtained by clicking on http://www.pnl.gov/rpp-wtp/ and downloading the .pdf file(s) to your computer. 



\section{Definitions of Frequently Used Terms}

$\begin{array}{ll}\text { BNFL } & \text { British Nuclear Fuels Ltd. } \\ \text { BNI } & \text { Bechtel National Inc. } \\ \text { CUF } & \text { Cells Unit Filter } \\ \text { DOE } & \text { U.S. Department of Energy } \\ \text { EFRT } & \text { External Flowsheet Review Team } \\ \text { HLW } & \text { high-level waste } \\ \text { IHLW } & \text { immobilized high-level waste } \\ \text { ILAW } & \text { immobilized low-activity waste } \\ \text { LAW } & \text { low-activity waste } \\ \text { ORP } & \text { U.S. Department of Energy Office of River Protection } \\ \text { PEP } & \text { Pretreatment Engineering Platform } \\ \text { PJM } & \text { pulsed jet mixer } \\ \text { PNNL } & \text { Pacific Northwest National Laboratory } \\ \text { PNWD } & \text { Battelle-Pacific Northwest Division } \\ \text { QA } & \text { quality assurance } \\ \text { QC } & \text { quality control } \\ \text { RPP-WTP } & \text { River Protection Project-Waste Treatment Plant } \\ \text { TRU } & \text { transuranic waste } \\ \text { UFP } & \text { ultrafiltration process } \\ \text { WTP } & \text { Waste Treatment Plant }\end{array}$





\section{Contract Reports}

\section{PNWD-2463 (BNFL-RPT-003, Rev. 1) - Inorganic and Radiochemical Analysis of AW-101 and}

AN-107 “Diluted Feed” Materials

\section{Focus Area: Characterization}

The inorganic and radiochemical analyses for diluted feed materials from Hanford tanks AW-101 and AN-107 are documented in this report. The analyses were conducted by PNWD in support of BNFL efforts to verify and qualify the waste treatment processes proposed for the WTP. The inorganic and radiochemical analysis results obtained from the diluted feed materials provided initial characterization information for subsequent process testing.

The characterization analyses of the diluted feed material for AW-101 and AN-107 include

- inductively-coupled plasma spectrometry for $\mathrm{Ag}, \mathrm{Al}, \mathrm{Ba}, \mathrm{Ca}, \mathrm{Cd}, \mathrm{Co}, \mathrm{Cr}, \mathrm{Cu}, \mathrm{Fe}, \mathrm{K}, \mathrm{La}, \mathrm{Mg}, \mathrm{Mn}, \mathrm{Mo}$, $\mathrm{Na}, \mathrm{Ni}, \mathrm{Pb}, \mathrm{Si}, \mathrm{Ti}, \mathrm{U}, \mathrm{Zn}$, and $\mathrm{Zr}$

- radiochemical analyses for total alpha and total beta activity, Am-241, Cs-137, Cm-243+244, Eu-154, Eu-155, Sr-90

- kinetic phosphorescence for total uranium

- ion chromatography for $\mathrm{Cl}^{-}, \mathrm{F}^{-}, \mathrm{NO}_{3}^{-}, \mathrm{PO}_{4}{ }^{-3}$, and $\mathrm{SO}_{4}{ }^{-2}$

- inductively-coupled plasma mass spectrometry for Tc-99

- free hydroxide determination

- total inorganic and organic carbon

- $\mathrm{pH}$ measurements.

PNWD also measured As, Ce, Cs, Nd, P, Sr, Y, Co-60, Cs-134, Pu-238, Pu-239+240, Cm-242, Br, $\mathrm{NO}_{2}^{-}$, and $\mathrm{C}_{2} \mathrm{O}_{2}{ }^{-2}$ and included the results in this report for information only.

All analytes of interest are reported, with estimated method detection limits provided where analytes of interest are not detected. Per the Quality Assurance (QA) Plan analysis protocols, process blanks, samples, duplicates, blank spikes (or lab control standards) and matrix spikes (or post spikes) were analyzed, as appropriate. This report presents only the results for the process blanks, samples, and duplicates. Recoveries for quality control samples (such as matrix spikes and blank spikes) are discussed in this report and evaluated for effect on reported results if they fail to meet the relevant QA acceptance criteria.

PNWD-2462 (BNFL-RPT-008) - Inorganic and Radiochemical Analysis of AW-101 and AN-107 Tank Waste

\section{Focus Area: Characterization}

This report presents the inorganic and radiochemical analyses for as-received materials from Hanford tanks AW-101 and AN-107. The analyses were conducted by PNWD in support of BNFL work to qualify and verify waste treatment processes for the WTP. The inorganic and radiochemical analysis results obtained from the as-received materials provided initial characterization information for subsequent process testing and to provide data to support permit application activities. 
All inorganic and radiochemical analytes of interest defined by these documents, except cyanide, mercury, carbon-14, and flashpoint are reported ${ }^{1}$, with estimated method detection limits provided where analytes of interest are not detected.

The characterization analyses of the as-received material for AW-101 and AN-107 waste included

- inductively-coupled plasma spectrometry for $\mathrm{Ag}, \mathrm{Al}, \mathrm{As}, \mathrm{B}, \mathrm{Ba}, \mathrm{Be}, \mathrm{Bi}, \mathrm{Ca}, \mathrm{Cd}, \mathrm{Co}, \mathrm{Cr}, \mathrm{Cu}, \mathrm{Fe}, \mathrm{K}, \mathrm{Li}$, $\mathrm{Mg}, \mathrm{Mn}, \mathrm{Mo}, \mathrm{Na}, \mathrm{Ni}, \mathrm{P}, \mathrm{Pb}, \mathrm{Pd}, \mathrm{Rh}, \mathrm{Sb}, \mathrm{Se}, \mathrm{Si}, \mathrm{Sn}, \mathrm{Tl}, \mathrm{U}, \mathrm{V}, \mathrm{W}, \mathrm{Y}, \mathrm{Zn}$, and Zr. (Note: Although not specified in the test plan, $\mathrm{Ce}, \mathrm{La}, \mathrm{Nd}$, and $\mathrm{Sr}$ also were measured and reported for information only.)

- radiochemical analyses for total alpha and total beta activity, H-3, C-14, Co-60, Se-79, Sr-90/Y-90, Nb-94, Ru-106/Rh-106, Sb-125, Sn-126, Cs-134, Cs-137, Eu-154, Eu-155, Pu-238, Pu-239+240, $\mathrm{Pu}-241, \mathrm{Am}-241$ (by GEA and AEA), Cm-242, and Cm-243+244

- inductively-coupled mass spectrometry for Pt, Ta, Tc-99, I-129, U-233, U-234, U-235, U-236, Np-237, U-238, Pu-239, Pu-240

- total uranium by kinetic phosphorescence

- ion chromatography for $\mathrm{Br}^{-}, \mathrm{Cl}^{-}, \mathrm{F}^{-}, \mathrm{NO}_{2}{ }^{-}, \mathrm{NO}_{3}{ }^{-}, \mathrm{PO}_{4}{ }^{-3}$, and $\mathrm{SO}_{4}{ }^{-2}$. (Note: oxalate, $\mathrm{C}_{2} \mathrm{O}_{2}{ }^{-2}$, was also measured and reported for information only.)

- mercury, cyanide, ammonia, and inorganic and organic carbon

- free hydroxide and $\mathrm{pH}$ determination (supernatant only)

- flashpoint determinations (supernatant only).

Per the analysis protocols established by the QA Plan, process blanks, samples, duplicates, blank spikes (or laboratory control standards) and matrix spikes (or post spikes) were analyzed, as appropriate. Recoveries for quality control samples (such as matrix spikes and blank spikes) are discussed in this report and evaluated for their effect on the reported results if they fail to meet the acceptance criteria of the QA Plan. This report presents the inorganic (including toxicity characteristic leaching procedure metals) and radiochemical results obtained to date. Organic results are reported in BNFL-RPT-001 (PNWD-2461).

\section{PNWD-2461 (BNFL-RPT-001, Rev. 1) - Organic Analysis of AW-101 and AN-107 Tank Waste}

\section{Focus Area: Characterization}

PNWD received 30 jars of waste material from Tank AW-101 and 17 jars of waste material from Tank AN-107. The contents of all jars of AW-101 were mixed to provide a single composite, as were the contents of all jars of AN-107. Each composite was homogenized, and representative subsamples were extracted for organic, radiochemical, and inorganic regulatory analyses.

The representative subsamples were analyzed for analytes of interest. The organic characterization analyses of the as-received material for AW-101 and AN-107 include:

- volatile organic analysis

- semi-volatile organic analysis

- polychlorinated biphenyls and pesticides

- polychlorinated dibenzo-p-dioxins and polychlorinated dibenzofurans

- oxalate, formate, acetate, and acrylate by ion chromatography

${ }^{1}$ Cyanide, mercury, carbon-14 and flashpoint were to be reported in a revision to this report but the revision was not published. 
- ethanol, methanol, 2-propanol, 1-propanol, n-butanol, triethylamine, 2-methyl-2-propanol, and 2-butanol by headspace analysis.

This report presents the organic results. The inorganic (including toxicity characteristic leaching procedure metals) and radiochemical results are reported in report BNFL-RPT-008 (PNWD-2462). Whenever possible the analyses were performed to SW-846 protocols so that the results may be used to support permitting activities as well as to provide limited characterization information for subsequent process testing.

\section{PNWD-3000 (BNFL-RPT-002) - Ultrafiltration and Characterization of AW-101 Supernatant and Entrained Solids}

\section{Focus Area: Characterization and Pretreatment}

One of the applications of crossflow filtration is to remove the entrained solids from Envelope A supernatants retrieved from the Hanford waste tanks. The filtration should remove sufficient solids to prevent plugging of the ion exchange column downstream and to ensure that insoluble ${ }^{90} \mathrm{Sr}$ and transuranic isotopes are removed.

The objective of the work described in this report was to test crossflow filtration using actual Envelope A Hanford tank waste. PNWD evaluated the permeability of an Envelope A feed through a single-element filter as a function of transmembrane pressure, axial velocity, solids concentration, and time. In addition, the efficiency of back pulse and chemical cleaning on the filter performance was evaluated. The chemical and radiochemical composition of the filtrate and solids was measured to determine efficiency of the filtration process.

This report describes the test apparatus, experimental approach, results of the tests, and the chemical and radiochemical analysis for supernatants and entrained solids taken from Hanford Tank AW-101.

\section{PNWD-2466 (BNFL-RPT-004) - AW-101 Entrained Solids - Solubility Versus Temperature}

\section{Focus Area: Pretreatment}

This report describes a test conducted by PNWD to assess the solubility of the solids entrained in the diluted AW-101 LAW sample. PNWD diluted the AW-101 sample using deionized water to mimic expected plant operating conditions. The solubility of the solids present in the diluted AW-101 sample was then assessed versus temperature conditions of 30,40 , and $50^{\circ} \mathrm{C}$. The tests were conducted to assess the composition of the LAW supernatant and solids versus expected plant operating conditions.

\section{PNWD-2464 (BNFL-RPT-005) - AN-107 Entrained Solids - Solubility Versus Temperature}

\section{Focus Area: Pretreatment}

This report describes a test conducted by PNWD to assess the solubility of the solids entrained in the diluted AN-107 LAW sample. PNWD diluted the AN-107 sample using deionized water to mimic expected plant operating conditions. The solubility of the solids present in the diluted AN-107 sample was then assessed versus temperature conditions of 30,40 , and $50^{\circ} \mathrm{C}$. The tests were conducted to assess the composition of the LAW supernatant and solids versus expected plant operating conditions. 


\section{PNWD-2465 (BNFL-RPT-006) - Washing of the AW-101 Entrained Solids}

\section{Focus Area: Pretreatment}

This report describes the test conducted by PNWD to assess the effects of inhibited water washing on the composition of the entrained solids in the diluted AW-101 LAW sample. The objective of this work was to gather data on the solubility of the AW-101 entrained solids in $0.01 \mathrm{M} \mathrm{NaOH}$ so that BNFL could evaluate whether these solids require caustic leaching. Based on the results of the $0.01 \mathrm{M} \mathrm{NaOH}$ washing, BNFL decided to not proceed with the caustic leaching test. The composition of the washed solids was such that caustic leaching would not result in significant reduction in the immobilized HLW volume.

\section{PNWD-2469 (BNFL-RPT-007) - Washing of the AN-107 Entrained Solids}

\section{Focus Area: Pretreatment}

BNFL requested PNWD test inhibited water $(0.01 \mathrm{M} \mathrm{NaOH})$ and caustic leaching $(3 \mathrm{M} \mathrm{NaOH})$ as methods for pretreating the solids entrained in the AN-107 sample. These methods are meant to remove certain nonradioactive components (e.g., $\mathrm{Na}, \mathrm{Al}, \mathrm{Cr}, \mathrm{P}$, and $\mathrm{S}$ ) from the HLW fraction so as to reduce the volume of immobilized HLW.

PNWD conducted a test to assess the effects of inhibited water washing on the composition of the entrained solids in the diluted AN-107 LAW sample. The objective of this work was to gather data on the solubility of the AN-107 entrained solids in $0.01 \mathrm{M} \mathrm{NaOH}$ so that BNFL could evaluate whether these solids require caustic leaching. Based on the results of the $0.01 \mathrm{M} \mathrm{NaOH}$ washing, BNFL decided to not proceed with the caustic leaching test. The composition of the washed solids was such that caustic leaching would not result in significant reduction in the immobilized HLW volume.

PNWD-2467 (BNFL-RPT-009) - Ion Exchange Distribution Coefficients for ${ }^{137}$ Cs and ${ }^{99}$ Tc removal from Hanford Tank Supernatants AW-101 (Envelope A) and AN-107 (Envelope C)

\section{Focus Area: Pretreatment}

The BNFL flowsheet for the pretreatment of the Hanford tank HLW included the use of SuperLig ${ }^{\circledR}$ materials in a dual-column system to remove ${ }^{137} \mathrm{Cs}$ and ${ }^{99} \mathrm{Tc}$ from the aqueous fraction of the waste. The SuperLig ${ }^{\circledR}$ materials include the cesium-selective SuperLig ${ }^{\circledR} 632$ and SuperLig ${ }^{\circledR} 644$ for removal of ${ }^{137} \mathrm{Cs}$ and SuperLig ${ }^{\circledR} 639$ for the removal of ${ }^{99} \mathrm{Tc}$ present as $\mathrm{TcO}_{4}{ }^{-}$.

The work reported in this document includes an evaluation of the equilibrium behavior of the SuperLig ${ }^{\circledR}$ materials for the removal of ${ }^{137} \mathrm{Cs}$ and $\mathrm{TcO}_{4}^{-}$, information on the composition of process feeds, and information on selected physical properties for the SuperLig ${ }^{\circledR}$ resins. The objectives of this work were to

- Evaluate the equilibrium behavior of the SuperLig ${ }^{\circledR}$ materials for the removal of ${ }^{137} \mathrm{Cs}$ and ${ }^{99} \mathrm{Tc}$ (as pertechnetate) from AW-101 (Envelope A) and AN-107 (Envelope C) clarified supernatants.

- Obtain information of the composition of ion exchange feed streams and the pertechnetate/nonpertechnetate fraction in the samples. 
- Determine some of the SuperLig ${ }^{\circledR}$ material physical properties including particle size distribution, dry density, and water content.

PNWD-2455 (BNFL-RPT-012) - Hanford Tank Waste Simulants Specification and Their Applicability for the Retrieval, Pretreatment, and Vitrification Processes

\section{Focus Area: Simulant Development}

This report provides a detailed review of the existing reports on simulated wastes for the remediation of single-shell and double-shell tank wastes at the Hanford Site. The compilation reviews all the simulants used over the past decade in testing for the retrieval, pretreatment, and vitrification processes. The retrieval and transport simulants may be useful for testing in-plant fluidic devices and, in some cases, for filtration technologies. The pretreatment simulants, which include simulants for envelopes A, B, C, and $\mathrm{D}$, will be useful for filtration, Sr/TRU removal, and ion exchange testing. The vitrification simulants will be useful for testing melter and melter feed preparation technologies and for waste form evaluations.

All of these simulants, their representative chemical and physical characteristics, and their preparation specification are summarized. PNWD reviewed the TWRS privatization mass and activity balance for the proposed low-activity waste and high-level waste feeds and addressed the application of simulants that mimic these types of waste composition. From this review, PNWD evaluated the appropriateness of using simulants for specific chemical and physical properties associated with each envelope.

PNWD-3001 (BNFL-RPT-014) - Small Column Ion Exchange Testing of SuperLig ${ }^{\circledR} 644$ for Removal of ${ }^{137}$ Cs from Hanford Tank Waste Envelope A (Tank 241-AW-101)

\section{Focus Area: Pretreatment}

The BNFL flowsheet for the pretreatment of the tank HLW included the use of SuperLig ${ }^{\circledR}$ materials to remove ${ }^{137} \mathrm{Cs}$ and ${ }^{99} \mathrm{Tc}$ from the aqueous fraction of the waste. The SuperLig ${ }^{\circledR}$ materials applicable to cesium removal include the cesium-selective SuperLig ${ }^{\circledR} 632$ and SuperLig ${ }^{\circledR} 644$.

The work documented in this report involved testing the SuperLig ${ }^{\circledR} 644$ ion exchange material in a small-dual column system. The sample processed was approximately $2.5 \mathrm{~L}$ of diluted waste from Tank 241-AW-101 (Envelope A). This waste previously had been clarified in a single-tube crossflow filtration unit. All ion exchange process steps were tested, including resin bed preparation, loading, feed displacement, water rinse, elution, and resin regeneration.

PNWD-3004 (BNFL-RPT-016) - Small Column Testing of SuperLig ${ }^{\circledR ~} 639$ for Removing ${ }^{99}$ Tc from Hanford Tank Waste Envelope A (Tank 241-AW-101)

\section{Focus Area: Pretreatment}

The BNFL flow sheet for the pretreatment of the Hanford tank HLW included the use of SuperLig® 639 (SL-639) in a dual-column system for the removal of technetium-99 $\left({ }^{99} \mathrm{Tc}\right)$ from the aqueous fraction of the waste.

The report documents the results of testing SL-639 sorbent in a small dual-column system. Approximately 1.2 L of diluted waste from Tank 241-AW-101 (Envelope A) was processed in the test. 
This waste previously had been clarified in a single-tube crossflow filtration unit, and Cs had been removed by ion exchange using SuperLig® 644 . All Tc removal process steps were tested, including resin bed preparation, loading, feed displacement, water rinse, elution, eluant rinse, and resin regeneration. A ${ }^{95 \mathrm{~m}} \mathrm{Tc}$ pertechnetate tracer $\left({ }^{95 \mathrm{~m}} \mathrm{TcO}_{4}{ }^{-}\right)$was used to follow the progress of the test. Technetium-99 concentrations were determined after the test.

The objectives of this work were to

- Demonstrate the ${ }^{99} \mathrm{Tc}$ decontamination of Envelope A (Tank AW-101) and provide a technetium decontaminated sample for downstream process testing (i.e., corrosion testing, Low Activity Waste (LAW) melter feed testing and vitrification).

- Demonstrate the effectiveness of all SL-639 process steps including loading, feed displacement, DI water washing, elution, and resin regeneration.

- Obtain process performance data for SL-639 at conditions different from those previously tested.

- Investigate SL-639/waste chemistry.

- Investigate the potential for resin and/or column fouling.

\section{PNWD-3013 (BNFL-RPT-017) - C-106 High-Level Waste Solids: Washing/Leaching and Solubility Versus Temperature Studies}

\section{Focus Area: Pretreatment}

This report describes a test conducted by PNWD to assess the effects of inhibited water washing and caustic leaching on the composition of the Hanford Tank C-106 HLW solids. The objective of this work was to determine the composition of the $\mathrm{C}-106$ solids remaining after washing with $0.01 \mathrm{M} \mathrm{NaOH}$ or leaching with $3 \mathrm{M} \mathrm{NaOH}$. Another objective of this test was to determine the solubility of various $\mathrm{C}-106$ components as a function of temperature.

\section{PNWD-3036 (BNFL-RPT-018) - Removal of Sulfate Ion From AN-107 by Evaporation}

\section{Focus Area: Pretreatment}

Hanford low-activity waste solutions contain sulfate, which can cause accelerated corrosion of the vitrification melter and unacceptable operating conditions. A method is needed to selectively separate sulfate from the waste. An experiment was conducted to evaluate evaporation for removing sulfate ion from Tank AN-107 low-activity waste. Two evaporation steps were performed. In the first step, the volume was reduced by 55\%; in the second step, the liquid volume was reduced another $22 \%$. Analysis of the solids precipitated during these evaporations revealed that large amounts of sodium nitrate and nitrite co-precipitated with sodium sulfate. Many other waste components precipitated as well. It can be concluded that sulfate removal by precipitation is not selective, and thus evaporation is not a viable option for removing sulfate from the AN-107 liquid.

This report describes an experiment using actual AN-107 waste to evaluate evaporation for removal of sulfate ion from the Tank AN-107 LAW (Envelope C) fraction. The test also provides information on the degree to which AN-107 can be concentrated without solids formation. Information on the evaporation of the pretreated $\mathrm{AN}-107$ waste is valuable for understanding storage conditions for the pretreated waste. 


\section{PNWD-3015 (BNFL-RPT-019) - Corrosion Tests of 316L and Hastelloy ${ }^{\circledR}$ C-22 in Simulated Tank Waste Solutions}

\section{Focus Area: Material Characterization}

The corrosion tests documented in this report supported confirmation of the design basis for the materials of construction of process vessels and equipment used to handle the feed to the LAW melter-evaporator. BNFL process and mechanical engineering will use the information derived from this task to select material of construction for process vessels and equipment. The two materials under investigation were 316L stainless steel and Hastelloy C-22.

Both the 316L stainless steel and Hastelloy C-22 were subjected to 100-day weight loss corrosion tests and electrochemical potentiodynamic evaluation. The weight loss results and visual observations indicated no corrosion problems associated with the Hastelloy C-22 in the environmental conditions studied in this test program. On two occasions, a few shallow pits were observed, but they were too shallow to measure (below $0.0005 \mathrm{in}$. or $0.01 \mathrm{~mm}$ depth). The electrochemical results supported the weight loss results.

The 316L material also showed no corrosion problems except at the vapor/liquid region of simulant A under boiling conditions, and here the rate was a negligible $0.5 \mathrm{mpy}(0.01 \mathrm{~mm} / \mathrm{y})$. More important, there was no knifeline attack observed at this region. The electrochemical results support the weight loss results. The two alloys have a similar corrosion behavior, based on the results from the immersion tests and electrochemical tests.

\section{PNWD-3014 (BNFL-RPT-020) - Automated ${ }^{99}$ Tc Analysis in AW-101 and AN-107 “Diluted Feed” Matrixes}

\section{Focus Area: Pretreatment}

An on-line/at-line monitor was needed to monitor total ${ }^{99} \mathrm{Tc}$ in column effluents during technetium removal from the aqueous fraction of the Hanford high-level tank wastes. The monitor must achieve detection limits of $1 \times 10^{-8} \mathrm{Ci} / \mathrm{mL}(0.6 \mu \mathrm{g} / \mathrm{mL})$. Measurements must be done in near real time, with an analysis frequency of $\sim 15$ min or faster. The monitoring technology must be sufficiently simple and robust for unattended operation at the plant settings.

The work contained in this report describes initial scoping studies to determine the applicability of PNWD's automated radiochemical analyzer methodology for ${ }^{99} \mathrm{Tc}$ monitoring in the diluted feed matrixes. An automated radiochemical separation instrument with on-line radiometric detection was assembled and tested. Automated separation procedures for analyzing acidic and caustic samples were tested using on-line radiometric detection. The automated radiochemical analysis method requires that Tc be present in the sample as pertechnetate. Manual sample oxidation procedures to convert all Tc to $\mathrm{Tc}(\mathrm{VII})$ were therefore developed and tested. The AW-101 and AN-107 samples were oxidized, and the resulting solutions were analyzed using automated analyzer and inductively coupled plasma-mass spectrometry (ICP-MS) techniques. The analytical results obtained using the radiochemical analyzer technique were in excellent agreement with the total Tc concentrations as determined by ICP-MS. The detection limits that can be achieved using an automated radiochemical analyzer are a factor of 40 below the target detection limit of $1 \times 10^{-8} \mathrm{Ci} / \mathrm{mL}$. Given the development of rapid automated sample-oxidation procedures, automated radiochemical analyzer technology shows promise for developing a relatively straightforward process monitoring instrumentation. 
PNWD-3027 (BNFL-RPT-021) - C-104 High-Level Waste Solids: Washing/Leaching and Solubility Versus Temperature Studies

\section{Focus Area: Pretreatment}

This report describes tests conducted by PNWD to assess the effects of inhibited water washing and caustic leaching on the composition of the C-104 HLW solids. The objective of this work was to determine the composition of the $\mathrm{C}-104$ solids remaining after washing with $0.01 \mathrm{M} \mathrm{NaOH}$ or leaching with $3 \mathrm{M} \mathrm{NaOH}$. Another objective of this test was to determine the solubility of the $\mathrm{C}-104$ solids as a function of temperature.

\section{PNWD-3028 (BNFL-RPT-022) - Small Column Testing of SuperLig ${ }^{\circledR} 639$ for Removing ${ }^{99}$ Tc from Hanford Tank Waste Envelope C (Tank 241-AN-107)}

\section{Focus Area: Pretreatment}

The BNFL flowsheet for pretreating HLW included the use of SuperLig® 639 (SL-639) in a dual-column system for removing technetium-99 $\left({ }^{99} \mathrm{Tc}\right)$ from the aqueous fraction of the waste.

This report documents the results of testing the SL-639 sorbent with diluted waste from

Tank 241-AN-107. The objectives of this work were to

- Demonstrate the ${ }^{99} \mathrm{Tc}$ decontamination of Envelope C (Tank AN-107) and provide a technetium decontaminated sample for downstream process testing (i.e. corrosion testing, LAW melter feed testing and LAW vitrification).

- Demonstrate the effectiveness of all SL-639 process steps including loading, feed displacement, deionized water washing, elution, resin regeneration, and subsequent reloading.

- Obtain process performance data for SL-639 at conditions different than those previously tested.

- Obtain process performance data for loading of SL-639 by AN-107 waste following partial loading by AW-101 waste.

- Investigate sorbent/waste chemistry, particularly the differences in the interaction of $\mathrm{TcO}_{4}$ and non-pertechnetate Tc with the sorbent.

- Investigate the potential for exchanger fouling.

PNWD-3029 (BNFL-RPT-023) - Mixing of Process Heels, Process Solutions, and Recycle Streams: Results of the Small-Scale Radioactive Tests

\section{Focus Area: Pretreatment}

Various recycle streams will be combined with the LAW or the HLW feed solutions during the processing of the Hanford tank wastes at the WTP. In addition, the LAW and HLW feed solutions will be mixed with heels present in the processing equipment.

This report describes a test conducted by PNWD to assess the effects of mixing specific process streams. Observations were made regarding adverse reactions (mainly precipitation) and effects on the Tc oxidation state (as indicated by $\mathrm{K}_{\mathrm{d}}$ measurements with SuperLig ${ }^{\circledR}$ 639). 
PNWD-3039 (BNFL-RPT-024) - Small Column Ion Exchange Testing of SuperLig ${ }^{\circledR} 644$ for Removal of ${ }^{137}$ Cs from Hanford Tank Waste Envelope C (Tank 241-AN-107)

\section{Focus Area: Pretreatment}

The BNFL flowsheet for the pretreatment of the Hanford high-level tank wastes included the use of SuperLig ${ }^{\circledR}$ materials for removing ${ }^{137} \mathrm{Cs}$ from the aqueous fraction of the waste. The SuperLig ${ }^{\circledR}$ materials applicable to cesium removal included the cesium-selective SuperLig® 632 and SuperLig® 644.

This report describes the testing of the SuperLigß 644 ion exchange material in a small dual-column system. The objectives of this work were to:

- Demonstrate the ${ }^{137} \mathrm{Cs}$ decontamination of Envelope C (Tank AN-107) and provide a cesium decontaminated sample for downstream process testing (i.e., ${ }^{99} \mathrm{Tc}$ removal, $\mathrm{SO}_{4}$ removal, corrosion testing, LAW melter feed testing and LAW vitrification).

- Demonstrate the effectiveness of all SL-644 ion exchange process steps, including loading, feed displacement, deionized water washing, elution, and resin regeneration.

- Obtain process performance data for SL-644 at conditions different than those previously tested.

- Investigate exchanger/waste chemistry.

- Investigate the potential for exchanger fouling.

\section{PNWD-3047 (BNFL-RPT-025) - Development of an Alternative Treatment Scheme for Sr/TRU Removal: Permanganate Treatment of AN-107 Waste}

\section{Focus Area: Pretreatment}

A number of Hanford tanks received waste containing organic complexants, which increase the solubility of Sr-90 and TRU elements. Wastes from these tanks require additional pretreatment to remove Sr-90 and TRU for immobilization as low activity waste (Envelope C). The baseline pretreatment process for $\mathrm{Sr}$ /TRU removal was isotopic exchange and precipitation with added strontium and iron. However, studies at both PNWD and Savannah River Technology Center have shown that the Sr/Fe precipitates were very difficult to filter. This was a result of the formation of poor filtering iron solids. An alternative treatment technology was needed for Sr/TRU removal. PNWD had demonstrated that permanganate treatment was effective for decontaminating waste samples from Tank SY-101 and proposed that permanganate be examined as an alternative Sr/TRU removal scheme for complexant-containing tank wastes such as AN-107.

PNWD conducted preliminary small-scale experiments to determine the effectiveness of permanganate treatment with AN-107 waste samples that had been archived from earlier studies. The objective was to determine the potential use of permanganate for $\mathrm{Sr}$ /TRU removal and the optimal conditions for $\mathrm{Sr} / \mathrm{TRU}$ decontamination.

The proof-of-principle experiments, three series of small-scale Sr/TRU decontamination tests, are described in this report. Test conditions and experimental procedures are described in Section 2. Experimental results from the three series of tests are described in Section 3. The major conclusion and recommendations that evolved from this work are given in Section 4. The appendices contain the test 
instructions, data sheets, logbook entries, analytical data, calculation, and staff role/responsibilities for this work.

\section{PNWD-3033 (BNFL-RPT-026) - Demonstration of Entrained Solids and Sr/TRU Removal Processes with Archived AN-107 Waste}

\section{Focus Area: Pretreatment}

Waste from Hanford underground storage Tank 241-AN-107 is a candidate LAW for Envelope C. Envelope $\mathrm{C}$ wastes require pretreatment to remove entrained solids, radioactive strontium, transuranics, radioactive cesium, and technetium before immobilization. The initial baseline pretreatment process included plans for entrained solids removal by crossflow filtration, Sr/TRU precipitation with added strontium and iron, and Sr/TRU precipitate removal by crossflow filtration. However, studies have shown that entrained solids and the $\mathrm{Sr} / \mathrm{Fe}$ precipitates were very difficult to filter from candidate Envelope $\mathrm{C}$ waste. An alternative pretreatment process being developed uses permanganate instead of iron. Permanganate treatment has been shown to be effective for decontaminating waste from Tank SY-101.

PNWD conducted small-scale tests with archived AN-107 waste to determine the effectiveness of the permanganate treatment process. The objective of this work was to demonstrate the entrained solids and $\mathrm{Sr}$ /TRU removal processes with archived AN-107 waste before proceeding with the integrated process testing of AN-107 diluted feed. This report contains the results of entrained solids removal, $\mathrm{Sr} / \mathrm{TRU}$ decontamination, and Sr/TRU solids removal testing conducted at PNWD with archived AN-107 waste. Test conditions and experimental procedures are described in Section 2. Results from entrained solids removal and treatment with added $\mathrm{Sr}$ and permanganate are described in Section 3. The major conclusion and recommendations that evolved from this work are given in Section 4. The appendices contain the test instruction, data sheets, logbook entries, analytical data, calculation, and staff role/responsibilities for this work.

\section{PNWD-3035 (BNFL-RPT-027) - Combined Entrained Solids and Sr/TRU Removal from AN-107 Diluted Feed}

\section{Focus Area: Pretreatment}

Waste from Hanford underground storage Tank 241-AN-107 is a candidate LAW for Envelope C. Envelope $\mathrm{C}$ wastes require pretreatment to remove radioactive strontium and TRU (along with cesium and technetium) before immobilization. The baseline pretreatment process planned for Sr/TRU removal was precipitation with added strontium and iron. However, studies have shown that the $\mathrm{Sr} / \mathrm{Fe}$ precipitates were very difficult to filter. An alternative treatment being evaluated uses permanganate instead of iron. Permanganate treatment has been shown to be effective for decontaminating waste from Tank SY-101.

PNWD conducted small-scale experiments with archived AN-107 waste over a period of about three months to determine the effectiveness of the permanganate treatment process. This report contains the results of Sr/TRU removal testing conducted with AN-107 diluted feed. Test conditions and experimental procedures are described in Section 2. Results from waste treated with added $\mathrm{Sr}$ and permanganate are described in regards to Sr/TRU decontamination, chemical composition, solids removal, and physical and rheological properties of the waste in Section 3. The major conclusion and recommendations that evolved from this work are given in Section 4. The appendices contain the test instruction, data sheets, logbook entries, analytical data, rheograms, calculation, and staff role/responsibilities for this work. 
PNWD-3037 (BNFL-RPT-028) - Analysis of Spent Ion Exchange Media: SuperLig ${ }^{\circledR} 639$ and SuperLig ${ }^{\circledR} 644$

\section{Focus Area: Pretreatment}

The BNFL flowsheet for the pretreatment of the Hanford high-level tank wastes included the use of SuperLig ${ }^{\circledR}$ materials for removing ${ }^{137} \mathrm{Cs}$ and ${ }^{99} \mathrm{Tc}$ from the aqueous fraction of the waste. The cesium-selective SuperLig ${ }^{\circledR} 644$ (SL-644) and the technetium-selective SuperLig ${ }^{\circledR} 639$ (SL-639) materials have been evaluated in tests with actual waste samples. These materials have a finite processing lifetime in the plant and will need to be disposed of. The composition and level of residual radionuclide contamination is important for assessing various disposal pathways for the spent SuperLig ${ }^{\circledR}$ materials.

This report contains the results of PNWD's analysis of subsamples of the SL-639 and SL-644 materials that have been used in small-column testing of actual waste samples The tested wastes included samples from tanks 241-AW-101 (Envelope A) and 241-AN-107 (Envelope C). The spent resins were analyzed with inductively coupled plasma/atomic emission spectrometry for metals, cold vapor atomic absorption spectroscopy for mercury, gamma energy analysis for radionuclides, and inductively coupled plasma/mass spectrometry for selected metals and radionuclides.

\section{PNWD-3050 (BNFL-RPT-029) - Development and Demonstration of a Sulfate Precipitation Process for Hanford Waste Tank 241-AN-107}

\section{Focus Area: Pretreatment}

The presence of sulfate ion in the Hanford LAW solutions generates several potential processing difficulties. Preliminary testing of the LAW vitrification system at the Vitreous States Laboratory (VSL) indicates a separate molten sulfur layer will form in the melter (nominally at $1150^{\circ} \mathrm{C}$ ) at sufficiently high sulfate concentrations. A molten sulfur layer in the LAW melter can lead to accelerated corrosion of the melter and unacceptable operating conditions (e.g., steam explosion).

BNFL evaluated several methods to mitigate the impacts of sulfate on the LAW vitrification system including pretreatment technologies, blending of high and low sulfate LAW solutions, modification to the LAW glass formulations, and volatilization of sulfur in the LAW melter as $\mathrm{SO}_{2}$ or $\mathrm{SO}_{3}$. BNFL evaluated four pretreatment technologies for separating sulfate from LAW solutions:

- $\quad$ ion exchange (SuperLig® 655 )

- evaporation

- precipitation

- low-temperature crystallization.

PNWD conducted a series of precipitation experiments on samples of Tank 241-AN-107 in an effort to remove sulfate from the matrix. This report describes the results of the experiments conducted to evaluate precipitation as a process for removal of sulfate ion from the waste currently stored in Tank 241-AN-107. The pretreated AN-107 liquid waste (supernatant) is categorized as LAW Envelope C waste. Actual tank waste samples were used in these tests. 


\section{PNWD-3024 (BNFL-RPT-030) - Characterization, Washing, Leaching, and Filtration of C-104 Sludge}

\section{Focus Area: Pretreatment}

Caustic leaching and/or water washing are planned for pretreatment of the Envelope D Hanford sludge before HLW vitrification. These pretreatment steps reduce the quantity of HLW generated by removing components such as $\mathrm{Al}, \mathrm{Cr}, \mathrm{Na}$, and $\mathrm{P}$ that are soluble either in water or high-temperature caustic and often limit the waste loading in the glass.

Crossflow filtration also is planned to separate the leach and wash solutions from the solids between each step. Unlike traditional dead-end filtration, in crossflow filtration, the filter cake is swept away by the fluid flowing across it. This filtration method is especially beneficial when there are very fine particles and when system simplicity is required.

The first objective of this work was to test crossflow filtration using actual Envelope D Hanford tank waste (C-104) in a modified Cells Unit Filter (CUF) filtration rig fabricated at PNWD. Similar to the studies with supernatants, the permeability of the diluted C-104 sludge through a single-element $0.1-\mu \mathrm{m}$ Mott filter was evaluated as a function of trans-membrane pressure, axial velocity, and time for both high and low solids concentrations. The radioactive tests with the single-element CUF provided information for equipment-performance evaluation and a design basis for a scaled process.

The second objective was to evaluate washing and leaching characteristics of the C-104 sludge. The slurried feed was dewatered and then washed multiple times with $0.01 \mathrm{M} \mathrm{NaOH}$ to determine the concentration of water-soluble components. The washed sludge was subsequently leached with $\mathrm{NaOH}$ at elevated temperatures to determine the concentration of caustic-soluble components. The chemical and radiochemical composition of the filtrate and the final leached solids was measured to determine the efficiency of the filtration, leaching, and washing processes.

This report describes the test apparatus, the experimental approach, the results of the tests, and the chemical and radiochemical analysis of the sludge from Tank C-104 and filtrates generated during the washing and caustic-leaching steps.

\section{PNWD-3042 (BNFL-RPT-033) - Development of Inactive High Level Waste Envelope D Simulants for Scaled Crossflow Filtration Testing}

\section{Focus Area: Simulant Development}

As part of the development of the full-scale filtration system for the WTP, a multi-tube crossflow filter was tested on nonradioactive simulants at BNFL's Sellafield plant. The data collected from this pilot-scale unit will be used in conjunction with the results from the actual waste testing with a single-tube crossflow filter to assist in the scale-up effort.

One objective of this work was to develop the nonradioactive physical simulants for use in the multi-tube filter. Two simulant compositions have been targeted: a neutralized current acid waste (NCAW) developed from a composite of AZ-101 and AZ-102 tank compositions, and a high-heat tank waste, based on the composition of the waste in Tank C-106. 
The second objective of this work was to verify the simulant properties and performance relative to the actual waste. Particle size and rheological data available from past experimental efforts were compared to these HLW simulants. The simulants were also tested in the cells unit filter (CUF) single-tube crossflow filter, providing a comparison between the simulant results and the available data with actual waste. By comparing the filtration and rheological behavior of actual and simulated waste, the validity of the simulants can be verified. Furthermore, a comparison between the simulant behavior in the CUF unit and in the multi-tube pilot-scale unit provides insight into the impacts of process scale-up.

This report describes the approach taken in developing the AZ-101/AZ-102 and C-106 tank waste simulants. It also provides the simulant formulation, including vendor purchasing information. The utility and limitations of the simulant are also delineated to define acceptable applications. The rheological, filtration, and particle size properties for each simulant are delineated. These properties are compared to the actual waste data, where available. This report also provides a means of transmitting to BNFL the raw filtration, rheological, and particle-size data for the simulants.

\section{PNWD-3034 (BNFL-RPT-034) - Rheological Studies on Pretreated Feed and Melter Feed from $A W-101$ and $A N-107^{2}$}

\section{Focus Area: Vitrification}

This report describes the experimental approach and results of testing to obtain physical and rheological data on actual LAW melter feed samples. The physical and rheological properties of the LAW melter feed are important in the selection of the WTP melter feed preparation flowsheet and processing equipment such as mixers, pumps, piping and sampling. Measurements on actual waste are required to validate and qualify results obtained with simulants.

Actual samples from tanks AW-101 and AN-107 were used; a composite for each of the tanks was prepared from multiple samples from each tank. Entrained solids were removed from the AW-101 composite by ultrafiltration. The cesium and technetium were then removed by ion exchange. Entrained solids, strontium, and transuranics (TRU) were removed from the AN-107 material during the $\mathrm{Sr} / \mathrm{TRU}$ removal process. Cesium was then removed from the AN-107 material by ion exchange.

Solids concentration, settling rate, density, and shear stress versus shear rate were measured on the samples after evaporation to three sodium concentrations (nominally 6,8 , and $10 \mathrm{M}$ ) at ambient temperature and at $50^{\circ} \mathrm{C}$. The same measurements were conducted on the three mixtures from Tank 241-AW-101 after the addition of glass formers. The $8 \mathrm{M} \mathrm{Na}$ AW-101 slurry was mixed for 1 week at a shear rate consistent with that expected in the WTP. During this mixing, shear stress versus shear rate was measured after 1 hour, 1 day, and 1 week. A shear stress versus shear rate analysis of this slurry was conducted again after 1 week with no mixing.

2 This report was later updated with the AN-107 sample results and published as PNNL-13353, WTP-RPT-002 Rev 1. 


\section{PNWD-3053 (BNFL-RPT-036) - Ion Exchange Studies for Removal of Sulfate from Hanford Tank}

Waste Envelope C (241-AN-107) Using SuperLig ${ }^{\circledR} 655$ Resin

\section{Focus Area: Pretreatment}

BNFL evaluated various pretreatment technologies to mitigate the impacts of sulfate on the LAW vitrification system. One pretreatment technology for separating sulfate from LAW solutions involved the use of SuperLig ${ }^{\circledR} 655$ (SL-655), a proprietary ion exchange material . This report describes PNWD-conducted testing of SL-655 with diluted waste from Tank 241-AN-107.

Batch contact studies were conducted from 4 to 96 hours to determine the sulfate distribution coefficient and reaction kinetics. A small-scale ion exchange column test was conducted to evaluate sulfate removal, loading, breakthrough, and elution from the SL-655. In all of these tests, an archived 241-AN-107 tank waste sample (pretreated to remove $\mathrm{Cs}$, Sr, and transuranic elements) was used. The experimental details and results are described in this report.

\section{PNWD-3044 (BNFL-RPT-037) - Thermodynamic Modeling of Sr/TRU Removal}

\section{Focus Area: Pretreatment}

This report summarizes PNWD's development and application of a thermodynamic modeling capability designed to treat the Envelope $\mathrm{C}$ wastes containing organic complexants. A complete description of the model development is presented. In addition, the model was used to help gain insight into the chemical processes responsible for the observed levels of $\mathrm{Sr}$, TRU, Fe, and $\mathrm{Cr}$ removal from the diluted feed from Tank 241-AN-107, which had been treated with $\mathrm{Sr}$ and permanganate. Modeling results are presented for $\mathrm{Sr}, \mathrm{Nd}(\mathrm{III}) / \mathrm{Eu}(\mathrm{III}), \mathrm{Fe}, \mathrm{Cr}, \mathrm{Mn}$, and the major electrolyte components of the waste (i.e., $\mathrm{NO}_{3}, \mathrm{NO}_{2}, \mathrm{~F}$, etc.). Overall, the added $\mathrm{Sr}$ is predicted to precipitate as $\mathrm{SrCO}_{3}(\mathrm{c})$ and the $\mathrm{MnO}_{4}{ }^{-}$to be reduced by the $\mathrm{NO}_{2}{ }^{-}$and precipitated as a Mn oxide. These effects result in only minor changes to the bulk electrolyte chemistry--specifically, decreases in $\mathrm{NO}_{2}{ }^{-}$and $\mathrm{CO}_{3}{ }^{2-}$ and increases in $\mathrm{NO}_{3}{ }^{-}$and $\mathrm{OH}^{-}$. All of these predictions are in agreement with the experimental observations. The modeling also indicates that the majority of the Sr, TRU (or $\mathrm{Nd}(\mathrm{III}) / \mathrm{Eu}(\mathrm{III})$ ) analogs, and Fe are tied up with the organic complexants. The $\mathrm{Sr}$ and permanganate additions are not predicted to affect these chelate complexes significantly owing to the precipitation of insoluble $\mathrm{Mn}$ oxides or $\mathrm{SrCO}_{3}$. These insoluble phases maintain low dissolved concentrations of $\mathrm{Mn}$ and $\mathrm{Sr}$ that do not affect any of the other components tied up with the complexants. Removal of the Fe and TRUs during the treatment process appears most likely a result of adsorption or occlusion on or into the $\mathrm{Mn}$ oxides or $\mathrm{SrCO}_{3}$, and not from the direct displacement from the complexants into precipitates. Recommendations are made for further studies needed to help resolve these issues.

\section{PNWD-3045 (BNFL-RPT-038) - Characterization, Washing, Leaching, and Filtration of AZ-102 Sludge}

\section{Focus Area: Pretreatment}

BNFL developed flowsheets include the use of caustic leaching and/or water washing to pretreat Envelope D Hanford sludge would remove a number of components to reduce the quantity of HLW generated. Crossflow filtration also would be used to separate the leach and wash solutions from the solids between each step. The work reported here tested crossflow filtration and evaluated the washing and leaching characteristics of sludge from Tank AZ-102. This report describes the test apparatus, 
experimental approach, results of the tests, and chemical and radiochemical analysis of the sludge from Tank AZ-102 and filtrates generated during the washing and caustic-leaching steps.

\section{PNWD-3051 (BNFL-RPT-039) - Active Waste Materials Corrosion and Decontamination Tests}

\section{Focus Area: Material Characterization}

Stainless steel alloys, 304L and 316L, were corrosion-tested in representative radioactive samples of three actual Hanford tank waste solutions (Tanks AW-101, C-104, AN-107). Both the 304L and 316L exhibited good corrosion performance when immersed in boiling waste solutions. The maximum general corrosion rate was $0.015 \mathrm{~mm} / \mathrm{y}(0.60 \mathrm{mil} / \mathrm{y})$. Generally, the $304 \mathrm{~L}$ had a slightly higher rate than the $316 \mathrm{~L}$. No localized attack was observed after 122 days of testing in the liquid phase, liquid/vapor phase, or vapor phase. Radioactive plate-out decontamination tests indicated that a 24-hour exposure to $1 \mathrm{M} \mathrm{HNO}_{3}$ could remove about $99 \%$ of the radioactive components in the metal film when exposed to the C-104 and AN-107 solutions. The decontamination results are less certain for the AW-101 solution because the initial contamination readings exceeded the capacity of the meter used for this test.

\section{PNWD-3046 (BNFL-RPT-046 Rev 1) - Inorganic, Radioisotopic, and Organic Analysis of 241-AP-101 Tank Waste}

\section{Focus Area: Characterization}

In response to a request from BNFL, PNWD conducted inorganic, organic, and radioisotopic analyses for a composite sample obtained from Tank 241-AP-101 (AP-101).

The characterization of the 241-AP-101 composite samples included

- inductively-coupled plasma spectrometry for $\mathrm{Ag}, \mathrm{Al}, \mathrm{Ba}, \mathrm{Bi}, \mathrm{Ca}, \mathrm{Cd}, \mathrm{Cr}, \mathrm{Cu}, \mathrm{Fe}, \mathrm{K}, \mathrm{La}, \mathrm{Mg}, \mathrm{Mn}, \mathrm{Na}$, $\mathrm{Nd}, \mathrm{Ni}, \mathrm{P}, \mathrm{Pb}, \mathrm{Pd}, \mathrm{Ru}, \mathrm{Rh}, \mathrm{Si}, \mathrm{Sr}, \mathrm{Ti}, \mathrm{U}, \mathrm{Zn}$, and Zr (Although not specified in the test plan, As, B, Be, $\mathrm{Co}, \mathrm{Li}, \mathrm{Mo}, \mathrm{Sb}, \mathrm{Se}, \mathrm{Sn}, \mathrm{Tl}, \mathrm{V}, \mathrm{W}$, and Y also were also measured and reported for information only.)

- radioisotopic analyses for total alpha and total beta activities, ${ }^{3} \mathrm{H},{ }^{14} \mathrm{C},{ }^{60} \mathrm{Co},{ }^{79} \mathrm{Se},{ }^{90} \mathrm{Sr},{ }^{99} \mathrm{Tc}$ as pertechnetate, ${ }^{106} \mathrm{Ru} / \mathrm{Rh},{ }^{125} \mathrm{Sb},{ }^{134} \mathrm{Cs},{ }^{137} \mathrm{Cs},{ }^{152} \mathrm{Eu},{ }^{154} \mathrm{Eu},{ }^{155} \mathrm{Eu},{ }^{238} \mathrm{Pu},{ }^{239+240} \mathrm{Pu},{ }^{241} \mathrm{Am},{ }^{242} \mathrm{Cm}$, and ${ }^{243+244} \mathrm{Cm}$

- inductively-coupled plasma mass spectrometry for ${ }^{237} \mathrm{~Np},{ }^{239} \mathrm{Pu},{ }^{240} \mathrm{Pu},{ }^{99} \mathrm{Tc},{ }^{126} \mathrm{Sn},{ }^{129} \mathrm{I},{ }^{231} \mathrm{~Pa},{ }^{233} \mathrm{U}$, ${ }^{234} \mathrm{U},{ }^{235} \mathrm{U},{ }^{236} \mathrm{U},{ }^{238} \mathrm{U},{ }^{241} \mathrm{AMU},{ }^{242} \mathrm{AMU},{ }^{243} \mathrm{AMU}, \mathrm{As}, \mathrm{B}, \mathrm{Be}, \mathrm{Ce}, \mathrm{Co}, \mathrm{Cs}, \mathrm{Eu}, \mathrm{I}, \mathrm{Li}, \mathrm{Mo}, \mathrm{Pr}, \mathrm{Rb}, \mathrm{Sb}, \mathrm{Se}$, Ta, Te, Th, Tl, V, and W

- total $\mathrm{U}$ by kinetic phosphorescence analysis

- ion chromatography for $\mathrm{Cl}, \mathrm{F}, \mathrm{NO}_{2}, \mathrm{NO}_{3}, \mathrm{PO}_{4}, \mathrm{SO}_{4}$, acetate, formate, oxalate, and citrate

- density, inorganic carbon and organic carbon by two different methods, mercury, free hydroxide, ammonia, and cyanide

- polychlorinated biphenyls.

This report presents the physical observations from AP-101 and individual density measurements from the various tank depths sampled. Precipitate production was evaluated at $10^{\circ} \mathrm{C}$ for seven days on a composite subsample. Also presented are the inorganic, radioisotopic, and organic analytical results for the triplicate AP-101 composite samples. Analyte results are compared to Envelope A limits, where applicable. Data limitations are also described. Quality control, detection limits, and other quality control indicators are discussed relevant to the reporting method. 


\section{PNWD-3054 (BNFL-RPT-048) - Demonstration and Optimization of BNFL's Pulsed Jet Mixing and RFD Sampling Systems Performance Using NCAW Simulant}

\section{Focus Area: Pretreatment}

The BNFL flowsheet for the pretreatment and vitrification of the Hanford tank HLW includes the use of several hundred reverse flow diverters (RFDs) for sampling and transferring the radioactive slurries and pulsed jet mixers to homogenize or suspend the tank contents.

The pulsed jet mixing and the RFD sampling devices represent very simple and efficient methods to mix and sample slurries, respectively, using compressed air to achieve the desired operation. The equipment has no moving parts, which makes them very suitable for mixing and sampling highly radioactive wastes. However, the effectiveness of the mixing and sampling systems are yet to be demonstrated when dealing with Hanford slurries, which exhibit a wide range of physical and rheological properties.

This report describes the PNWD testing of the BNFL's pulsed jet mixing and RFD sampling systems to

- Demonstrate the effectiveness of the pulsed jet mixing system to thoroughly homogenize Hanford-type slurries over a range of solids loading.

- Minimize/optimize air usage by changing sequencing of the pulsed jet mixers or by altering cycle times.

- Demonstrate that the RFD sampler can obtain representative samples of the slurry up to the maximum WTP baseline concentration of $25 \mathrm{wt} \%$.

The pulse jet mixers readily homogenized the supernate tank contents, at both $28 \mathrm{wt} \%$ and $36 \mathrm{wt} \%$ solids. There was some stratification in the top half of the tank at $17 \mathrm{wt} \%$ solids. This small amount of stratification was due to the design of the pulse tubes being based on actual tank waste settling data rather than the simulant.

The scope of the work also included evaluating whether sequencing the operation or reducing the frequency of pulsing could optimize the air requirements to the pulse tubes. By sequencing the operation of the pulsed jet mixers, the simulant could be kept suspended quite readily. Because homogenization of tank contents is required only when sampling or possibly during transfers, the pulse jet mixers may be sequenced for general operations, which results in an $80 \%$ reduction in compressed air and associated vent requirements.

Overall, the PNWD performance tests on the BNFL pulsed jet mixing and RFD sampling system indicated that these systems are capable of handling slurries of high solids loading. The absence of any moving parts makes these systems extremely attractive to handle highly radioactive wastes.

\section{PNWD-3085 (WTP-RPT-012) - Numbers of Samples, Analyses, and Measurements for Vitrification Estimation, Compliance, and Process Control - Methodology and Preliminary Assessment}

\section{Focus Area: Waste Form Qualification}

This report describes PNWD's initial work to develop sample size formulas and apply the formulas to calculate sample sizes. Various samples, chemical analyses of samples, and measurements will be required to monitor and control the IHLW and ILAW vitrification processes and to implement 
qualification and production strategies for complying with applicable specifications. Many of the process-product control and compliance strategies will be statistical, meaning that variations and uncertainties will be accounted for in making decisions and demonstrating compliance.

Section 2.1 provides a general overview of the IHLW and ILAW vitrification processes, and Section 2.2 describes four general categories of objectives for sampling, chemical analyses, or measurements. Sections 3, 4, and 5 present the statistical sample size formulas and results of applying the sample size formulas for various combinations of input parameters (for example, uncertainty magnitudes and confidence levels). However, in this initial effort, it was possible to address only a fraction of the many process control and compliance situations for which sample size formulas and determinations are needed. Section 6 outlines most of the remaining situations that will have to be addressed in future work. Additional situations likely will be identified as process-product control and compliance strategies are more fully developed. Hence, the topic coverage and results in this report should be considered preliminary.

\section{PNWD-3099 (WTP-RPT-013) - X\%/Y\% Tolerance Interval Approach to Determine Sample Sizes and Demonstrate IHLW or ILAW Produced Over a Waste Type is Compliant with Chemical Durability Specifications}

\section{Focus Area: Waste Form Qualification}

The RPP-WTP Project strategies for complying with applicable IHLW and ILAW specifications are presented in the Waste Compliance Plan (WCP) and the Products and Secondary Wastes Plan (PSWP). Many of the RPP-WTP Project compliance strategies are statistical in nature, because sources of variation and uncertainty will be quantified and accounted for in demonstrating compliance with the specifications.

The WCP and PSWP compliance strategies for the PCT and VHT chemical durability specifications do not definitively specify the type of statistical interval approach to be used to demonstrate that IHLW or ILAW produced from a given HLW or LAW waste is compliant. The statistical tolerance interval approach has been chosen as defensible and appropriate for demonstrating compliance for IHLW or ILAW produced from a waste type. A statistical X\%/Y\% upper tolerance interval (X\%/Y\% UTI) allows stating with high confidence $(\mathrm{X} \%)$ that at least some high percentage $(\mathrm{Y} \%)$ of a distribution is less than an upper limit. Hence, an $\mathrm{X} \% / \mathrm{Y} \% \mathrm{UTI}$ is well suited to demonstrating the immobilized waste (IHLW or ILAW) produced from a given waste type (HLW or LAW) has chemical releases less than the upper limit provided in a specification. This report 1) develops and presents X\%/Y\% UTI tolerance interval formulas, 2) uses the formulas to investigate the consequences of different parameters affecting the size of the $\mathrm{X} \% / \mathrm{Y} \%$ UTIs, and 3) illustrates using the $\mathrm{X} \% / \mathrm{Y} \%$ UTI formulas with a simulated data set to demonstrate compliance with the WAPS 1.3 specification for IHLW produced from a waste type.

The report introduction presents and discusses the IHLW and ILAW chemical durability (PCT and VHT) specifications, summarizes the RPP-WTP Project compliance strategies for these specifications, and elaborates on the objectives of the work and results included in this report.

Section 2 defines and discusses several aspects of statistical tolerance intervals. Section 3 develops and presents the formulas for calculating X\%/Y\% UTIs for the PCT and VHT release situations addressed in this report. Section 4 presents the results of applying the $\mathrm{X} \% / \mathrm{Y} \% \mathrm{UTI}$ formulas for many combinations of input parameters to provide guidance to the RPP-WTP Project on answering questions about sample sizes, precision, and other issues. However, the input parameter values used for the calculations in Section 4 assume that the natural logarithm of release is modeled as a function of glass composition. Preliminary models for PCT (IHLW and ILAW) and TCLP (IHLW) are in terms of ln(release), while 
preliminary models for VHT (ILAW) utilize a different transformation of release. Section 5 illustrates the application of the $\mathrm{X} \% / \mathrm{Y} \%$ UTI formulas to a simulated data set meant to represent PCT releases of IHLW over the course of a waste type. Section 6 discusses work that must be conducted during qualification activities to provide future required inputs for applying the $\mathrm{X} \% / \mathrm{Y} \% \mathrm{UTI}$ method to demonstrate PCT and VHT compliance during IHLW and ILAW production operations.

\section{PNWD-3195 (WTP-RPT-015) - Aging Study and Small Column Ion Exchange Testing of SuperLig ${ }^{\circledR} 644$ for Removal of ${ }^{137}$ Cs from Simulated AW-101 Hanford Tank Waste}

\section{Focus Area: Pretreatment}

The RPP-WTP baseline process for ${ }^{137} \mathrm{Cs}$ removal from Hanford high-level tank waste is ion exchange. The Cs-selective organic ion exchanger material, SuperLig ${ }^{\circledR} 644$ (SL-644), was planned for Cs removal from the aqueous waste fraction. This report describes the results of PNWD's batch distribution contacts of aged SL-644 and freshly produced SL-644 as part of its Cs ion exchange studies to verify design and operating parameters for plant-scale ion exchange systems. The report also presents results from small column testing of two production batches of the SL-644 ion exchange material. The effect of particle size on the latter batch was also evaluated using the dry-sieved portion $212-$ to $425-\mu \mathrm{m}$ particle size. In all cases, the sample processed was simulated AW-101 Hanford tank waste diluted to nominally $5 \mathrm{M} \mathrm{Na}$.

The objectives of this work were

- to determine if the Cs exchange capacity of SL-644 resin has decreased after storage in contact with air for approximately two years

- to demonstrate the ion exchange system and resin performance for ${ }^{137} \mathrm{Cs}$ decontamination from tank waste simulant for subsequent use on actual tank waste

- to develop loading and elution breakthrough profiles with the AW-101 simulant.

Success criteria for Cs removal were defined by the Cs load/breakthrough curve and the final effluent

${ }^{137} \mathrm{Cs}$ concentration. The test specification defined successful Cs removal as $50 \%$ breakthrough from the lead column occurring at $\geq 150$ bed volumes (BVs) of AW-101 simulant (Envelope A) waste loading. The final effluent was to contain $\leq 0.087 \mu \mathrm{Ci}{ }^{137} \mathrm{Cs} / \mathrm{mL}$. These criteria were met with the newly-received SL-644 resin, of 212- to 425- $\mu \mathrm{m}$ particle size. The success criterion for the aging study was to ensure the Cs distribution coefficients $\left(\mathrm{K}_{\mathrm{d}}\right)$ resulted in a feed condition $\mathrm{K}_{\mathrm{d}}$ value of $\geq 450 \mathrm{~mL} / \mathrm{g}$ for a two-year aged batch of SL-644. The aged SL-644 resin met this success criterion.

\section{PNWD-3120 (WTP-RPT-018) - Development of an Enhanced Thermodynamic Database for the Pitzer Model in ESP: The Fluoride and Phosphate Components}

\section{Focus Area: Pretreatment}

The development of an enhanced database of thermodynamic modeling parameters for the $\mathrm{Na}-\mathrm{OH}-\mathrm{NO}_{3}-\mathrm{NO}_{2}-\mathrm{SO}_{4}-\mathrm{CO}_{3}-\mathrm{F}-\mathrm{PO}_{4}-\mathrm{H}_{2} \mathrm{O}$ system is presented. The model development emphasizes the chemical reactions involving the fluoride and phosphate components and is based upon the thermodynamic model of Pitzer and coworkers. Extensive comparisons of the model with experimental data in common-ion ternary and more complex solutions are presented to establish the validity of the final model. Comparisons are also made with the Environmental Simulation Program (ESP, Version 6.4) using both the public and certain special databases developed for these chemical systems. Overall, the new 
model gave a quite satisfactory representation of the experimental data for these chemical systems. The model's limitations, which were due principally to a lack of experimental data for certain systems, also is discussed. At the time this report was written, it was anticipated that this database would form the foundation for the version of ESP that included the Pitzer model. The new version of the Pitzer model was slated for release for beta testing at the end of FY 2001. Initial applications of the new model are presented, illustrating improved predictions of the new model parameterizations for the Sr/TRU separation process.

\section{PNWD-3173 (WTP-RPT-020, Rev.1) - Chemical Analysis and Physical Property Testing of 241-AN-102 Tank Waste-Supernatant and Centrifuged Solids}

\section{Focus Area: Characterization}

The four objectives of the work documented in this report were

- to ensure that sample material used for analysis is homogenized

- to separate homogenized composite into the liquids fraction and solids fraction

- to analyze the liquids and solids fractions for the inorganic, radiochemical, and selected organic constituents required for the process definition, while conforming to all appropriate laboratory quality control (QC) protocols and QC acceptance criteria

- to compare the results of the analyses to the WTP specifications. For the comparison to the specifications, the insoluble solids were defined as the total dried solids remaining after phase separating centrifuged solid minus the contribution to the dried solids from the interstitial liquid. For this report, "insoluble solids" are assumed to be the "undissolved solids," although some of the solids may be the result of salt precipitates from the saturated supernatant.

Data and results limitations are described. Initial sample processing, QC sample results, method detection limits, and other QC indicators are documented.

\section{PNWD-3172 (WTP-RPT-021 Rev. 1) - Chemical and Physical Properties Testing of 241-AN-102 Tank Waste Blended with 241-C-104 Wash/Leachate Solutions}

\section{Focus Area: Characterization}

This report summarizes the blending of Hanford waste from underground storage Tank 241-AN-102 (AN-102) combined with wash and leachate solutions from Tank 241-C-104 (C-104) and the characterization of the resulting AN-102/C-104 blended feed. The blended feed was measured for selected chemical, radiochemical, and organic analytes, and the analyte concentrations compared to the chemical and radiochemical WTP envelope specifications.

To obtain the C-104 filtrate, leachate, and wash solutions, the HLW sludge from Tank C-104 was retrieved, homogenized, and settled. The feed was filtered using a crossflow filtration system. Solids remaining after filtration were washed and leached with $3 \mathrm{M}$ sodium hydroxide. The initial C-104 filtrates, plus wash and leach solutions produced, were characterized and then used as the C-104 blending material in this task.

High-level waste slurry from Tank AN-102 was retrieved using grab samples, in bottles, then homogenized and characterized. Supernatant and solids from homogenized jars of AN-102 were blended 
to make waste material consisting of $2 \mathrm{wt} \%$ undissolved solids to be used as feed material in this task. Measurements of selected physical properties (i.e., heat capacity, viscosity, and particle size) for the $2 \mathrm{wt} \%$ solids AN-102 waste are reported.

In this report, data and results limitations are described. Physical measurements performed on the diluted AN-102 waste material, and the initial compatibility testing, blending parameters, and chemical, radioisotope, and organic analytical results on the AN-102/C-104 blended feed are reported. The QC sample results, method detection limits, and other QC indicators also are described.

\section{PNWD-3174 (WTP-RPT-022) - Chemical Analysis and Physical Property Testing of Diluted 241-AP-101 Tank Waste}

\section{Focus Area: Characterization}

This report documents the physical property testing and inorganic and radiochemical characterization of diluted waste from underground storage Tank 241-AP-101 (AP-101) conducted by PNWD for BNI. The objectives were to:

- Prepare a composite sample from multiple bottles of AP-101 waste samples.

- Verify the homogeneity of the composite sample.

- Prepare a diluted feed by adjusting the composite sample sodium concentration to $4.7 \mathrm{M}$.

- Analyze the AP-101 diluted feed waste sample.

- Compare analytical results with the LAW feed specifications for the WTP. The results confirmed that waste contained in Tank AP-101 meets the criteria for low-activity waste Envelope A feed.

\section{PNWD-3141 (WTP-RPT-029) - Optimization of Sr/TRU Removal Conditions with Samples of AN-102 Tank Waste}

\section{Focus Area: Pretreatment}

The WTP baseline for pretreating LAW at Hanford includes a precipitation step for removing radioactive strontium (Sr-90) and TRU isotopes before the waste is vitrified. This report summarizes testing to determine the effects of temperature and low levels of reagent on Tank AN-102 waste liquids and to identify the conditions for later integrated process testing with a mixture of Tank AN-102 waste and HLW pretreatment streams (filtrate, wash, and leach solution from HLW pretreatment of Tank C-104 wastes). These conditions include determining the minimum amount of strontium and permanganate needed for decontaminating the liquid waste to meet LAW requirements for vitrification. The success criteria included demonstrating that the treated waste meets BNI specifications for removing Sr-90 and TRU elements from the LAW solution.

The optimization experiments discussed in this report were performed in radioactive hot cells using approximately $20-\mathrm{mL}$ samples of waste with various amounts of strontium, permanganate, and/or hydroxide. Experiments were conducted with 4-hour solids digest time at ambient temperature and $50^{\circ} \mathrm{C}$. Supernatant decontamination data were obtained from the test data. The Sr-90 and TRU DFs were compared to determine the efficiency of the Sr/TRU removal process. Preferred conditions were identified for future testing.

This report documents the series of small-scale Sr/TRU decontamination tests. Test conditions and experimental procedures are described in Section 2. Experimental results from the tests are detailed in 
Section 3. The major conclusions and recommendations from this work are given in Section 4. The appendices contain the test instructions, data sheets, logbook entries, analytical data, calculations, and staff roles/responsibilities.

\section{PNWD-3189 (WTP-RPT-034) - Verification of Process Conditions for Sr/TRU Removal from AN-102/C-104 Waste Blend}

\section{Focus Area: Pretreatment}

The WTP baseline for pretreating Envelope C LAW at Hanford includes a precipitation step for removing radioactive strontium (Sr-90) and TRU isotopes before the waste is vitrified.

The objective of the work reported here was to verify that optimized process conditions--using the minimum among of strontium and permanganate needed to decontaminate the liquid waste--would provide adequate $\mathrm{Sr} / \mathrm{TRU}$ decontamination of the AN-102/C-104 waste blend. For this integrated process verification testing, a blended waste was used that combined samples from Tank AN-102 and sludge washing/leaching solutions from Tank C-104 Mixing the sludge washing/leaching solutions with the AN-102 sample resulted in a waste blend of approximately $3 \mathrm{M}$ sodium. This solution was evaporated to concentrate the sodium to approximately $5 \mathrm{M}$ sodium as required for the Sr/TRU removal process. Before integrated process verification tests were conducted on a 1-L batch of blended waste, small-scale experiments were performed to verify process conditions for Sr-90 and TRU removal - specifically, to evaluate if low reagent addition (no additional hydroxide, $0.02 \mathrm{M} \mathrm{Sr}$, and $0.02 \mathrm{M}$ permanganate) is adequate for $\mathrm{Sr} / \mathrm{TRU}$ decontamination of the blended waste.

The verification tests were conducted at ambient hot cell temperature $\left(26^{\circ} \mathrm{C}\right)$ under only two conditions: $\mathrm{Sr}$ at $0.02 \mathrm{M}$ and $\mathrm{Sr}$ at $0.02 \mathrm{M}$ plus permanganate at $0.02 \mathrm{M}$. Experiments were performed in radioactive hot cells using approximately $20-\mathrm{mL}$ samples of waste. The precipitate was digested for 4 hours, at ambient hot cell temperature $\left(26^{\circ} \mathrm{C}\right)$. Supernatant decontamination data were obtained from the test data. The Sr-90 and TRU decontamination factors (DFs) were compared to determine the efficiency of the $\mathrm{Sr}$ /TRU removal process. Preferred Sr/TRU removal conditions were identified for the integrated process verification test on a 1-L sample of the waste blend.

The treatment conditions provided adequate Sr/TRU decontamination of the AN-102/C-104 waste blend. The free hydroxide concentration in the blended waste was adequate for decontamination with added strontium and permanganate. As expected, no, or very little, TRU decontamination occurred without the addition of permanganate. The integration of sludge wash/leach streams with AN-102 waste had very little impact on meeting the Sr/TRU limits for ILAW. The most significant impact of blending was the reduced levels of Sr-90 and TRU in the feed to the process.

The results from this series of small-scale Sr/TRU decontamination tests are presented in this report. Test conditions and experimental procedures are described, experimental results from the tests are discussed, and the major conclusions and recommendations are given. The appendices contain the test instructions, data sheets, logbook entries, analytical data, calculations, and staff roles/responsibilities for this work. 


\section{PNWD-3216 (WTP-RPT-019) - Performance of Tubular Porous Metal Crossflow Filters}

\section{Focus Area: Pretreatment}

In developing Envelope D simulants for scaled crossflow filtration testing in support of the WTP project, PNWD tested simulants in the cells unit filter (CUF), and a large number of crossflow filtration flux results were obtained using a 0.1-micron Graver, a 0.1-micron liquid-service, industrial-grade Mott, and 0.5-micron liquid-service, industrial-grade Mott filter elements. The goal of conducting parametric CUF tests with various filter elements was to replicate the operating and experimental conditions of the actual waste trials and to validate simulant filtration performance. A large amount of filtration data were obtained, but only those results that provided direct simulant filtration performance data compared with actual waste results were reported.

This report documents the unpublished crossflow filtration data generated from testing the Envelope D HLW filtration simulants during the development phase of these simulants. The report is a compilation of previous test data and not the work performed directly in support of the WTP. The goal of testing in FY 2000 was not to examine the performance of various filters in a comprehensive parametric fashion but to present the data because they provide valuable insight into optimum filter elements for the design of the WTP. A detailed filtration flux data package for each filter element at various test matrix conditions is also provided in the report.

\section{PNWD-3229 (WTP-RPT-020, Rev. 1) - Chemical Analysis and Physical Property Testing of 241-AN-102 Tank Waste-Supernatant and Centrifuged Solids}

\section{Focus Area: Characterization}

This report summarizes PNWD's sample receipt, compositing, homogenization, and initial characterization activities of the AN-102 tank waste. The objectives of the work were

- to ensure that sample material used for analysis is homogenized

- to separate homogenized composite into the liquids fraction and solids fraction

- to analyze the liquids and solids fractions for the inorganic, radiochemical, and selected organic constituents required for the process definition, while conforming to all appropriate laboratory quality control (QC) protocols and QC acceptance criteria

- to compare the results of the analyses to the WTP specifications.

In the report, data and results limitations are described. Initial sample processing, QC sample results, method detection limits, and other QC indicators are documented.

\section{PNWD-3228 (WTP-RPT-021, Rev. 1) - Chemical and Physical Properties Testing of 241-AN-102 Tank Waste Blended with 241-C-104 Wash/Leachate Solutions}

\section{Focus Area: Characterization}

The blending of Hanford waste from underground storage Tank 241-AN-102 (AN-102) combined with wash and leachate solutions from Tank 241-C-104 (C-104) and the characterization of the resulting AN-102/C-104 blended feed are detailed in this report. The blended feed was measured for selected chemical, radiochemical, and organic analytes, and the analyte concentrations compared to the chemical and radiochemical WTP envelope specifications. 
To obtain the C-104 filtrate, leachate, and wash solutions, the HLW sludge from Tank C-104 was retrieved, homogenized, and settled. The feed was filtered using a crossflow filtration system. Solids remaining after filtration were washed and leached with $3 \mathrm{M}$ sodium hydroxide. The initial C-104 filtrates, plus wash and leach solutions produced, were characterized and then used as the C-104 blending material in this task.

High-level waste slurry from Tank AN-102 was retrieved using grab samples, in bottles, then homogenized and characterized. Supernatant and solids from homogenized jars of AN-102 were blended to make waste material consisting of $2 \mathrm{wt} \%$ undissolved solids to be used as feed material in this task. Measurements of selected physical properties (i.e., heat capacity, viscosity, and particle size) for the $2 \mathrm{wt} \%$ solids AN-102 waste are reported.

In this report, data and results limitations are described. Physical measurements performed on the diluted AN-102 waste material, and the initial compatibility testing, blending parameters, and chemical, radioisotope, and organic analytical results on the AN-102/C-104 blended feed are reported. The QC sample results, method detection limits, and other QC indicators also are described.

\section{PNWD-3239 (WTP-RPT-024) - Radiation Stability Testing of SuperLig ${ }^{\circledR} 639$ and SuperLig ${ }^{\circledR} 644$ Resins}

\section{Focus Area: Pretreatment}

Unit operations of the WTP process include the separation of ${ }^{137} \mathrm{Cs}$ and ${ }^{99} \mathrm{Tc}$ by ion exchange from the liquid portion of the waste. SuperLig® 644 (SL-644) and SuperLig639® (SL-639) ion exchange resins were selected by the project to perform ${ }^{137} \mathrm{Cs}$ and ${ }^{99} \mathrm{Tc}$ separations, respectively.

The cesium (SL-644) and technetium (SL-639) resins were evaluated to determine their replacement frequency and the potential formation of hazardous or regulated organic compounds for WTP flowsheet development and spent resin disposal requirements, respectively.

The objectives of the investigation documented in this report were

- to perform irradiation experiment from 0 to $10^{8} \mathrm{R}$ with eight different combinations of resin and solutions

- to determine the decrease in resin capacity as a function of radiation dose and contact solution by measuring batch-distribution coefficients of the irradiated and control resin samples

- to determine the quantity and generation rate, and identify gaseous and volatile organic compounds evolved during irradiation tests

- to determine the concentration of semi-volatile organic compounds present in the liquid phase present after sample irradiation.

- to qualify the corrosion of stainless steel vessels used in $1 \mathrm{E}+08 \mathrm{R}$ irradiation tests.

All objectives were satisfied. This report documents testing, results, and analysis associated with the SL-644 and SL-639 radiolytic degradation investigation. 


\section{PNWD-3251 (WTP-RPT-026) - Equilibrium Batch Contact Testing of SuperLig ${ }^{\circledR} 639$}

\section{Focus Area: Pretreatment}

Unit operations of the WTP process include the separation of ${ }^{99} \mathrm{Tc}$ by ion exchange from the liquid portion of the waste. The SuperLig ${ }^{\circledR} 639$ (SL-639) ion exchange resin was selected to perform this ${ }^{99} \mathrm{Tc}$ separation.

PNWD evaluated the SL-639 resin to determine its behavior under various potential processing conditions in support of a model under development at the Savannah River Technical Center (SRTC) that will be able to predict the response of SL-639 under various processing conditions. The results from the PNWD tests will be incorporated into the model. Objectives of the work documented in this report were

- to evaluate the impact of the solution's nitrate to pertechnetate ratio on the SL-639 distribution ratio

- to evaluate the impact of the solution's chloride to pertechnetate ratio on the SL-639 distribution ratio

- to evaluate the impact of the solution's ionic strength on the SL-639 distribution ratio

- to evaluate the impact of temperature and time on the SL-639 distribution ratio.

These results were achieved through the conduct of testing. A batch of SuperLig® 639 was preconditioned by contact with an alkaline solution at $5 \mathrm{M}$ sodium. Excess hydroxide and sodium were removed by repeated contacts with deionized water, and the resin was dried to a constant weight. Approximately $0.1 \mathrm{~g}$ of resin was contacted with $10 \mathrm{~mL}$ of a pertechnetate $\left({ }^{99} \mathrm{Tc}\right)$-containing test solution. Sample aliquots were taken before and after contact with the resin, and their activity was analyzed by liquid scintillation counting.

This report documents testing, results, and analysis associated with the measurement of kinetic and equilibrium batch contacts involving SL-639. The report is intended to aid the RPP-WTP project in developing the computer model to be used to predict performance of the Tc ion exchange system in the WTP over a wide variety of conditions.

\section{PNWD-3201 (WTP-RPT-027) - Thermal and Radiolytic Gas Generation from Washed AN-102 Sludge}

\section{Focus Area: Pretreatment}

This report summarizes progress made in evaluating mechanisms by which flammable gases are generated in washed Tank 241-AN-102 (AN-102) sludge based on the results of laboratory tests using actual sludge samples from Tank AN-102. Gas generation from the sludge sample was measured as a function of temperature with and without the application of an external radiation source $\left({ }^{137} \mathrm{Cs}\right.$ capsule).

The objective of this work was to establish the composition ratio of gas generated in actual tank sludge due to chemical and radiolytic processes as a function of temperature. The gas-generation tests focused first on the effect of temperature on the composition and rate of gas generation. Generation rates of hydrogen, nitrous oxide, nitrogen, and methane increased with temperature, and the composition of the gas mixture produced varied with temperature. The gas-generation rate was examined at $45^{\circ}, 60^{\circ}, 75^{\circ}$, $90^{\circ}$, and $105^{\circ} \mathrm{C}$.

Gas-generation measurements were made using reaction vessels and a gas manifold system similar to those used in earlier studies with simulated waste. The self-dose rate from the radionuclide inventory of 
Tank AN-102 samples was calculated to assess the amount of radiolytically induced gas from internal radiation sources.

The AN-102 washed solids exhibited exothermic behavior, but the heat released fell below the Hanford threshold criterion ( $480 \mathrm{~J} / \mathrm{g}$ dry waste) measured by differential scanning calorimetry. The heat measured was substantially less than the theoretical maximum expected for the reaction of nitrate and nitrite salts with oxalate present in the tank waste. Analytical reports detailing analytic measurements of the washed AN-102 waste used in this study are summarized in the appendixes to this report.

PNWD-3222 (WTP-RPT-030) - Small Column Testing of SuperLig ${ }^{\circledR} 639$ for Removing ${ }^{99}$ Tc from Hanford Tank Waste Envelope A (Tank 241-AP-101)

\section{Focus Area: Pretreatment}

This report documents the small-scale column testing of the $\mathrm{TcO}_{4}{ }^{-}$-selective sorbent SuperLig ${ }^{\circledR} 639$ (SL-639) with waste from Tank 241-AP-101 (AP-101). The purpose of the PNWD Tc ion exchange process verification tests was to verify design and operating parameters for plant-scale ion exchange systems.

The test objectives were to

- Demonstrate the effectiveness of all SL-639 process steps.

- Prepare loading breakthrough profiles and elution profiles with diluted AP-101.

- Prepare batch-distribution isotherms.

- Produce and characterize a Tc eluate solution for additional testing.

- Produce a final effluent that removed at least $98 \%$ of the technetium from the AP-101 tank waste feed within a process goal of 250 bed volumes of feed.

Test results documented in this report were to be used also to validate ion exchange models.

\section{PNWD-3202 (WTP-RPT-032) - Effect of Eluant Flow Direction on the Elution Characteristics of SuperLig 644 Ion Exchange Resin}

\section{Focus Area: Pretreatment}

Unit operations of the WTP process include the separation of ${ }^{137} \mathrm{Cs}$ and ${ }^{99} \mathrm{Tc}$ from the liquid portion of the waste by ion exchange. SuperLig® 644 (SL-644) and SuperLig ${ }^{\circledR} 639$ (SL-639) ion exchange resins were selected to perform the ${ }^{137} \mathrm{Cs}$ and ${ }^{99} \mathrm{Tc}$ separations, respectively.

The objective of the task described by this report was to investigate the effect of eluant flow direction on the volume of eluant required to elute the SL-644 ion exchange resin and the elution characteristics. The objective of the testing was met: up-flow elution of the SL-644 resin is not more efficient than down-flow elution. 


\section{PNWD-3265 (WTP-RPT-037) - Batch Contact Testing of SuperLig @644}

\section{Focus Area: Pretreatment}

Unit operations of the WTP process include the separation of ${ }^{137} \mathrm{Cs}$ by ion exchange from the liquid portion of the waste. The SuperLig ${ }^{\circledR} 644$ (SL-644) ion exchange resin was selected to perform this ${ }^{137} \mathrm{Cs}$ separation.

PNWD evaluated the SL-644 resin to determine its behavior under various potential processing conditions. The results from these tests will be incorporated into a model developed at the Savannah River Technical Center capable of predicting the response of SL-644 under various processing conditions.

The objectives of PNWD's testing were

- to evaluate the impact of the solution's sodium-to-cesium ratio on the SL-644 Cs-distribution ratio

- to evaluate the impact of the solution's potassium-to-cesium ratio on the SL-644 Cs-distribution ratio

- to evaluate the impact of the solution's ionic strength on the SL-644 Cs-distribution ratio

- to evaluate the impact of time on the SL-644 Cs-distribution ratio

- to evaluate the SL-644 uranium-distribution ratio

- to evaluate the impact of changing hydroxide concentration on the SL-644 Cs-distribution ratio.

A batch of SuperLig ${ }^{\circledR} 644$ was preconditioned by contact with distilled water, followed by contact with $0.5 \mathrm{M}$ nitric acid. Excess nitric acid was removed by repeated contacts with deionized water, and the resin was dried to a constant weight. A large number of batch contacts were performed by contacting approximately $0.1 \mathrm{~g}$ aliquots of resin with $10 \mathrm{ml}$ of a cesium (137Cs spiked)-containing test solutions. Sample aliquots were taken before and after contact with the resin, and their activity was analyzed by gamma energy analysis using a liquid nitrogen cooled Ge detector.

The results achieved are described in this report.

\section{PNWD-3225 (WTP-RPT-039) - Preliminary Evaluation of Spent Silver Mordenite Disposal Forms Resulting from Gaseous Radioiodine Control at Hanford's Waste Treatment Plant}

\section{Focus Area: Vitrification}

PNWD determined the performance of selected spent-silver mordenite disposal forms in support of efforts to identify a regulatory-compliant waste form for spent-silver mordenite used to control radioiodine releases from the WTP. The objective of this work did not include optimization of the disposal form. In the qualification testing of silver mordenite, reduced silver mordenite, fluoride-treated silver mordenite, iodine-loaded reduced silver mordenite, and their grouted forms, PNWD found that grouted silver mordenite with added calcium iodide and grouted iodine-loaded reduced silver mordenite released the U.S. Environmental Protection Agency and Washington State regulated metals at levels below the EPA and Washington State Universal Treatment Standards for land disposal. 
PNWD-3267 (WTP-RPT-041) - Small Column Ion Exchange Testing of SuperLig ${ }^{\circledR 644}$ for Removal of ${ }^{137}$ Cs from Hanford Waste Tank 241-AZ-102 Concentrate (Envelope B)

\section{Focus Area: Pretreatment}

The WTP baseline process for ${ }^{137} \mathrm{Cs}$ removal from Hanford high-level tank waste is ion exchange. The pretreatment flowsheet included the use of Cs-selective, elutable, organic ion exchanger SuperLig® 644 (SL-644) material for Cs removal from the aqueous waste fraction. SL-644 has been shown to be effective in removing Cs from a variety of Hanford tank wastes.

PNWD performed Cs ion exchange studies to verify design and operating parameters for plant-scale ion exchange systems. Test results were to be used also to validate ion exchange models. This report summarizes testing of the SL-644 in batch-contact studies and in a dual small-column system.

The Cs ion exchange test objectives were to develop load and elution breakthrough profiles using waste from Tank 241-AZ-102 concentrated to $4.6 \mathrm{M} \mathrm{Na}$ (AZ-102C); produce and characterize the Cs eluate; remove ${ }^{137} \mathrm{Cs}$ from the $\mathrm{AZ}-102 \mathrm{C}$ to meet LAW vitrification criteria; and develop batch-distribution coefficients for AZ-102C. The final effluent was to contain $<0.322 \mu \mathrm{Ci}{ }^{137} \mathrm{Cs} / \mathrm{mL}$, based on a $5 \mathrm{wt} \%$ waste $\mathrm{Na}_{2} \mathrm{O}$ loading in the waste glass. All testing objectives were met.

\section{PNWD-3315 (WTP-RPT-046) - Chemical Degradation of SuperLig ${ }^{\circledR} 644$ Ion Exchange Resin}

\section{Focus Area: Pretreatment}

Unit operations of the WTP process include the separation of ${ }^{137} \mathrm{Cs}$ and ${ }^{99} \mathrm{Tc}$ by ion exchange from the liquid portion of the waste. SuperLig® 644 (SL-644) and SuperLig639® (SL-639) ion exchange resins were selected by the project to perform ${ }^{137} \mathrm{Cs}$ and ${ }^{99} \mathrm{Tc}$ separations, respectively.

The primary objective of the task described in this report was to determine the degradation in SL-644 resin performance over repeated cycles of waste processing and elution in a column system. Secondary objectives included:

- determination of the extent to which the SL-644 resin consumes oxygen by monitoring the oxygen concentrations in the feeds and effluents

- preliminary assessment of some hazardous waste characteristics of the resin to support future development of a spent-resin disposal pathway.

- determination of the impact of LAW processing rate and $\mathrm{Cs}^{+}, \mathrm{K}+$, and $\mathrm{OH}$ concentrations on the resin breakthrough performance.

\section{PNWD-3260 (WTP-RPT-049) - Methodology for Adjusting and Normalizing Analyzed Glass Compositions}

\section{Focus Area: Waste Form Qualification}

This report documents PNWD's initial work to develop a procedure for performing glass composition adjustments (if needed) and normalizations on analyzed glass compositions. The procedure includes the following features: 
- data screening

- non-detect replacement

- blank correction

- bias detection and correction (if needed)

- $\quad$ normalization of analyzed (and corrected, if needed) glass compositions.

The report provides specific methods and formulas for blank correction, bias correction, and normalization. Specific methods for data screening and non-detect replacement are addressed elsewhere. Steps of the procedure implementing these features and the corresponding equations are presented in the report. Discussions of the options considered and equation derivations are presented in the appendices. The normalization approach is based on minimizing the sum of the weighted, squared differences between the analyzed glass component concentrations (after any needed blank or bias corrections) and the normalized concentrations. Different weighting schemes were considered within this weighted least squares normalization approach. Weights equal to the variances of the glass weight percent concentrations are recommended.

\section{PNWD-3301 (WTP-RPT-051) - Evaluation of Corona Oxidation as Back-up Technology for Organic Destruction in the Secondary Off-Gas Treatment System}

\section{Focus Area: Vitrification}

This report summarizes progress made in evaluating corona oxidation as an alternative to thermal catalytic oxidation for organics destruction in the secondary off-gas system of the WTP melters. The objective was to conduct laboratory and field tests to compare the two technologies. Figures of merit included power requirements, footprint, and degree of organics destruction.

Laboratory tests and a field trial were conducted to assess the ability of corona oxidation to replace catalytic oxidation for organics destruction in melter off-gas. Three compounds were target species: chlorobenzene, trichloroethylene, and naphthalene. Of the three, chlorobenzene and naphthalene are the most thermally stable. Chlorobenzene was selected as a model compound for corona oxidation experiments in the laboratory. Laboratory experiments focused on determination of power requirements for oxidation using three levels of contaminant in air.

In addition to the laboratory and field experiments, a cost and risk-reward analysis was performed. The methodology and results are documented in this report.

\section{PNWD-3235 (WTP-RPT-054) - Hanford Tank 241-AZ-102 Waste Concentration and Composition}

\section{Focus Area: Pretreatment}

The WTP baseline process for ${ }^{137} \mathrm{Cs}$ removal from Hanford high-activity tank waste is ion exchange. The pretreatment flowsheet includes the use of Cs-selective, organic ion exchanger SuperLig ${ }^{\circledR} 644$ (SL-644) material for cesium removal from the aqueous waste fraction. However, tests conducted at Savannah River Technology Center resulted in poor ion exchange performance when tested with waste from Tank 241-AZ-102 (AZ-102). It was postulated that the low Na molarity (2.77) of the AZ-102 supernatant contributed to the poor $\mathrm{Cs}$ ion exchange performance and that the ion exchange removal of $\mathrm{Cs}$ from AZ-102 concentrated to nominally $5 \mathrm{M} \mathrm{Na}$ would be more effective. 
PNWD performed Cs ion exchange studies and AZ-102 characterization, concentration, and subsequent concentrate characterization. The Cs ion exchange activities were to verify design and operating parameters for plant-scale ion exchange systems. Test results were to be used also to validate ion exchange models.

The objectives of this work were to composite the AZ-102 tank waste samples, perform limited characterization on the composite, concentrate the AZ-102 to nominally $5 \mathrm{M} \mathrm{Na}$, perform limited characterization of the concentrate, and provide the concentrated waste to the Cs ion exchange task for follow-on Cs ion exchange processing. All objectives were met.

This report describes the analytical testing of the AZ-102 as-received sample, the concentration process, and the AZ-102 concentrate and solids byproduct analyses and compositions.

\section{PNWD-3248 (WTP-RPT-057) - AP-101 Diluted Feed (Envelope A) Simulant Development Report}

\section{Focus Area: Pretreatment}

The WTP requires the use of nonradioactive tank waste simulants for process verification, waste form qualification tests, and plant cold commissioning. PNWD conducted testing and validation of the capability of LAW pretreatment processes for removing entrained solids, ${ }^{137} \mathrm{Cs},{ }^{99} \mathrm{Tc},{ }^{90} \mathrm{Sr}$, and TRU elements to meet product requirements for immobilized LAW. The objective of this testing was to develop a procedure for preparing a simulant to mimic the chemical and physical properties of the AP-101 supernatant fraction. There were no entrained solids in this waste. This objective was demonstrated by preparing a 10-L batch of AP-101 simulant. The simulant metals and anionic constituents' concentrations were to agree with actual AP-101 waste concentrations within $\pm 10 \%$, or within analytical error of the method as determined by inductively coupled plasma atomic emission spectrometry and inorganic ion chromatography. The simulant $10-\mathrm{L}$ batch prepared for this task met all the specified criteria with the following exceptions: $\mathrm{Cr}$ was $20 \%$ low, oxalate was $44 \%$ low, total organic carbon was $21 \%$ low, and the added $\mathrm{Si}$ and $\mathrm{Cu}$ were not detected. The Tank 241-AP-101 (AP-101) simulant will be used for conducting $\mathrm{Cs}$ and Tc ion exchange process verification testing.

\section{PNWD-3258 (WTP-RPT-060) - Filtration of Envelope C Waste Simulant Treated by the Sr/TRU Precipitation Process}

\section{Focus Area: Pretreatment}

The WTP baseline for pretreating Envelope C LAW at Hanford includes a filtration step for removing entrained solids and the $\mathrm{Sr}$ /TRU precipitate before the waste is vitrified. The purpose of the work discussed in this report was to conduct crossflow filtration tests with a treated simulant representing the "active" (actual) waste blend, a mixture of Tank AN-102 samples and C-104 sludge pretreatment solutions (supernatant, wash, caustic leach, and rinse solutions) referred to as the AN-102/C-104 waste blend.

The main text of this report describes the test conditions and experimental procedures, discusses the results, and provides conclusions based on the results. The appendices contain the simulant recipe and particle size distribution data. 


\section{PNWD-3261 (WTP-RPT-061) - Development and Assessment of the TEMPEST CFD Model of the Pulsed Jet Mixing Systems}

\section{Focus Area: Pretreatment}

The flowsheets for the WTP pretreatment and vitrification of the Hanford high-level waste include the use of several hundreds of pulsed jet mixers (PJMs) throughout the entire plant.

PNWD developed and experimentally validated a computational fluid dynamic (CFD) model of the PJM systems using the in-house TEMPEST CFD. The CFD code is intended to be used to predict the performance of the PJM equipment and verify that the design basis requirements are satisfied.

The objectives of the work were to develop and experimentally validate the TEMPEST CFD model of the PJM system using

- $\quad$ small-tank hydrodynamic (water) data

- large-tank hydrodynamic (water) data

- column simulant settling data

- large-tank simulant data.

All except validation with the large-tank simulant data were accomplished. Inability to validate the model using the large-tank simulant data was due primarily to the asymmetries of the flow fields in the tank, which made the data insufficient to complete the validation of code.

\section{PNWD-3257 (WTP-RPT-063) - Gas Generation and Energetics Studies of an Envelope C Waste Treated by the Sr/TRU Precipitation Process}

\section{Focus Area: Pretreatment}

The WTP baseline for pretreating Envelope C LAW at Hanford includes a precipitation step for removing Sr-90 and TRU isotopes before the waste is vitrified. The resulting solids, designated as HLW, are removed, washed, and concentrated by crossflow filtration. The Sr/TRU removal process is based on precipitation by adding strontium nitrate for Sr-90 removal and permanganate for TRU removal.

Optimization of the Sr/TRU precipitation reaction conditions includes determining the gas generation and chemical energetics release from $\mathrm{Sr} / \mathrm{TRU}$ precipitates. The objective of the work reported here was to measure gas generation and energetics of actual solid samples from the $\mathrm{Sr} / \mathrm{TRU}$ removal treatment of samples of Tank 241-AN-102 (AN-102) waste mixed with leach solutions from pretreatment of 241-C-104 (C-104) sludge (solids referred to as AN-102/C-104 Sr/TRU precipitate).

The AN-102/C-104 Sr/TRU precipitate was washed using inhibited water ( $\left.0.01^{\prime} \mathrm{M} \mathrm{NaOH}\right)$ and dewatered to dryness using vacuum filtration. A subsample of the vacuum-dried solids was used for the energetics testing. The remaining solids were resuspended in inhibited water for gas generation testing to better mimic the slurry expected from crossflow filtration. Gas generation from the AN-102/C-104 Sr/TRU precipitate was measured as a function of temperature with and without the application of an external radiation source $\left({ }^{137} \mathrm{Cs}\right.$ gamma capsule). These tests will help address safety concerns and provide information on potential emissions to the off-gas ventilation system of the pretreatment vessel. 
This report describes the gas generation test samples and the experimental conditions and equipment used for the tests. The results of the gas generation experiments are discussed. The energetics measurements of AN-102/C-104 Sr/TRU precipitate are provided, and overall conclusions are given.

\section{PNWD-3279 (WTP-RPT-064) - Rheological and Physical Properties of AP-101 LAW Pretreated Waste and Melter Feed}

\section{Focus Area: Vitrification}

This document presents physical and rheological properties of AP-101 waste that is in a state similar to two streams anticipated in the WTP - the pretreated LAW stream that consists of the effluent from the cesium and technetium ion exchange columns and the LAW melter feed material consisting of the pretreated LAW waste stream mixed with a formulation of glass-former chemicals. The experimental approach taken by PNWD is described in this report, as are the test results.

\section{PNWD-3289 (WTP-RPT-067) - Thermodynamic Modeling of AZ-101 Slurry Leaching}

\section{Focus Area: Pretreatment}

PNWD modeled the results from sludge leaching studies of Tank AZ-101 waste samples using the Environmental Simulation Program (ESP) Version 6.6. ESP simulations using two different databases (Pitzer and Bromley Zematis) were in reasonably good agreement for most of the components but differed significantly for some of the minor components (phosphate, lanthanum, neodymium). The models predict that the solids present in the slurry were composed predominantly of oxide/hydroxide phases with only minor amounts of carbonate and sulfate. With the exception of aluminum hydroxides, these oxide/hydroxide phases are predicted to remain insoluble during treatment. The principal anions in solution, nitrate $\left(\mathrm{NO}_{3}^{-}\right)$and $\left(\mathrm{NO}_{2}^{-}\right)$, were predicted to be completely soluble.

Significant amounts of aluminum are predicted to dissolve in the leach step. The models predict that if the aluminum is present in the initial slurry as the more soluble gibbsite phase, then all of the aluminum should be completely removed at the experimental temperature of $85^{\circ} \mathrm{C}$. However, if the aluminum is present as the more insoluble boehmite phase, then aluminum should be only partially soluble. The minor amounts of precipitated sulfate, fluoride, and oxalate predicted to be initially present in the sludge are removed in the first wash step. In general, the calculated supernatant concentrations followed the same trends observed experimentally and were often quite close quantitatively to the experimental values.

Based upon these results, several recommendations are made on how to process AZ-101 sludge more efficiently: 1) eliminating the second wash step and possibly eliminating the wash process entirely, 2) adjusting the reaction time in the leach step to enhance any removal of soluble gibbsite, 3) testing higher hydroxide concentrations in the leach step to remove the boehmite, and 4) using a higher base concentration in the rinse steps to suppress the tendency for aluminum hydroxide post-precipitation. 


\section{PNWD-3263 (WTP-RPT-068) - Assessment of the Sr/TRU Removal Precipitation Reaction Mechanisms Using Waste Simulant Solutions}

\section{Focus Area: Pretreatment}

This report discusses PNWD's investigations into the mechanism of the strontium/permanganate treatment process for removal of Sr-90 and TRU from tank supernatant destined for immobilization as LAW. Experiments were conducted with simple mixtures of organic complexants and an inactive, simulated supernatant based on the composition of AN-102 waste mixed with C-104 sludge pretreatment solutions. The purpose of these mechanistic studies was to determine the importance of oxidation, absorption, precipitation, and ligand displacement on TRU decontamination. Studies were conducted with simple mixtures of organic complexants and simulated supernatant solutions to develop a better understanding of the TRU decontamination mechanisms.

The objective of the work was to further investigate Mn reaction chemistry relevant to waste processing and to perform tests with an inactive AN-102/C-104 waste blend simulant to investigate treatment reaction mechanisms and to scope experiments to be performed on actual active waste.

The reaction mechanism tests are documented in this report. Test conditions and experimental procedures are described, results from the tests are presented and discussed, and the major conclusions and recommendations are given. The report appendix contains sample data, concentration data for key elements, and calculated decontamination factors for the nonradioactive spike elements.

\section{PNWD-3283 (WTP-RPT-070) - The Corrosion Effects of Mercury and Mercury Compounds on WTP Materials: Electrochemical Tests}

\section{Focus Area: Characterization}

This report summarizes work PNWD performed in support of the WTP. The work discussed here consisted of electrochemical corrosion testing of candidate materials of construction for process equipment and piping that may be exposed to mercury-containing waste solutions and process solutions in the plant. The tests conducted for this study were screening tests for follow-on long-term immersion testing and were designed to 1) eliminate unsuitable alloys from further consideration and 2) identify appropriate test parameters and their ranges for long-term immersion testing.

The overall study comprised a test program that included three phases: 1) short-duration electrochemical corrosion tests as scoping studies to initially evaluate the possible effects of $\mathrm{Hg}$ on candidate materials at a variety of conditions, followed by 2) longer-term aqueous immersion tests for process temperatures less than $100^{\circ} \mathrm{C}$ and 3 ) high-temperature gas exposure tests for process temperatures greater than $100^{\circ} \mathrm{C}$.

The testing and results of Phase 1 are given in this report. Materials and parameters, as well as the test matrix used for most of the testing, are described. The test results, including corrosion potentials, corrosion rates, and cyclic polarization curves, are discussed. Conclusions and recommendations are presented. The appendices contain the planned test matrix, a statistical analysis of the data, and a literature review conducted to assess available information on corrosion by mercury. The literature survey showed that limited testing has been reported, especially at conditions relevant to this study. 


\section{PNWD-3327 (WTP-RPT-074) - Development and Testing of the Automated ${ }^{99}$ Tc Monitor}

\section{Focus Area: Pretreatment}

An on-line/at-line analytical method is required for the WTP to detect ${ }^{99} \mathrm{Tc}$ in the effluent from the technetium removal columns at the concentration required to comply with the immobilized LAW product specifications. Development of a reliable at-line process monitor will help to address contractual requirements (total ${ }^{99} \mathrm{Tc}$ concentration in the LAW melter feeds) as well as operational and throughput requirements via control and monitoring of the Tc ion exchange column operation. The monitor must achieve detection limits of $1.0 \times 10^{-6} \mathrm{Ci} / \mathrm{L}{ }^{99} \mathrm{Tc}$ in LAW matrices of 5 molar sodium. Measurements must be done in near real time, with the analysis frequency of several samples per hour (up to 4 to 6 samples per hour may be required). The monitor must be accurate within $15 \%$ of the baseline inductively coupled plasma mass spectrometry (ICP-MS) method and must provide precision of $10 \%$ relative standard deviation. The monitor instrumentation must be simple and robust for remote at-line operation at the WTP.

In fiscal year 2000, PNWD personnel demonstrated a separation/beta scintillation system that is capable of achieving the required detection level for ${ }^{99} \mathrm{Tc}$. PNWD personnel adapted an existing extraction chromatographic TEVA-resin column separation and on-line scintillation detector system to monitor ${ }^{99} \mathrm{Tc}$ in LAW solutions. This method required previous manual oxidation of the LAW samples to ensure that all technetium was present as pertechnetate. PNWD personnel conducted comparison analyses using the automated analyzer and ICP-MS. The analytical results achieved with the automated analyzer were in agreement with those obtained by ICP-MS for AN-107 and AW-101 samples.

In fiscal year 2001, PNWD initiated development of a fully automated Tc monitor instrument that performs sample delivery, oxidation, and detection steps in a single functional unit. The objectives of this work were to

- Design, develop, and integrate hardware and instrumentation required to perform automated radiochemical measurement of total ${ }^{99} \mathrm{Tc}$.

- Develop and demonstrate reliable, rapid sample acidification and microwave-assisted sample oxidation procedures that convert all Tc to pertechnetate.

- Develop and demonstrate an anion exchange column separation scheme that enables reliable separation of ${ }^{99} \mathrm{Tc}(\mathrm{VII})$ from radioactive and stable interferences present in LAW matrices.

- Develop and demonstrate calibration/quantification methods that will be suitable for use in the plant setting and will facilitate automated, remote calibration and performance verification.

- Develop and demonstrate flow-through scintillation detection and quantification of the separated ${ }^{99} \mathrm{Tc}$.

- Develop a fully-automated analysis method based on the sample treatment, separation, and detection procedures.

- Test automated instrumentation and analysis procedures using simulants and actual waste samples. Compare analysis results obtained using an automated Tc monitor instrument with the baseline ICP-MS data for the analysis of Envelope A, B, and C matrixes with varying Tc concentration.

- Demonstrate the feasibility of unattended, continual operation over at least 40 hours.

- Based on the testing, identify design requirements and modifications for use in the design of the actual process monitor instrument.

This report describes the design, development, and testing of the prototypical fully automated ${ }^{99} \mathrm{Tc}$ radiochemical measurement system prototype conducted by PNWD during fiscal years 2001 through 2003. 
PNWD-3300 (WTP-RPT-076) - Identification of Washed Solids from Hanford Tanks 241-AN-102 and 241-AZ-101 with X-Ray Diffraction, Scanning Electron Microscopy, and Light-Scattering Particle Analysis

\section{Focus Area: Characterization}

This report describes the identification of phases in the washed solids from actual sludge taken from a composite sample of Tanks 241-AN-102 (AN-102) and 241-AZ-101 (AZ-101) waste. The wastes will be phase separated in the WTP, where solids will be washed, then forwarded for processing into a HLW fraction, combined with other HLW waste processing streams, and vitrified into a HLW glass. Modeling these waste-processing steps for process optimization and cold commissioning requires using a simulant that accurately reflects the tank waste solids composition and particle size distribution (PSD).

PNWD tested AN-102 and AZ-101 solids to define better the composition, morphology, and associated PSD. The objective of this work was to determine the structure, composition, and size distribution of individual phases in the washed solids sample. The techniques used were $\mathrm{x}$-ray diffraction, scanning electron microscopy with $\mathrm{x}$-ray energy dispersive spectroscopy, and laser light scattering PSD. The particle size distribution of solids sampled from AN-102 labeled as AN-102 WS9 is described in this report.

\section{PNWD-3273 (WTP-RPT-077) - Demonstration of Ability to Mix in a Small-Scale Pulsed Jet Mixer Test Facility}

\section{Focus Area: Pretreatment}

This report documents the testing of small-scale pulsed-jet mixer (SS-PJM) focused on addressing several issues associated with the effectiveness of the PJMs in the baseline design of strontium/transuranic (Sr/TRU) precipitation and sludge-washing processes in WTP. The objectives of the current work involve evaluating the applicability of PJMs to mix solutions of different densities and to generate density gradient data for CFD validation. In these experiments, a low-density reagent liquid (water at specific gravity (SG) 0.99) was carefully introduced into the SS-PJM tank on top of an inventory of a high-density waste-simulant liquid (sodium thiosulfate solution with SG of $\sim 1.31$ ). The transient fluid densities at three locations in the tank were then measured at different operating conditions of the mixer. All experiments employed a video camera for flow/mixing visualization.

In addition to the SS-PJM tests, simulations were intended to be performed using the TEMPEST CFD model of the PJM system to:

1. Validate the model using the data from at least one SS-PJM test-data set.

2. Predict PJM performance in the plant-scale vessel. 


\section{PNWD-3303 (WTP-RPT-081) - Large Tank Experimental Data for Validation of the FLUENT CFD}

Model of Pulsed Jet Mixers

\section{Focus Area: Pretreatment}

PNWD was contracted to provide simulant mixing test results for the validation of the FLUENT computational fluid dynamics (CFD) model of the pulsed jet mixing (PJM) systems. Several hundred of these PJMs are expected to be used in the WTP.

The three objectives of the work performed included:

- reconfiguring the large tank test stand to be as geometrically symmetric as possible and determining the as-built dimensions of the test system

- conducting hydrodynamic tests to check for symmetry of the fluid flow in the tank

- performing mixing tests to generate concentration and velocity data using glass-bead/water simulants with a nominal volume mean particle size of 10 and 35 microns at varying solids loading and/or modes of PJM operation.

This report summarizes the modifications made to be the large tank test configuration to make it geometrically symmetric and presents the experimental data generated after the modifying the test system. The data presented in this report include 1) as-built dimensions of the test configuration after PJM realignment, 2) hydrodynamic velocity data, and 3) velocity and density data with a simulant consisting of glass-beads in water with a nominal volume mean particle size of 10 and 35 microns.

\section{PNWD-3330 (WTP-RPT-088) - AP-101 Simulant Validation for Cesium Ion Exchange Processing Using SuperLig ${ }^{\circledR} 644$}

\section{Focus Area: Pretreatment}

The WTP baseline process for ${ }^{137} \mathrm{Cs}$ removal from Hanford high-level tank waste is ion exchange. The pretreatment flowsheet included the use of Cs-selective, elutable, organic ion exchange material, SuperLig ${ }^{\circledR} 644$ (SL-644), for Cs removal from the aqueous waste fraction. Testing with actual tank waste is expensive because of its high radiological dose and associated requisite containment facilities. To mitigate testing costs, Hanford tank waste simulants are used to test the ion exchanger.

PNWD was contracted to develop a simulant of the supernatant waste in Tank 241-AP-101 (AP-101), diluted to $5 \mathrm{M} \mathrm{Na}$, and to validate this simulant for use in Cs ion exchange studies. The simulant will be used for Cs ion exchange studies to verify design and operating parameters for the WTP plant-scale ion exchange systems.

\section{PNWD-3288 (WTP-RPT-097) - Initial Suitability Evaluation of Steam-Reformed Low Activity Waste for Direct Land Disposal}

\section{Focus Area: Vitrification}

A single sample of fluidized bed steam reformer product was subjected to detailed characterization and laboratory testing to determine whether the product would be an acceptable alternative to glass for 
immobilizing low-activity waste at Hanford. The laboratory testing provided a data set suitable for direct comparison with typical low-activity waste glasses tested under identical conditions.

PNWD conducted two different tests, the single-pass flow-through and pressurized unsaturated flow test. These tests form part of the recommended strategy for evaluating long-term waste form performance for the LAW disposal system and have been used extensively to evaluate various LAW glass formulations. The results and conclusions from this testing program are summarized in this report.

PNWD-3198, Rev. 1 (WTP-RPT-016, Rev. 1) - Small Column Ion Exchange Testing of SuperLig ${ }^{\circledR 644}$ for Removal of ${ }^{137}$ Cs from Hanford Waste Tank 241-AP-101 Diluted Feed (Envelope A)

\section{Focus Area: Pretreatment}

The WTP baseline process for ${ }^{137} \mathrm{Cs}$ removal from Hanford high-level tank waste is ion exchange. The flowsheet includes the use of Cs-selective, organic ion exchanger SuperLig® 644 (SL-644) material for Cs removal from the aqueous waste fraction.

PNWD was contracted to perform Cs ion exchange studies to verify design and operating parameters for plant-scale ion exchange systems. Test results will also be used to validate ion exchange models.

This report summarizes testing of the SL-644 in batch-contact studies and in a dual small-column system. The test matrix was Envelope A waste from Tank 241-AP-101. Batch contacts were performed with the waste at three Cs concentrations with a phase ratio of 100 (liquid volume to exchanger mass ratio) with both SL-644 and crystalline silicotitanate (IE-911, an alternative Cs ion exchanger). Ion exchange processing was conducted with two small columns in series with resin bed volumes of $10.6 \mathrm{~mL}$ during the conditioning phase with $0.25 \mathrm{M} \mathrm{NaOH}$, and $9.7 \mathrm{~mL}$ during the AP-101DF loading phase. Proper functioning of the ion exchange apparatus and resin beds had initially been tested with an AW-101 simulant. Approximately 1.2 L, equivalent to 112 bed volumes of AP-101DF waste, was processed. All ion exchange process steps were tested, including resin bed preparation, loading, feed displacement, water rinse, elution, eluant rinse, and resin regeneration.

\section{PNWD-3252, Rev. 1 (WTP-RPT-031, Rev. 1) - Small Column Testing of SuperLig ${ }^{\circledR} 639$ for Removing ${ }^{99}$ Tc from Hanford Tank Waste 241-AN-102 Supernate (Envelope C) Mixed with Tank 241-C-104 Solids (Envelope D) Wash and Permeate Solutions}

\section{Focus Area: Pretreatment}

The WTP baseline process for ${ }^{99} \mathrm{Tc}$ removal from Hanford tank waste is ion exchange. The flowsheet includes the use of $\mathrm{TcO}_{4}^{-}$-selective sorbent SuperLig ${ }^{\circledR} 639$ (SL-639) for Tc removal from the aqueous waste fraction. The process testing was performed on a blended tank waste feed prepared by combining Tank 241-C-104 (C-104) high-level waste pretreatment stream solutions (filtrate, wash, and leach solutions) with Tank 241-AN-102 (AN-102) tank waste supernate. At the time of testing, this combination represented the baseline process flowsheet for the AN-102 tank waste supernate at the WTP.

This report documents the dual-column testing of the SL-639 sorbent with waste from Tank AN-102 blended with C-104 filtrate, wash, and leach solutions (AN-102/C-104). The Tc ion exchange process studies are to verify design and operating parameters for plant-scale ion exchange systems. Test results were to be used also to validate ion exchange models. 
The objectives of this work were to

- Demonstrate the effectiveness of all SL-639 process steps, including loading, feed displacement, deionized water washing, elution, and resin regeneration.

- Investigate the potential for resin and/or column fouling.

- Demonstrate the ${ }^{99} \mathrm{Tc}$ decontamination of an Envelope C material (Tank AN-102 blended with permeate from the filtration, washing and leaching of C-104 solids).

- Provide batch-distribution measurements on actual tank-waste feed.

PNWD-3240 (WTP-RPT-033, Rev. 1) - Small Column Ion Exchange Testing of SuperLig ${ }^{\circledR} 644$ for Removing ${ }^{137}$ Cs from Hanford Waste Tank 241-AN-102 Supernate (Envelope C) Mixed with Tank-241-C-104 Solids (Envelope D) Wash and Permeate Solutions

\section{Focus Area: Pretreatment}

The WTP baseline process for ${ }^{137} \mathrm{Cs}$ removal from Hanford high-level tank waste is ion exchange. The current flowsheet includes the use of Cs-selective, organic ion exchanger SuperLig® 644 (SL-644) material for Cs removal from the aqueous waste fraction.

This report summarizes batch-contact studies of SL-644 and crystalline silicotitanate and IE-911 dual small-column testing of the SL-644 ion exchange material. The test matrix for the small-column ion exchange and SL-644 batch-contact tests was 241-AN-102 Hanford tank waste supernatant, mixed with caustic leaching and wash solutions from the pretreatment of Tank 241-C-104 solids and evaporated to nominally $5 \mathrm{M} \mathrm{Na}$ (hereafter referred to as $\mathrm{AN}-102 / \mathrm{C}-104$ ). The test matrix for the IE-911 batch contact was 241-AN-102 supernatant diluted to nominally $6 \mathrm{M} \mathrm{Na}$ (hereafter called AN-102). Approximately $753 \mathrm{~mL}$ of AN-102/C-104 were processed through the ion exchange column system. The ion exchange process steps tested include resin-bed preparation, loading, feed displacement, water rinse, elution, and resin regeneration.

The objectives of the batch-contact studies were to

- Determine distribution coefficients as a function of $\mathrm{Na} / \mathrm{Cs}$ molar concentration for SL-644 in the AN-102/C-104 matrix and for IE-911 in the AN-102 matrix.

- Demonstrate the 137Cs decontamination of Envelope C tank waste sample AN-102/C-104 and provide a Cs-decontaminated sample for downstream process testing.

- Develop Cs loading and elution profiles.

- Produce and characterize a Cs-eluate solution for use in evaporation tests and HLW vitrification.

- Demonstrate the effectiveness of all SL-644 ion exchange process steps, including loading, feed displacement, deionized water washing, elution, and resin regeneration.

PNWD-3206, Rev. 1 (WTP-RPT-043, Rev. 1) - Filtration, Washing, and Caustic Leaching of Hanford Tank AZ-101 Sludge

\section{Focus Area: Pretreatment}

PNWD testing performed to gather data on the performance of crossflow filtration when processing solids from Tank AZ-101 is summarized in this report. The second objective was to evaluate washing and leaching characteristics of Tank AZ-101 sludge and determine the filterability of the treated sludge. 
The report describes the test apparatus, experimental approach, results of the tests, and chemical and radiochemical analyses of the sludge from Tank AZ-101 and permeates generated during the washing and caustic-leaching steps. Section 2 describes the test conditions. Section 3 discusses the results of the filtration, sludge washing, and caustic leaching tests. Section 4 gives the physical properties (including rheology, particle size distribution, and energetics screening measurements) of AZ-101 slurry samples. Conclusions from the testing and analyses are provided in Section 5. The appendices contain additional testing information, as well as details on analytical requirements, raw filtration data, statistical analysis, modeling, analytical results, rheology, and particle size distribution measurements.

\section{PNWD-3264 (WTP-RPT-044, Rev. 1) - Combined Entrained Solids and Sr/TRU Removal from AN-102 Waste Blended with C-104 Sludge Pretreatment Solutions}

\section{Focus Area: Pretreatment}

The objective of the work reported here was to treat a larger, 1-L, batch of AN-102/C-104 waste blend and conduct filtration tests to demonstrate that the blending does not affect decontamination and solids removal by crossflow filtration. Treatment and digest were conducted at ambient hot cell temperature (approximately $31^{\circ} \mathrm{C}$ ) with $\mathrm{Sr}(\mathrm{NO} 3)$ addition at $0.02 \mathrm{M}$ followed by permanganate addition at $0.02 \mathrm{M}$. The precipitate was digested for 4 hours, and samples removed at various times. Supernatant decontamination data were obtained from the test data. The Sr-90 and TRU decontamination factors were compared to determine the efficiency of the Sr/TRU removal process. The treated waste was transferred to a Cells Unit Filter, and a matrix of filtration tests was completed to determine the permeate flux as a function of process conditions. The filtration results were statistically analyzed to determine the significance of the various process conditions. A filtration model was used to evaluate the components of filtration resistance.

The results from Sr/TRU removal treatment and filtration tests are presented in this report. Test conditions and experimental procedures are described in Section 2. Experimental results from the tests are discussed in Section 3. The major conclusions and recommendations are given in Section 4. The appendices contain the test instruction, data sheets, logbook entries, and analytical data.

\section{PNWD-3345 (WTP-RPT-047) - Chemical Degradation of SuperLig ${ }^{\circledR} 639$ Ion Exchange Resin}

\section{Focus Area: Pretreatment}

Unit operations of the WTP process include the separation of ${ }^{137} \mathrm{Cs}$ and ${ }^{99} \mathrm{Tc}$ by ion exchange from the liquid portion of the waste. SuperLig® 644 (SL-644) and SuperLig 639® (SL-639) ion exchange resins were selected by the project to perform ${ }^{137} \mathrm{Cs}$ and ${ }^{99} \mathrm{Tc}$ separations, respectively. In this study, PNWD examined the chemical degradation aspects of SL-639.

The primary objective of this task was to determine the degradation in resin performance over repeated cycles of waste processing and elution in a column system. The SL-639 resin underwent 26 cycles of waste processing and elution to accomplish this objective. Secondary objectives include:

- preliminary assessment of some hazardous waste characteristics of the resin to support future development of a spent resin disposal pathway

- determination of the impact of the LAW processing rate and Tc and nitrate concentrations on the resin breakthrough performance. 
This report documents testing, results, and analyses associated with the SL-639 chemical-degradation investigation. The purpose of the investigation was to provide information for an assessment of the degradation in resin performance over repeated cycles of waste processing and elution and spent-resin disposal.

\section{PNWD-3215 (WTP-RPT-048, Rev. 1) - Chemical Analysis and Physical Property Testing of 241-AZ-101 Tank Waste-Supernatant and Centrifuged Solids}

\section{Focus Area: Waste Characterization}

PNWD conducted integrated process verification and waste-form qualification tests on Hanford waste from underground storage Tank 241-AZ-101 (AZ-101) in support of the WTP. Testing included sample compositing, homogenization, and characterization; followed by pretreatment process testing and vitrification of the resulting LAW and high-level waste HLW streams.

To support this testing, portions from 18 segments of one core sample retrieved from Tank AZ-101 in August 2000 were provided to PNWD. Following confirmation that none of the bottles containing liquid were contaminated with hydrostatic head fluid, these samples were homogenized into a single slurry composite and carefully separated into 15 subsamples. Specified subsamples were tested for physical properties, including density, percent solids, rheology, heat capacity, and particle size. Four composite subsamples were selected for inorganic, radiochemical, and selected organic analysis. The subsamples were phase separated by centrifuging into supernatant and wet centrifuged solids and both phases characterized for numerous inorganic analytes, organic analytes, and radionuclides. Analyses were performed in triplicate on both the wet centrifuged solids and supernatant phases.

The characterization of the representative AZ-101 composite sub-samples for both supernatant and wet centrifuged solids included but was not limited to

- $\quad$ inductively coupled plasma atomic emission spectrometry radiochemical analyses, including ${ }^{99} \mathrm{Tc}^{+7}$

- inductively coupled plasma mass spectrometry

- total uranium by kinetic phosphorescence analysis

- ion chromatography (IC, inorganic and organic anions)

- titration for hydroxide

- total inorganic carbon and total organic carbon

- $\quad$ selected organic analytes (e.g., organic acids and chelators)

- $\quad$ selected physical properties: density, weight percent solids, and weight percent oxide, heat capacity, particle size distribution, and rheology.

This report includes a discussion of sample receiving, evaluation for hydrostatic head fluid contamination, compositing and sub-sampling, physical measurement methods, phase separation and analytical sample processing. Results and data limitations, method modifications, and general observations are discussed in Section 8, Analytical Results. Initial sample processing, QC sample results, method detection limits, and other QC indicators are described in Section 9, Procedures, Quality Control, and Data Limitations. 
PNWD-3262, Rev. 1 (WTP-RPT-052, Rev. 1) - Evaluation of Temperature and Caustic Effects on Tank Waste Solubility for Hanford Tank 241-AN-102

\section{Focus Area: Pretreatment}

This report describes a limited set of tests conducted by PNWD to assess the impact of changes in temperature and caustic concentration on the solubility of the solids present in Tank AN-102waste. Changes in tank waste composition might impact envelope limits or result in precipitation and clogging of lines during transport or pretreatment.

PNWD evaluated the distribution of tank components present in the AN-102 waste sample between the solids and liquids at two temperatures, $15^{\circ} \mathrm{C}$ and $50^{\circ} \mathrm{C}$. The tests assessed the composition of the LAW supernatant and $\mathrm{HLW}$ solids at $25^{\circ} \mathrm{C}$ for one elevated caustic concentration.

The objectives of the tests were to:

- determine the solubility at $15^{\circ}$ and $50^{\circ} \mathrm{C}$ for the solids present in $\mathrm{AN}-102$ tank waste.

- determine the solids solubility versus concentration of $\mathrm{NaOH}$ at $25^{\circ} \mathrm{C}$ for the solids present in $\mathrm{AN}-102$ tank waste.

- $\quad$ perform a statistical evaluation of the solids and liquids composition data, incorporating the previously obtained solids and liquids characterization data.

PNWD-3266, Rev 1 (WTP-RPT-053, Rev. 1) - Small Column Ion Exchange Testing of SuperLig®644 for Removal of ${ }^{137}$ Cs from Hanford Waste Tank 241-AZ-101 (Envelope B)

\section{Focus Area: Pretreatment}

PNWD performed Cs ion exchange studies to verify design and operating parameters for plant-scale ion exchange systems in the WTP. Test results will be used also to validate ion exchange models.

The objectives of the Cs ion exchange tests were to:

- Develop load and elution breakthrough profiles using waste from Hanford tank 241-AZ-101 (AZ-101, Envelope B).

- Produce and characterize the Cs eluate for use in evaporation and vitrification tests.

- Remove ${ }^{137} \mathrm{Cs}$ from the AZ-101 matrix to meet low-activity LAW vitrification criteria.

- Develop batch-distribution coefficients for AZ-101.

PNWD-3281, Rev. 1 (WTP-RPT-058, Rev. 1) - Small Column Testing of SuperLig ${ }^{\circledR ~} 639$ for Removing ${ }^{99}$ Tc from Hanford Tank Waste Envelope B (Tank 241-AZ-101)

\section{Focus Area: Pretreatment}

This report documents dual-column testing of the SuperLig® 639 (SL-639) sorbent with waste from Tank 241-AZ-101 (AZ-101). These studies are to verify design and operating parameters for plant-scale ion exchange systems. Test results will be used to also validate ion exchange models. 
Approximately $1.6 \mathrm{~L}$ of tank-waste feed was processed through dual small-scale ion exchange columns. This tank-waste feed underwent solids removal by crossflow filtration, and then was vacuum filtered and processed for Cs removal by ion exchange using SuperLig® 644 before technetium ion exchange. The removal goal for the AZ-101 feed is to reduce the total Tc concentration by at least $98 \%$ after processing $\geq 250$ bed volumes of solution.

The objectives of this work were to:

- Demonstrate the effectiveness of all SL-639 process steps, including loading, feed displacement, water rinse, elution, and resin regeneration.

- Investigate the potential for resin and/or column fouling.

- Demonstrate the ${ }^{99} \mathrm{Tc}$ decontamination of an Envelope B material (Tank AZ-101); remove at least $98 \%$ of technetium within 250 bed volumes of processed feed.

- Elute technetium from the resin to a target technetium $\mathrm{C} / \mathrm{C}_{0}<1 \%$, within $22 \mathrm{BV}$ of eluant.

- Provide a technetium-decontaminated sample for downstream process testing (i.e., LAW melter-feed testing and vitrification).

- Provide batch-distribution measurements on actual tank-waste feed.

This report discusses the experimental conditions for the column ion exchange test procedure. The results of the feed composition, the batch distribution, the AZ-101 column test, the comparison of the AZ-101 initial feed and effluent composite composition, and the technetium mass balance are presented.

\section{PNWD-3334 (WTP-RPT-069) - Chemical Analysis and Physical Property Testing of 241-AP-104 Tank Waste}

\section{Focus Area: Characterization}

PNWD conducted integrated process verification and waste-form qualification tests on Hanford waste from underground storage Tank 241-AP-104 (AP-104) in support of the WTP. Testing included sample compositing, homogenization, and characterization, which are described in this report. Characterization of the AP-104 waste provides an opportunity to underpin the pretreatment facility design basis. Additionally, it provides data to the WTP to validate assumptions in the flowsheet and to support process verification testing and safety-related activities.

The primary objectives were to:

- Receive, composite, homogenize, and subsample AP-104 waste.

- Measure physical properties of a composite subsample.

- Perform chemical and radiochemical analysis of a composite subsample.

- Determine compliance to Contract Specification 7 (Envelope A) of DE-AC27-01RV14136.

- Report analysis results. 


\section{PNWD-3360 (WTP-RPT-078) - Results of Small-Scale Particle Cloud Tests and Non-Newtonian Fluid Cavern Tests}

\section{Focus Area: Pretreatment}

The objective of the small-scale particle cloud tests performed by PNWD was to generate experimental data for use by BNI in its effort to evaluate the FLUENT computer code models. The cloud height tests were conducted to obtain experimental measurements of the effective mixing heights for BNI to use in benchmarking the FLUENT computer code.

The cloud height measurements were obtained for a single steady-state jet directed downward in an elliptical bottom tank. The cloud tests used glass beads in water to evaluate the height of the suspended slurry as a function of jet velocity.

The cavern tests were conducted to obtain experimental data to validate the non-Newtonian fluid modeling capabilities of the computer code for fluid properties similar to those of certain tank wastes. A transparent material that exhibited a yield stress and shear thinning behavior was used to obtain measurements of steady-state cavern heights as a function of jet velocity. The simulant also exhibited time-dependent behavior. To evaluate the influence of the time-dependent behavior, constant shear rate tests were carried out. The measured shear stresses dropped continually for the first 20 minutes. After approximately 20 minutes, the change in shear stress was less than $1 \%$. The magnitude of the change in rheological properties at steady-state conditions over the time steady-state measurements were made was negligible.

This document summarizes the tests and presents the experimental results produced at the small-scale pulsed jet mixer test setup housed at PNWD.

\section{PNWD-3341 (WTP-RPT-080) - Mixing of WTP Process Solutions}

\section{Focus Area: Pretreatment}

Large storage tanks will be used in the WTP to receive Hanford tank waste. However, heels from the previous waste transfer are likely to be present, resulting in the mixing of tank wastes from different sources. In addition, various liquid-process solutions will be generated by WTP operations, resulting in the potential mixing of these solutions with the tank wastes as well.

This investigation was intended to evaluate potential impacts from the mixing of these disparate waste streams. The report was intended to aid the WTP project by performing a survey of the effects of combining mixtures of markedly different compositions to see if conditions likely to cause a process upset are generated either immediately or upon contact over a period of days to weeks.

Objectives were to perform, analyze the data from, and report on the following tests:

- Combine actual Hanford tank supernatants and recycle solutions involving

o minor amounts of one supernatant with a major amount of a second supernatant

o the system described above with a solution derived from water washing or caustic leaching of the actual tank solids or an appropriate simulant/substitute

0 the system described immediately above with an offgas simulant (vitreous state laboratory-high level waste-submerged bed scrubber condensate) from HLW vitrification

- Measure the initial technetium $K_{\mathrm{d}}$ with SuperLig® 639 for each mixed solution. 
- Measure the initial viscosity for each mixed solution.

- Monitor each mixed solution visually for at least one week to detect any changes.

- Measure the final technetium $K_{d}$ with SuperLig® 639 for each mixed solution.

- Measure the final viscosity for each mixed solution.

- Monitor any changes in the solution by multi-nuclear magnetic resonance spectroscopy.

- Isolate and characterize any significant amounts of precipitated solids.

This report documents testing, results, and analysis associated with the mixing of actual Hanford tank supernatants and process solutions.

\section{PNWD-3340 (WTP-RPT-082) - Assessment of Sr/TRU Removal Mechanisms Using AN-102 and AN-107 Tank Waste Samples}

\section{Focus Area: Pretreatment}

This report discusses investigations into the mechanism of the $\mathrm{Sr}$ /permanganate treatment process for removing Sr-90 and TRU from tank supernatant destined for immobilization as LAW. Experiments were conducted with actual waste samples from Envelope C tanks, AN-102 and AN-107.

The purpose of these mechanistic studies was to determine the role of permanganate reactions in TRU decontamination. Of specific interest was the importance of various mechanisms, such as oxidation, absorption, precipitation, and ligand displacement, on TRU decontamination. Past studies, supported by additional results from these investigations, have demonstrated the effectiveness of Sr-90 removal by isotopic dilution and precipitation as $\mathrm{SrCO}_{3}$ by added nonradioactive $\mathrm{Sr}\left(\mathrm{NO}_{3}\right)_{2}$.

Previous mechanistic investigations were conducted with waste simulant solutions. The results of the simulant tests were used to define experiments for actual waste testing. The results from the actual waste tests are provided in this report and support observations reported from the simulant studies. This is important because the earlier conclusions were based on the removal of surrogate elements, not actual TRU components. Although the chemistry is expected to be similar for the waste simulant solutions, the exact composition of organics and complexants in the actual waste is not fully known or understood. Consequently, tests with actual wastes provide further support for conclusions and recommendations based on simulant results.

\section{PNWD-3344 (WTP-RPT-083) - Thermodynamic Data Development for Modeling Sr/TRU Separations: Sr-EDTA, Sr-HEDTA, and Mn-Gluconate Complexation}

\section{Focus Area: Pretreatment}

In this study, thermodynamic data were obtained and calculations performed for simple mixtures of organic complexants and simulated supernatant solutions to develop a better understanding of the Sr/TRU removal process. This report summarizes the results of studies conducted to develop improved thermodynamic data for modeling $\mathrm{Sr}$ and $\mathrm{Mn}$ species to support an understanding of the mechanism of $\mathrm{Sr}$ /TRU precipitation from solution. The data development emphasizes three areas: the complexation of Sr by ethylenediaminetetraacetate (EDTA), the complexation of Sr by N-(2-hydroxyethyl) ethylenedinitrilotriacetic acid (HEDTA), and the complexation of Mn(II, III, and IV) by sodium gluconate. EDTA and HEDTA were chosen for study because they represent the chelates of primary importance in solubilizing $\mathrm{Sr}$ in Envelope $\mathrm{C}$ wastes. Sodium gluconate was chosen as a model for the 
type of complexants for tri- and higher valence metal ions. Furthermore, sodium gluconate was used at Hanford in waste processing.

The results from all of the modeling work in support of the Sr/TRU removal process are summarized in this report. The Sr-EDTA modeling work is described in Section 2, Sr-HEDTA work in Section 3, and Mn-gluconate work in Section 4. The major conclusions and recommendations are given in Section 5. The appendix includes the analyses of the potentiometer data for Mn-gluconate complexes.

\section{PNWD-3369 (WTP-RPT-085) - Liquidus Temperature Testing and Model Evaluation Results}

\section{Focus Area: Vitrification/WFQ}

The objectives of this study were to 1) develop glass-composition and liquidus-temperature $\left(T_{L}\right)$ data for use in model development for WTP HLW glass melts, and 2) evaluate available models relating $\mathrm{T}_{\mathrm{L}}$ to HLW glass composition. Liquidus temperature can be defined as the highest temperature at which a melt is in thermodynamic equilibrium with its primary crystalline phase. It is important to WTP HLW glass processing because the deleterious effects of crystal accumulation in the melter may be avoided if the melter is operated at a temperature above $\mathrm{T}_{\mathrm{L}}$. The data and models are required for formulation of optimized HLW glass compositions, process modeling, process control, and rapid adjustments to HLW composition changes.

\section{PNWD-3353 Rev 1 (WTP-RPT-089, Rev. 1) - Analysis of SuperLig ${ }^{\circledR} 644$ Resin Used in Hanford Tank Waste Processing}

\section{Focus Area: Pretreatment}

PNWD analyzed spent ion exchange resin, SuperLigß 644 (SL-644), after processing eight cycles of waste (one cycle with simulant waste and seven cycles with actual Hanford tank waste) under laboratory-controlled conditions. The objectives of this work were to identify and quantify residual metals on the resin beds and to identify and quantify residual radionuclides on the resin beds. The spent-resin analysis results will help define residual process-related metals and radionuclide composition expected during actual WTP operations.

\section{PNWD-3370 (WTP-RPT-090) - Assessment of Abnormal Process Conditions for Sr/TRU Removal Using a Waste Simulant}

\section{Focus Area: Pretreatment}

The purpose of these PNWD studies was to determine the impact of various process conditions on the overall Sr/TRU removal process and define a subset of conditions for testing with actual waste samples. Experiments were conducted with a waste simulant prepared to mimic the waste composition in Tank AN-102. A test matrix was developed with a wide range of concentrations and reaction conditions. Of specific interest were the importance of varying initial waste concentration; added free hydroxide; reagent concentrations; precipitation temperature; reaction time; and deviation in process sequence, such as no mixing after reagent addition, reversing the order of reagent addition, and split reagent additions.

In this report, the conditions and experimental procedures used for testing with the waste simulant are described in Section 2. Section 3 presents the results and discussion, with the conclusions and 
recommendations given in Section 4. The appendices contain the simulant recipe and the quantities of simulant and reagents used.

\section{PNWD-3338 (WTP-RPT-091) - Assessment of Abnormal Process Conditions for Sr/TRU Removal Using AN-102 Tank Waste Samples}

\section{Focus Area: Pretreatment}

This report discusses results of testing designed to assess the impact of abnormal process conditions for removing Sr-90 and TRU from Envelope $\mathrm{C}$ tank supernatant destined for immobilization as LAW.

Experiments were conducted with actual waste samples from Tank AN-102. The purpose of these studies was to determine the impact of various process conditions on the overall $\mathrm{Sr}$ /TRU decontamination and on the treated supernatant composition. Of specific interest is the importance of varying reagent concentrations, precipitation temperature, reaction time, and deviation in process sequence, such as no mixing for 24 hours after reagent addition, reversing the order of reagent addition, and split reagent additions. Previous studies with actual tank samples have shown that reagent concentration, precipitation temperature, and reaction time have significant impact on the Sr/TRU removal process. These conditions were varied over a wider range, with samples of the same diluted waste, to allow direct comparison of the results and assess the impact of the process variables. The matrix of tests conducted with actual waste samples was developed from results of tests with waste simulant solutions. The results from the actual waste tests are provided in this report.

\section{PNWD-3470 (WTP-RPT-092) - Vitrification and Product Testing of AP-101 Pretreated LAW Envelope A Glass}

\section{Focus Area: Waste Form Qualification}

The primary objective for vitrifying the Tank AP-101 (Envelope A) pretreated waste sample was to characterize the glass produced from the crucible melt. The work scope reported here is divided into seven work elements: 1) glass fabrication, 2) chemical composition analyses, 3) radiochemical composition analyses, 4) waste sodium loading, 5) identification of crystalline and noncrystalline phases, 6) waste-form leachability, and 7) toxicity characteristic leaching procedure. The various properties of the glass were then compared to those of a simulant glass fabricated to the same target composition and characterized by the Vitreous State Laboratory at Catholic University of America. The results of these tasks help demonstrate WTP project ability to satisfy the product requirements concerning chemical and radionuclide reporting, waste loading, identification and quantification of crystalline and noncrystalline phases, and waste-form leachability.

\section{PNWD-3389 (WTP-RPT-093) - Aging Effects of Stored SuperLig ${ }^{\circledR} 644$ Ion Exchange Resin}

\section{Focus Area: Pretreatment}

Unit operations of the WTP process include the separation of cesium-137 by ion exchange from the liquid portion of the waste. SuperLig ${ }^{\circledR} 644$ (SL-644) ion exchange resin was selected by the project to perform the cesium-137 separation. The deterioration in performance of an ion exchange resin during storage is an important characteristic to understand for design and operational purposes. The rate of deterioration under different conditions will determine the shelf life of the resin and provide information for an assessment of the best means of its storage. 
The primary objective of this task was to determine the effect of storage conditions on resin performance. The purpose was to provide information for an assessment of the best means of storing the SL-644 ion exchange resin. The parameters evaluated included storage temperature, storage medium (dry or under water), storage environment (air or inert gas), storage time (up to 6 months), and resin form (as-received, acid, or sodium).

This report documents the testing, analysis, results, and interpretations associated with the SL-644 storage investigation. The report is intended to aid in decision making regarding the design and operation of the cesium ion exchange and resin-storage systems in the WTP.

\section{PNWD-3367 (WTP-RPT-095) - Rheological and Physical Properties of AZ-101 LAW Pretreated Waste and Melter Feed}

\section{Focus Area: Vitrification}

This report presents physical and rheological properties of AZ-101 waste that is in a state similar to two streams anticipated in the WTP. The first stream considered was the pretreated LAW stream that consists of the effluent from the cesium ion exchange column. The second stream is the LAW melter feed material, which consists of the pretreated LAW waste stream mixed with a formulation of glass-former chemicals.

The objectives of this work were to obtain accurate measurement of solids concentration, densities, and rheological properties on samples of actual AZ-101 pretreated LAW Envelope B waste and corresponding melter-feed samples. The physical and rheological properties of these process streams are important considerations in selecting flowsheet and processing equipment such as mixers, pumps, piping, and tanks. Measurements on actual waste are also required to verify and validate results obtained with simulants. Actual samples from Tank AZ-101 were used in this testing. Physical and rheological properties of these melter-feed samples were measured. Mixing and aging studies were also conducted on one melter-feed sample. This report describes the experimental approach and results of the testing.

\section{PNWD-3366 (WTP-RPT-096) - Rheological and Physical Properties of AZ-101 HLW Pretreated Sludge and Melter Feed}

\section{Focus Area: Vitrification}

This document describes work performed to determine physical and rheological properties of AZ-101 waste that is in a state similar to two streams anticipated in the WTP. The physical and rheological properties of these process streams are important considerations in selecting flowsheet and processing equipment such as mixers, pumps, piping, and tanks. The first stream considered was the pretreated HLW stream that consists of the AZ-101 slurry of washed and leached solids from the crossflow ultrafiltration process. The second stream is the HLW melter-feed material. This material consists of the pretreated HLW waste stream mixed with a formulation of glass-former chemicals.

The objectives of this work were to accurately measure the physical and rheological properties on actual AZ-101 pretreated HLW (HLW Envelope D) samples and corresponding melter-feed samples. The physical and rheological properties of these process streams are important considerations in selecting flowsheet and processing equipment such as mixers, pumps, piping, and tanks. Measurements on actual waste are also required to verify and validate results obtained with simulants. 
The AZ-101 HLW pretreated sludge was received at a concentration of $10.3 \mathrm{wt} \%$ undissolved solids (UDS). The AZ-101 pretreated HLW was adjusted to various UDS concentrations for physical and rheological property measurements. The solids concentration was adjusted to bound the physical and rheological property measurements about a WTP operating point of $20 \mathrm{wt} \%$ UDS. The UDS concentrations tested include 10-, 15-, and $22 \mathrm{wt} \%$ UDS AZ-101 HLW pretreated sludge. The physical and rheological properties were measured; rheological testing was conducted at $25^{\circ} \mathrm{C}$ and $40^{\circ} \mathrm{C}$. Settling and physical properties testing was conducted at hot cell ambient temperature.

Project-approved glass-former chemicals were added to a $20 \mathrm{wt} \%$ UDS HLW pretreated sludge sample to produce a HLW "melter feed" stream. Physical and rheological properties of these melter-feed samples were measured. Mixing and aging studies were also conducted on the 20 -wt $\%$ UDS melter-feed sample. This testing entailed placing a $20-\mathrm{wt} \%$ UDS pretreated HLW sample in a mixing vessel at a power-to-volume ratio consistent with that expected in the WTP. Glass formers were added, and the mixing continued for 1 week. During this week, rheograms were obtained after 1 day and 1 week of mixing. This report describes the experimental approach and results of the testing.

\section{PNWD-3398 (WTP-RPT-098) - Technical Basis for LAW Vitrification Stream Physical and Rheological Property Bounding Conditions}

\section{Focus Area: Vitrification}

This document describes part of the PNWD work to develop a set of bounding physical and rheological properties for waste materials that can be reasonably processed and likely encountered in the WTP vitrification facilities. Ultimately, a set of bounding physical and rheological properties will be used to design the process equipment.

The following strategy was used to meet the task objectives:

1. Identify physical and chemical parameters that are significant to WTP vitrification-stream processing through the use of dimensional analysis.

2. Compile and compare previous historical information on the parameters identified in Step 1 for actual and simulated process streams.

3. Recommend ranges for the parameters identified in Step 1 that include upper and lower bounding ranges that will likely result in performance degradation issues if exceeded.

To determine the bounds for each operation, one must understand what general waste properties are anticipated and how changes in those properties can affect process operation. The process bounds are then established at the point where the properties of the material induce unacceptable risk to plant performance. Hence this set of bounding physical and rheological properties can be used to judge when a given pretreated waste or melter feed may cause transfer or processing problems by causing the system to have to operate outside its design capabilities. The technical basis for these processing bounds is established in this report. 
PNWD-3387 (WTP-RPT-103) - Comparison Testing of Multiple Resorcinol-Formaldehyde Resins for the River Protection Project-Waste Treatment Plant

\section{Focus Area: Pretreatment}

The pretreatment flowsheet for the WTP included the use of Cs-selective, elutable, organic ion exchange material, SuperLig® 644 (SL-644), for Cs removal from the aqueous-tank-waste fraction. This material was developed and supplied solely by IBC Advanced Technologies, Inc., American Fork, Utah. To provide an alternative to this sole-source resin supply, BNI initiated the process of selecting and testing an alternative ion exchange resin for Cs removal in the WTP. Resorcinol-formaldehyde (RF) resin was selected as the most viable alternative.

PNWD was contracted to evaluate different RF resins, provide data supporting WTP selection of one type of RF resin for further developmental work, and set preliminary RF resin purchase specifications. This report documents those tasks.

\section{PNWD-3390 (WTP-RPT-104) - Pre-conditioning and Regeneration Requirements of Ground Gel Resorcinol Formaldehyde Ion Exchange Resin}

\section{Focus Area: Pretreatment}

Unit operations of the WTP process include the separation of cesium-137 by ion exchange from the liquid portion of the waste. SuperLig ${ }^{\circledR} 644$ (SL-644) ion exchange resin was selected by the project to perform the cesium separation. However, another ion exchange resin, ground-gel resorcinol formaldehyde (RF), was undergoing testing as an alternative to the sole-source supply of SL-644.

The pre-conditioning and regeneration requirements for an ion exchange resin are important to understand because they can impact the chemical and physical characteristics of the resin. Evaluating the chemical and physical impacts of different pre-conditioning procedures will determine the best procedure for application in further laboratory and pilot-scale tests and the WTP.

The primary objectives of this task were to

- Establish resin pre-conditioning and regeneration procedures.

- Demonstrate that the selected ion exchange resin pre-conditioning and regeneration steps are sufficient to remove metals and prepare resin for batch contact and column tests in laboratory and pilot-scale ion exchange tests.

The parameters evaluated included reagent concentration and the number of pre-conditioning cycles. This report documents the testing, results, and analysis associated with the RF pre-conditioning and regeneration investigation.

PNWD-3388 (WTP-RPT-105) - Elution Testing of Resorcinol-Formaldehyde Resins with AN-105 Simulant

\section{Focus Area: Pretreatment}

Unit operations of the LAW treatment process at the WTP include the separation of ${ }^{137} \mathrm{Cs}$ by ion exchange from the liquid portion of the waste. SuperLig ${ }^{\circledR} 644$ (SL-644) was selected by the project as the baseline 
ion exchange resin to perform the ${ }^{137} \mathrm{Cs}$ separation. To provide an alternative to this sole-source resin supply, an alternative ion exchange resin, resorcinol-formaldehyde (RF), is being evaluated for Cs

removal. The PNWD tests described in this report were undertaken to compare the elution behavior of two types of RF resin, ground gel and spherical.

\section{PNWD-3464 (WTP-RPT-106) - Vitrification and Product Testing of AZ-101 Pretreated LAW Envelope B Glass}

\section{Focus Area: Waste Form Qualification}

When completed, the WTP will separate waste into LAW and HLW and will separately vitrify these wastes into borosilicate glasses. In support of that function, PNWD vitrified a sample of the

Tank AZ-101 (Envelope B) pretreated waste was to characterize the glass produced from the crucible melt. The work scope described in this report is divided into 7 work elements: 1) glass fabrication, 2) chemical composition analyses, 3) radiochemical composition analyses, 4) waste loading,

5) identification of crystalline and noncrystalline phases, 6) waste-form leachability, and 7) the U.S.

Environmental Protection Agency Toxicity Characteristic Leaching Procedure. The various properties of the glass were then compared to those of a simulant glass fabricated to the same target composition and characterized by the Vitreous State Laboratory at Catholic University of America.

The objective of this testing was to demonstrate the WTP ability to satisfy the product requirements concerning chemical and radionuclide reporting, waste loading, identification and quantification of crystalline and noncrystalline phases, and waste-form leachability as well as to validate the use of simulants for estimation of glass properties.

\section{PNWD-3465 (WTP-RPT-107) - Rheological and Physical Properties of AP-104 LAW Pretreated Waste and Melter Feed}

\section{Focus Area: Vitrification}

This report presents physical and rheological properties of AP-104 waste that is in a state similar to two streams anticipated in the WTP. The first stream considered was the pretreated LAW stream that consists of the effluent from the cesium ion exchange column. The second stream is the LAW melter-feed material. This material consists of the pretreated LAW waste stream mixed with a formulation of glass-former chemicals.

A sample of AP-104 pretreated LAW was received at an initial sodium concentration of $5.0 \mathrm{M}$. The sample was concentrated to $6 \mathrm{M}, 8 \mathrm{M}$, and $10 \mathrm{M}$ Na concentrations. Physical properties were determined for the three samples at $25^{\circ} \mathrm{C}$ and $40^{\circ} \mathrm{C}$. A rheometer was used to measure the rheological properties of the three samples at $25^{\circ} \mathrm{C}$ and $40^{\circ} \mathrm{C}$.

The three pretreated waste samples were then mixed with project-approved glass-former chemicals in a formulation representative of the LAW melter-feed stream in the WTP. The melter feeds were agitated to suspend the solids, and aliquots were drawn from all three homogenized samples at room temperature. The settling behavior of these melter-feed aliquots was measured at $25^{\circ} \mathrm{C}$ and $40^{\circ} \mathrm{C}$. The physical properties of the aliquots were then measured at $25^{\circ} \mathrm{C}$ and $40^{\circ} \mathrm{C}$. Next, the samples were allowed to remain undisturbed for 48 hours at $40^{\circ} \mathrm{C}$. A shear vane and a rheometer were used to determine the shear strength of the melter-feed settled solids at ambient and $40^{\circ} \mathrm{C}$. The rheological properties of the melter 
feeds were measured with a rheometer at $25^{\circ} \mathrm{C}$ and $40^{\circ} \mathrm{C}$. Rheological measurements were performed on the $8 \mathrm{M} \mathrm{Na}$ melter-feed sample based on mixing/aging times of 1 hour, 1 day, and 1 week. Rheological properties of the settled-solids fraction of the $8 \mathrm{M} \mathrm{Na}$ melter feed were also measured. Lastly, particlesize distribution was measured on the $6 \mathrm{M} \mathrm{Na}$ melter-feed sample. This report describes the experimental approach and results of the tests.

\section{PNWD-3399 (WTP-RPT-109) - Elution Testing of SuperLig ${ }^{\circledR} 644$ with AN-105 Simulant}

\section{Focus Area: Pretreatment}

Unit operations of the LAW treatment process include the separation of cesium-137 $\left({ }^{137} \mathrm{Cs}\right)$ by ion exchange from the liquid portion of the waste. SuperLig ${ }^{\circledR} 644$ (SL-644) was selected by the project as the baseline ion exchange resin to perform the ${ }^{137}$ Cs separation. The PNWD tests described in this report were undertaken to establish the conditions for eluting a loaded column so that it could successfully operate in the polishing-column position. In addition, the conditions for eluting a column for spent resin disposal were examined.

\section{PNWD-3496 (WTP-RPT-110) - Test Results for Pulse Jet Mixers in Prototypic Ultrafiltration Feed} Process and High-Level Waste Lag Storage Vessels

\section{Focus Area: Pretreatment}

PNWD was contracted to provide BNI with results of simulant tests using the scaled prototypic ultrafiltration process (UFP) and lag storage (LS) vessels and associated pulse jet mixer (PJM) equipment for the WTP. The UFP vessel, the LS vessel, and the concentrate receipt vessel (CRV) are to be used in the WTP for mixing radioactive waste from the underground Hanford storage tanks (note: the CRV tank was deleted from the baseline design of the WTP after the Phase I testing was completed). BNI, through its subcontract with PNWD, is testing a PJM-fitted mixing vessel at multiple scales to experimentally verify dimensional scaling effects in PJM systems. The scaling methodologies of the mixing system for a generic four-PJM vessel will be validated by tests conducted at three scales: large-scale(nearly full-scale), approximately one-quarter scale, and small scale (approximately one-eighth). The CRV scaled prototype was tested at Savannah River Technology Center. This report documents the prototype scaled testing conducted at PNWD in Richland for the LS and UFP vessels.

\section{PNWD-3463 (WTP-RPT-115) - Gas Generation Testing and Support for the Hanford Waste Treatment and Immobilization Plant}

\section{Focus Area: Pretreatment}

This project was initiated to provide design tools for estimating rates of hydrogen gas generation by waste streams in the WTP. A model for predicting hydrogen generation rates in Hanford's stored tank wastes has been developed. However, as the waste is processed in the WTP, its properties and conditions are subject to change. Assessments of which processing steps would most affect hydrogen generation identified several effects that needed to be understood. These included the effects of beta/gamma and alpha radiolysis and of adding hydroxide, permanganate, air, sugar, and glass-forming materials at various stages in the processing prior to the vitrification step. Although many issues could be resolved through technical evaluations of existing information, some issues required experimental testing. 
The report summarizes the experimental work. Six Technical Issue Reports (TIRs) were written to evaluate the major issues and are included as appendices. The objective of this experimental work was to assess the contribution of oxygen to the rate of hydrogen generation from actual and simulated Hanford waste. The data discussed in this report provide information on the gas generation capacity and reactivity of Hanford tank material.

\section{PNWD-3437 (WTP-RPT-122) - Test Summary: WTP Flowsheet Evaluation of Mercury-Containing Hanford Waste Simulant}

\section{Focus Area: HLW/Vitrification}

Mercury is found in the Hanford tank farm wastes. The chemistry of mercury under thermal processing conditions suggests that several different chemical species of mercury can be formed. The physical properties of those species provide different pathways for the mercury in the WTP, which require different abatement schemes to control mercury releases.

The major objectives of this test were to characterize the off-gas behavior of mercury under representative WTP vitrification processing conditions over selected waste-loading ranges of mercury, halogen, and reductant and to project mercury-partitioning characteristics during simulated secondary-waste pretreatment concentration operations using condensate generated during the vitrification test conditions. The activities conducted to accomplish these objectives included:

- designing experimental testing conditions to simulate as closely as practical those key WTP conditions that may affect mercury speciation

- performing a research-scale melter test to sample and characterize mercury speciation in off-gas and condensate streams over a range of vitrification process conditions involving feed concentrations of mercury, chlorine, and reductant

- sampling and characterizing mercury speciation in evaporator condensable and noncondensable streams when concentrating mercury-containing condensate solutions generated during the vitrification testing phase.

In addition to and in support of the above-discussed primary objectives, the compositions and masses of all process influent and effluent streams were also characterized, allowing glass leachability to be assessed and a melter mass balance to be derived. To accomplish this,

- Continuous emission monitors were used to monitor melter noncondensable flue-gas emissions.

- Samples of feed, glass, and all aqueous streams generated from off-gas treatment devices were periodically collected in support of post-test analyses and subsequent flowsheet characterization.

\section{PNWD-3441 (WTP-RPT-126) - Statistical Assessment of Bias and Random Uncertainties in WTP HLW CRV Mixing and Sampling}

\section{Focus Area: Waste Form Qualification}

The vitrification process at the WTP for immobilized high-level waste (IHLW) will be subject to variation and several uncertainties. The compositions, compliance properties (i.e., Product Consistency Test, Toxicity Characteristic Leaching Procedure, and waste loading), and process control properties 
(e.g., viscosity and $1 \%$ crystallinity temperature) of the IHLW melts and products will be subject to variation because the compositions of waste feeds will vary over time.

This report documents the work and results to statistically assess the impacts on IHLW compliance and processing properties of bias and random uncertainty in mixing/sampling waste from the high-level waste concentrate receipt vessel (CRV). The impacts of other random uncertainties in the IHLW process, the number of process samples, and glass formulation were also investigated and are addressed in this report. The term "mixing/sampling" is used to denote that the effects (bias or random uncertainty) of mixing and sampling were considered jointly in this work.

\section{PNWD-3568, Rev 1 (WTP-RPT-072, Rev. 1) - Statistical Methods and Results for WTP IHLW and ILAW Compliance}

\section{Focus Area: Waste Form Qualification}

The immobilized high-level waste (IHLW) and immobilized low-activity waste (ILAW) vitrification processes of the WTP will be subject to variation and several uncertainties. The compositions and compliance properties of the IHLW and ILAW melts and products will be subject to variation because the compositions of waste feeds will vary over time. In addition, the state of knowledge at any step of the IHLW or ILAW processes will be subject to mixing, sampling, chemical analysis, volume measurement, blending, weighing, transfer, and other uncertainties.

This report documents the outcomes of the first of two phases of work at PNWD to develop statistical methods and results associated with the WTP's statistically based compliance strategies for IHLW and ILAW. Each statistical method intended for use in demonstrating compliance during IHLW and ILAW production operations is illustrated with a realistic example.

The report provides an overview of the work performed relative to objectives, success criteria, quality requirements, test conditions, and known discrepancies. Section 8 of the report provides a more detailed summary of the methods developed and the results of the investigations performed.

\section{PNWD-3495 (WTP-RPT-111) - Non-Newtonian Slurry Simulant Development and Selection for Pulse Jet Mixer Testing}

\section{Focus Area: Pretreatment and Vitrification}

This document describes work performed by PNWD to determine scaled performance data for pulse jet mixers (PJM) in prototypic ultrafiltration feed process and HLW lag storage vessels. Pulse jet mixer technology has been selected for mixing non-Newtonian fluids in the WTP.

This report describes the development of nonhazardous, non-Newtonian simulants that were used to evaluate the mixing performance of PJM systems. Both transparent and opaque simulants were developed and used in this testing. 
PNWD-3551 (WTP-RPT-113) - Technical Basis for Testing Scaled Pulse Jet Mixing Systems for Non-Newtonian Slurries

\section{Focus Area: Pretreatment}

This report addresses the research conducted to develop scaling relationships that can be applied to perform scaled tests of pulse jet mixing (PJM) in non-Newtonian slurry. The scaling relationships will be used to assess performance of pulse jet configurations in WTP vessels. The research incorporates theoretical analysis and data taken at three scales of test fixtures: full scale, 1/4 scale, and 1/9 scale.

PNWD-3552 (WTP-RPT-114, Rev. 1) - Final Report: Gas Retention and Release in Hybrid Pulse Jet Mixed Tanks Containing Non-Newtonian Waste Simulants

\section{Focus Area: Pretreatment}

Pulse jet mixers (PJMs) along with air spargers and steady jets generated by recirculation pumps have been selected for use in mixing the HLW slurries in the WTP lag storage vessels and the ultrafiltration feed process vessels. These mixing technologies are collectively called PJM/hybrid mixing systems.

BNI established a test program to quantify gas-retention and release behavior in nonradioactive, nonNewtonian waste simulants (rheologically representative of actual waste) that are mixed with PJM/hybrid mixing systems. This report summarizes the results of numerous experiments conducted by PNWD in six different test stands. PNWD-3499 (WTP-RPT-116) - Vitrification and Product Testing of AZ-101-Pretreated High-Level
Waste Envelope D Glass

\section{Focus Area: Vitrification and Waste Form Qualification}

The WTP will separate the Hanford radioactive tank waste into LAW and HLW and will separately vitrify these wastes into borosilicate glasses. To demonstrate the feasibility of vitrification and the durability of the glass, PNWD produced and tested a vitrified Tank AZ-101 Envelope D HLW sample previously supplied to the WTP project by DOE. This document describes work performed in accordance with the PNWD test plan.

PNWD-3512 (WTP-RPT-117) - Oxidative-Alkaline Leaching of Washed 241-SY-102 and 241-SX-101 Tank Sludges

\section{Focus Area: Pretreatment}

This report describes PNWD activities to evaluate the process variables of time, temperature, and the sequence of caustic-leach/oxidative-alkaline leach contacts through bench-scale testing of sludges from tanks 241-SY-102 and 241-SX-101. The existing literature related to oxidative-alkaline leaching of chromium was initially reviewed to limit testing to those conditions that are the most likely to be successful for use in the WTP. Based on that review, permanganate was recommended as the reagent of choice for these tests. The review also identified a side reaction that might interfere with the permanganate reaction - consumption of permanganate by the oxidation of formate and residual organic species (complexants/extractant/solvents and aging/degradation products). The testing described in this 
report used well-washed sludges and did not address any potential impact from such residual organic species.

\section{PNWD-3494 (WTP-RPT-121) - Chemical Tracer Techniques for Assessing Mixing Performance in Non-Newtonian Slurries for WTP Pulsed Jet Mixer Systems}

\section{Focus Area: Pretreatment}

Pulsed jet mixer (PJM) technology has been selected for use to mix non-Newtonian fluids in the WTP. This report describes the development of chemical tracer methods used to evaluate the mixing performance of PJM systems, sparging tubes, recirculation pumps (steady state jets), and combinations of the three. Both transparent and opaque simulants were used in this testing.

The objective of this PNWD research was to develop tracer methods for assessing the fraction mixed in mixing experiments. To accomplish this, several dyes were tested in preliminary trials to decide which was best suited for the purposes of these experiments. Calibration curves of the dyes that were chosen as the best candidates were made in water and Laponite. Based on the results of these tests, Brilliant Blue (BB) and Ethyl Orange optical tracers were chosen as the primary tracer dyes for the percent mixing tests with the transparent laponite simulant. A study of dye absorption kinetics was made with BB on the Kaolin:Bentonite simulant to determine the contact time needed to allow the BB to reach an equilibrium with the simulant. Dye adsorption isotherms were made to determine the distribution coefficients (Kd) needed to calculate the extent of mixing. Sodium chloride was recommended as a chemical tracer for use with the kaolin:bentonite opaque simulant.

\section{PNWD-3586 (WTP-RPT-128) - Hybrid Mixing System Test Results for Prototype Ultrafiltration Feed Process and High-Level Waste Lag Storage Vessels}

\section{Focus Area: Pretreatment}

PNWD investigated further alternative pulsed jet mixer (PJM) configurations to assess the effects of slurry rheology changes, reduced tank volume, PJM jet velocity and nozzle size, sparging, and recirculation pump operation. Phase II PJM/hybrid mixing systems completed additional testing to demonstrate that the modified configurations mixed non-Newtonian slurries within WTP requirements.

The testing configurations provided by the WTP project were selected to minimize the impact on the current plant design. The main objectives of testing were to:

- Provide testing results to optimize the PJM/hybrid mixing system operating parameters (PJM nozzle velocity, cycle frequency, etc.) and position ( $\mathrm{x}, \mathrm{y}$, and $\mathrm{z}$ coordinates, nozzle angle, etc.) that will result in a well-mixed condition in UFP and LS test stands.

- Demonstrate complete mixing (i.e., no stagnant regions) with turbulent conditions in the majority of the slurry volume for the final UFP and LS configurations. Turbulent mixing conditions enhance heat transfer within the vessel and facilitate the suspension of waste particles.

This document describes the mixing processes and presents an overview of the PJM/hybrid design and scaling approach. It also describes an experimental approach and presents PJM/hybrid system optimization and final configuration results. This report and testing data support the ultrafiltration feed process (UFP) and HLW lag storage (LS) design efforts by documenting the results of the phase II PJM scaled test platform testing. 


\section{PNWD-3541 (WTP-RPT-129) - Technical Basis for Scaling of Air Sparging Systems for Mixing in Non-Newtonian Slurries}

\section{Focus Area: Pretreatment}

This document describes the mixing processes and presents an overview of the pulsed jet mixer (PJM)/hybrid design and scaling approach. It also describes an experimental approach and presents $\mathrm{PJM} /$ hybrid system optimization and final configuration results. This report and testing data support the ultrafiltration feed process and HLW lag storage design efforts.

Two non-Newtonian simulants were investigated, a transparent simulant and an opaque simulant. The first portion of this report discusses work involving the transparent simulant at small scale, used primarily for flow visualization. The second portion of the report discusses work involving the opaque simulant at large scale. The opaque simulant possesses rheological properties similar to the wastes expected to be processed in the WTP. The combination of large-scale testing with full-scale rheological properties helped address the primary design questions through this testing. Consequently, the results of the opaque simulant testing provide the primary technical basis for scaling the WTP air sparge system.

\section{PNWD-3600 (WTP-RPT-137) - Oxidative Alkaline Leaching of SX-101 and SY-102 and Its Impact on Immobilized High-Level Waste}

\section{Focus Area: Pretreatment}

Research to optimize tank waste composition to prepare the waste for vitrification has determined that temperature and hydroxide concentration are the most important factors impacting washed sludges from Hanford tanks SX-101 and SY-102 during caustic leaching and oxidative alkaline leaching. However, further study was needed to determine 1) the effects of a simple caustic leach with no oxidative alkaline leach, 2) the impact of oxidative leaching on potentially HLW limiting elements (chromium, aluminum, plutonium, sulfur, and any others), and 3) whether meaningful simulants can be developed to further optimize oxidative leaching test methods.

This report describes three tasks to accomplish these objectives:

- Identify the leach factors for simple caustic leaching only and for oxidative leaching only for sludges SX-101 and SY-102 from previously published data.

- Assess whether the impact of sulfur distribution by oxidative alkaline leaching and simple caustic leaching can be determined.

- Evaluate the possibility of using an alternative approach for evaluating the impact of problematic glass components by testing these glass component behaviors with a simulant, well designed (and preferentially validated) to respond as would actual Hanford sludge to the changing conditions. Assess the usefulness of such a sludge simulant for performing such an evaluation.

Section 2 evaluates the impact of an individual caustic leach or oxidative leach on washed tank solids from tanks SY-102 and SX-101. Section 3 reviews caustic leaching data for removing sulfur, and Section 4 describes the impacts of using sulfur for sludge pretreatment testing. 
PNWD-3675 (WTP-RPT-112) - Final Report: Technical Basis for HLW Vitrification Stream Physical and Rheological Property Bounding Conditions

\section{Focus Area: Vitrification}

The objective of this work was to develop a set of bounding physical and rheological properties for HLW that likely will be encountered in the WTP vitrification facilities and that can be reasonably processed. To determine the bounding conditions for each unit operation, one must understand what general waste properties are anticipated and how changes in these properties impact process operation. The process bounding conditions are then established at the point where the properties of the material introduce unacceptable risk to plant performance. Hence, one can use this set of bounding physical and rheological properties to determine if a given pretreated waste or melter feed will cause processing problems by forcing the system to operate outside its designed capabilities. The technical basis for these processing boundaries is established in this document.

\section{PNWD-3678 (WTP-RPT-120) - Hanford Immobilized High-Level Waste Canister Drop Testing}

\section{Focus Area: Waste Form Qualification}

Two prototypic immobilized high-level waste (IHLW) canisters were filled with non-radioactive IHLW simulant glass, drop tested from 7 meters, and subsequently examined and leak tested. One canister, HT002, had a 3/8-inch wall thickness; the other canister, HT503, had a 10-gage (0.135-inch) wall thickness. Both canisters passed Waste Acceptance System Requirements Document (WASRD) 4.8.8 requirements. Additionally, the canisters were measured before and after the drop, and overall canister deformations were quantified. Both canisters were axially compressed from the drop, and the diameters of the canisters near the bottom expanded. The 10-gage wall canister had greater deformation than canister with the thicker 3/8-inch wall. Deformations of the 3/8-inch-wall canister were sufficiently small that it was not readily apparent that the canister had been dropped. Deformations of the 10-gage-wall canister were clearly visible. The drop impact formed many horizontal "wrinkles" or bulges in the wall around the lower half of the canister.

Strain circles were added in strips in eight sections around the bottoms of the canister walls and on the reverse-dished canister bottoms. Some of the bulges formed in sections that had been marked by strain circles. The largest strains measured by the strain circles were still low $(<1 \%)$ and could not be statistically differentiated from zero within the accuracy of the method $\pm 3 \%$. Typical strains to failure for $304 \mathrm{~L}$ stainless steel are on the order of $40 \%$. The conclusion from the strain circles is that no area of the canisters was strained close to failure.

\section{PNWD-3677 (WTP-RPT-127) - Overview of the Pulse Jet Mixer Non-Newtonian Scaled Test Program}

\section{Focus Area: Pretreatment}

Pulse jet mixers (PJMs), along with air spargers and steady jets generated by recirculation pumps, have been selected for mixing the HLW slurries in the HLW lag storage (LS) vessels, the HLW blend vessel, and the ultrafiltration feed process (UFP) vessels of the WTP. These mixing technologies are collectively called PJM/hybrid mixing systems. 
This report provides a summary of an extensive effort spanning more than two years to develop and demonstrate pulse jet mixing systems for implementation in the WTP vessels expected to contain non-Newtonian waste slurries.

\section{PNWD-3676 (WTP-RPT-132) - Technical Basis for Predicting Mixing and Flammable Gas Behavior in the Ultrafiltration Feed Process and High-Level Waste Lag Storage Vessels with Non-Newtonian Slurries}

\section{Focus Area: Pretreatment}

The WTP will process and treat radioactive waste that is stored in tanks at the Hanford Site. Pulse jet mixers (PJMs) along with air spargers and steady jets generated by recirculation pumps have been selected to mix the HLW slurries in several tanks: the HLW lag storage (LS) vessels, the HLW blend vessel, and the ultrafiltration feed process (UFP) vessels. These mixing technologies are collectively called PJM/hybrid mixing systems.

The work documented in this report addresses the mixing and gas retention and release tests conducted by PNWD in a half-scale replica of the lag storage (LS) vessel constructed in one of the large tanks in a PNWD test facility. The tank was equipped with 1) PJMs and sparger arrays representative of the LS vessel; 2) auxiliary systems for providing air to the test equipment and injecting hydrogen peroxide and tracer; and 3 ) instrumentation and data acquisition systems to monitor the gas volume fraction, evaluate mixing, and operate the system. The testing used a kaolin/bentonite clay simulant with non-Newtonian rheological properties representative of actual waste slurries. The tests covered the variables and range of operating conditions to demonstrate that design goals can be met. High ( $>30 \mathrm{~Pa}$ ) rheology clay slurry was used as the simulant. Hydrogen peroxide was injected into the slurry and decomposed, generating oxygen gas to simulate the hydrogen gas mixture generation. Test runs were made with PJMs and spargers and spargers operating over only the duty cycles being considered for WTP operation.

This report addresses the mixing and gas retention and release tests conducted in the half-scale replica of the LS vessel. The data obtained from these tests are combined with results from other work to provide a scale-up to WTP conditions. In this report, Section 2 lists the quality assurance requirements under which this work was conducted; Section 3 presents the test configuration; Section 4 describes the test approach and operations; and Section 5 discusses the data analysis and reduction methods. Section 6 presents the results of each of the tests, and Section 7 contains the scale-up to plant conditions. Appendices provide details and supplemental information.

PNWD-3697 (WTP-RPT-134) - Spherical Resorcinol-Formaldehyde Resin Testing for ${ }^{137}$ Cs Removal from Simulated and Actual Hanford Waste Tank 241-AP-101 Diluted Feed (Envelope A) Using Small Column Ion Exchange

\section{Focus Area: Pretreatment}

Spherical resorcinol-formaldehyde (RF) resin in the form of microbeads was selected for additional testing in a lead-lag column format on actual Hanford tank wastes.

The test objectives were to

- Provide sufficient characterization data to evaluate ion exchange performance for spherical RF resin. 
- Perform column testing with AP-101 simulant and AP-101 actual tank waste and determine the loading and elution performance under nominal WTP processing conditions.

This report summarizes the preparation of a dual small-column $(11-\mathrm{mL})$ system with spherical RF resin and the sequential testing with waste simulant AP-101 and actual waste AP-101. Cesium load and elution performances were determined under nominal baseline plant operation conditions for two complete process cycles. The fate of $\mathrm{U}, \mathrm{Pu}, \mathrm{K}$, and other metals was evaluated during the actual AP-101 tank waste test.

\section{PNWD-3699 (WTP-RPT-141) - Waste, Process, and Product Variations and Uncertainties for Waste Treatment Plant IHLW and ILAW}

\section{Focus Area: Waste Form Qualification}

The work documented in this report had two main objectives:

- to gather and summarize the best, currently available WTP estimates of variations and uncertainties that will affect various stages of the WTP IHLW and ILAW vitrification processes

- to quantify variations and uncertainties expected in WTP IHLW and ILAW glass compositions, compliance properties, and processing properties. Quantifying uncertainties in glass compositions and properties involved propagating the applicable uncertainties using a Monte Carlo simulation approach. Estimates of variations in pretreated waste over an HLW or LAW waste type were also included in the Monte Carlo simulations to quantify variations in WTP IHLW and ILAW compositions and properties corresponding to HLW and LAW waste types.

In this report, Section 2 provides a general overview of the IHLW and ILAW vitrification processes, discusses the steps of the IHLW and ILAW process control and compliance strategies, describes the concept of a waste type for HLW and LAW, and identifies the basis for quantifying variations and uncertainties. Section 3 discusses the IHLW and ILAW compositions and properties for which variations and uncertainties are quantified in this report as well as the sources of variation and uncertainties in the HLW and LAW vitrification processes that affect IHLW and ILAW compositions and properties. Section 4 summarizes current estimates of variations and uncertainties associated with several steps of the WTP HLW and LAW vitrification processes. Section 5 describes the computer experiment and Monte Carlo simulation methods used to study the effects of process variation and uncertainties on IHLW and ILAW compositions and properties. Section 6 presents the equations for calculating IHLW and ILAW compositions, and the property-composition models for calculating properties of HLW and LAW melts and glasses as a function of composition (and where applicable, melt temperature). Sections 7 and 8 present the results of the computer experiment and Monte Carlo investigations to quantify variations and uncertainties in IHLW (Section 7) and ILAW (Section 8) compositions and properties. Section 9 summarizes the work and results, and makes recommendations for data needed to support future efforts to better quantify WTP IHLW and ILAW variations and uncertainties. Section 10 discusses how the results in this report meet, or can be used to meet, WTP needs. Section 11 lists the references cited in the text of the report. Appendices provide equations and other information too detailed to include in the main body of the report. 
PNWD-3751 (WTP-RPT-135, Rev. 1) - Small Column Ion Exchange Testing of Spherical Resorcinol-Formaldehyde Resin for ${ }^{137}$ Cs Removal from Pre-Treated Hanford Tank 241-AN-102 Waste (Envelope C)

\section{Focus Area: Pretreatment}

Spherical resorcinol-formaldehyde (RF) resin in the microbead form was selected for testing in a lead-lag column format with actual Hanford tank wastes. This report describes waste pretreatment and ion exchange performance testing with the spherical RF resin.

The test objectives were to

- Provide sufficient characterization data to evaluate ion exchange performance for spherical RF resin.

- Perform column testing with pretreated AN-102 tank waste and determine the loading and elution performance under nominal WTP processing conditions.

\section{PNWD-3763 (WTP-RPT-142) - Laboratory Scale Hydraulic Testing of Spherical Resorcinol Formaldehyde Ion Exchange Resins}

\section{Focus Area: Pretreatment}

This report describes permeability and hydraulic tests on the spherical resorcinol formaldehyde (RF) ion exchange resins generated from scale-up production tests. The primary objectives of the tests were to:

- Measure the bed permeability, particle breakage, and axial and radial pressure resulting from chemical cycling in a bench-scale ion exchange system that simulates full-scale operation and compare these results for the RF resin batches produced by different production conditions, and by different vendors.

- Estimate the full-scale hydraulic performance of the resins to assist in column operation and design.

- Provide a comparison of the hydraulic performance of the candidate RF resins and SuperLig® 644 resin.

- Measure approximate resin chemical performance degradation caused by hydraulic cycling for one chosen resin formulation.

This report documents the testing, results, and analysis associated with the spherical RF hydraulics characterization investigation conducted to provide information for 1) selecting an RF resin production type most likely to meet WTP requirements, 2) confirming that the spherical RF resin can be successfully prepared at scale-up proportions (100-gallon production batches), and 3) refining production specifications based on results of hydraulic testing.

PNWD-3785 (WTP-RPT-143, Rev. 1) - Comparison Testing of Multiple Spherical Resorcinol-Formaldehyde Resins for the River Protection Project-Waste Treatment Plant

\section{Focus Area: Pretreatment}

Preliminary testing with resorcinol-formaldehyde (RF) indicated it had adequate capacity, selectivity, and kinetics to perform in the WTP according to the flowsheet needs. It appeared to have superior elutability and hydraulic performance compared to the existing alternatives: ground gel RF and SuperLig ${ }^{\circledR} 644$ 
(SL-644). Additional testing was needed to study the effects of spherical RF formulation and curing on Cs ion exchange performance. Furthermore, because the spherical RF had historically been produced in bench-scale quantities, testing was needed to also evaluate impacts associated with large-scale production.

PNWD evaluated different formulations of spherical RF resins. The primary test objective was to provide data supporting WTP selection of one formulation of spherical RF resin for scale-up production and plant application. This objective was implemented through sub-objectives, including

- Determine Cs loading and elution behavior as a function of spherical resin formulation

- Compare RF resin performance data with SL-644 resin performance data

- Obtain performance data to support refinement of purchase specifications for RF resin

- Provide performance data using RF resin from the scale-up vendor, and scale-up production.

This report presents the results obtained over 2 years supporting the study and satisfying the task objectives. To this end, 59 spherical RF resins were received, 28 of which were selected for specific performance testing. Resin morphology, physical characteristics, and loading and elution performances are presented.

\section{PNWD-3752 (WTP-RPT-144) - Spherical Resorcinol-Formaldehyde Resin Analysis Following Actual} Hanford Tank Waste Processing

\section{Focus Area: Pretreatment}

Spherical resorcinol-formaldehyde (RF) resin microbeads were tested previously in a lead-lag column system on Hanford tank wastes. One shakedown test was conducted on the system with AP-101 simulated Hanford tank waste followed by two actual tank waste tests, one with AP-101 and one with AN-102.

The test objectives for actual waste processing were to:

- Provide sufficient characterization data to evaluate ion exchange performance for spherical RF resin.

- Perform column testing with AP-101 simulant and two actual waste samples (AP-101 and AN-102) and determine the loading and elution performance under nominal WTP processing conditions in support of commissioning.

- Analyze spent resin to provide information on the retention of metals on the resin.

This report summarizes the spent resin preparation and analysis of spherical RF resin, Lot 5E-370/641, and describes characterization of each resin bed following processing with these wastes.

\section{PNWD-3828 (WTP-RPT-146) - Pulse Jet Mixer Controller and Instrumentation Testing}

\section{Focus Area: Pretreatment}

Many of the vessels in the WTP pretreatment facility will contain pulse jet mixers (PJMs) that will provide some or all of the mixing in the vessels. This technology was selected for use in so-called "black cell" regions of the WTP where maintenance capability will not be available for the operating life of the WTP. PJM technology was selected for use in these regions because it has no moving mechanical parts 
that require maintenance. Vessels with the most concentrated slurries will also be mixed with air spargers and/or steady jets in addition to the mixing provided by the PJMs.

This report contains the results of tests conducted in a half-scale replica of the lag storage vessel in a PNWD test facility. The overall objectives of the work presented in this report are to generate sufficient experimental data to enable BNI to:

- Determine the selected WTP pressure transmitter ability to detect changes in the PJM drive and suction pressures required to properly control PJMs operations and safety functions.

- Determine the effects of jet pump pair supply air line length on pressure change detection, including the equivalent WTP piping configuration.

- If unable to achieve acceptable results with existing control configuration, determine whether the deionized water wash line can be used as an alternative pressure measurement location.

- Determine the sensitivity of the control system to process changes, e.g., level, water, and simulant (rheology and density).

These tests used clay with rheological properties at the upper rheological bound and water that represented the lower rheological bound to provide data on various aspects of the WTP. The tests were conducted with a prototypic PJM control system. Data are provided for assessments of:

- five different pressure transmitters

- various air-line lengths on the suction and drive legs of the PJM air supply

- use of a water flush line as an alternative pressure measurement location

- the sensitivity of the PJM control system to process changes such as tank level and rheology.

Although not an objective, the testing also included obtaining data to evaluate the effect of simulant type and level on the drive and suction times of the PJMs. These data were then used to develop a predictive model to estimate the time to overblow the PJMs.

\section{PNWD-3786 (WTP-RPT-147) - Effect of Anti-Foam Agent on Gas Retention and Release Behavior in Simulated High-Level Waste}

\section{Focus Area: Pretreatment}

This report addresses the reduction and analyses performed by PNWD on data obtained from gas retention and release tests conducted in a small mixing vessel at Savannah River National Laboratory (SRNL) to determine the effect of a selected anti-foam agent on gas retention and release behavior. These tests investigated bubbles representing the gases generated within radioactive waste but did not study the large sparged air bubbles used to enhance mixing in hybrid systems. Because the SRNL test mixing system differs from the PJM/hybrid mixing system, the results are not directly applicable to plant behavior.

This report describes the reduction and analysis of the data from the SRNL tests and presents the results. Section 3 briefly describes the test apparatus and conduct of the tests. The data reduction model is presented in Section 4, and the results are given in Section 5. Conclusions on the value and uncertainty in the waste factor, $\mathrm{F}_{\mathrm{w}}$, and the implications for scaling analysis are presented in Section 6. References are listed in Section 7, and test conditions and analysis results are listed in the appendix. 


\section{PNWD-3824 (WTP-RPT-153) - Estimate of Hanford Waste Insoluble Solid Particle Size and Density Distribution}

\section{Focus Area: Pretreatment}

Because of the variability of the waste, WTP process piping must be capable of transporting a wide range of materials, including Newtonian and non-Newtonian fluids, slurries with differing solids concentrations, and slurries with mechanical and chemical plugging potential. A minimum pipeline velocity is required to avoid mechanical plugging for slurries. This minimum or critical velocity is a function of the solid particle size and morphology, particle density, solid concentration, the carrier fluid, and the pipeline configuration. It is defined as the minimum velocity demarcating flows in which the solids form a bed at the bottom of the pipe to fully suspended flow.

This report addresses the analyses performed by the Particulate Characterization Working Group (PCWG) and Risk Assessment Working Group comprising staff of PNWD, BNI, CH2M HILL Hanford Group, Inc, the U.S. Department of Energy Office of River Protection, and Yasuo Onishi Consulting, LLC, on data obtained from documented Hanford waste analyses to determine a best-estimate insoluble solid particle size and density distribution and its relation to slurry transport.

Section 3 presents the data sources considered and the development of the best-estimate data sets for particle size distributions and solid-phase compounds. The relation of the available data sets with regard to the insoluble solid inventory at Hanford is discussed. Quantifiable uncertainties in the data are elucidated. The particle size and density distribution (PSDD) models are presented in Section 4, and the PSDD results and critical velocity criterion calculations are given in Section 5. Conclusions and recommendations are presented in Section 6, and references are listed in Section 7. Supporting information is included in the appendixes.

\section{PNWD-3827 (WTP-RPT-155) - Assessment of Pulse Tube Mixing for Vessels Containing Non-Newtonian Slurries}

\section{Focus Area: Pretreatment}

Many of the vessels in the WTP pretreatment facility will contain pulse jet mixers (PJMs) that will provide some or all of the mixing in the vessels. This technology was selected for use in so-called "black cell" regions of the WTP where maintenance capability will not be available for the operating life of the WTP. PJM technology was selected because it has no moving mechanical parts that require maintenance. The vessels with the most concentrated slurries will also be mixed with air spargers and/or steady jets in addition to the mixing provided by the PJMs.

This report contains the results of pulse tube mixing tests conducted in a half-scale replica of the lag storage vessel constructed in a PNWD test facility. The tests used clay with rheological properties at the upper rheological bound to assess pulse tube mixing for vessels containing non-Newtonian slurries.

The tests described in this report were directed at evaluating the extent of mixing of the pulse tube contents with stroke lengths ranging from half to full stroke using the following techniques:

- A video camera inserted into the top of one of the pulse tubes was used to observe the behavior of the slurry remaining in the PJM following the drive phase and to determine the height of slurry jet penetration during PJM refill as affected by PJM nozzle refill velocity. 
- A sodium chloride tracer was used to assess the extent of mixing in the pulse tube operated at halfand full stroke as a function of the number of pulses. The tracer was used to also determine the mixing cavern size as a percentage of the slurry volume. 


\section{Contract Reports}

\section{PNNL-13353 (WTP-RPT-002, Rev. 1) - Rheological Studies on Pretreated Feed and Melter Feed from $A W-101$ and $A N-107$}

\section{Focus Area: Vitrification}

The scope of the present work was to obtain physical and rheological data on actual LAW melter feed samples. The physical and rheological properties of the LAW melter feed are important considerations in the selection of the melter feed preparation flowsheet and processing equipment such as mixers, pumps, piping, and sampling. Measurements on actual waste are required to validate and qualify results obtained with simulants. Actual samples from tanks AW-101 and AN-107 were used in this testing. Using this material, a composite was prepared for each of the tanks. Entrained solids were removed from the AW-101 composite by ultrafiltration. The cesium was then removed by ion exchange. Entrained solids, $\mathrm{Sr}$, and transuranics (TRU) were removed from the AN-107 material during the Sr/TRU removal process. Cesium was then removed from the AN-107 material by ion exchange.

Solids concentration, settling rate, density, and shear stress versus shear rate were measured on the samples after evaporation to three sodium concentrations. The same measurements were conducted on the three mixtures from Tank 241-AW-101 after the addition of glass formers. Measurements were repeated on the $\mathrm{AN}-107$ sample at sodium concentrations of 5,6, and $8 \mathrm{M}$ after addition of glass formers. The $8 \mathrm{M} \mathrm{Na}$ AW-101 and AN-107 slurries were mixed for 1 week at a shear rate consistent with that expected in the facility. During this mixing, shear stress versus shear rate was measured after 1 hour, 1 day, and 1 week. A shear stress versus shear rate analysis of this slurry was conducted again after 1 week with no mixing. This report describes the experimental approach and results of the testing.

PNNL-13372 (WTP-RPT-003) - Vitrification and Product Testing of AW-101 and AN-107 Pretreated Waste

\section{Focus Area: Vitrification}

PNNL was contracted to produce and test a vitrified ILAW waste form archived samples of Envelope A and C LAW samples. The primary objective for vitrifying the LAW samples was to generate glass products for subsequent product testing. The work presented in this report is divided into five work elements: 1) Glass Fabrication, 2) Chemical Composition, 3) Radiochemical Composition, 4) Crystalline and Noncrystalline Phase Determination, and 5) Release Rate (Modified PCT). These work elements will help demonstrate WTP ability to satisfy the product requirements concerning, chemical and radionuclide reporting, waste loading, identification and quantification of crystalline and non-crystalline phases, and waste form leachability.

\section{PNNL-13359 (WTP-RPT-004) - Rheological Studies on Pretreated Feed and Melter Feed from C-104 and $A Z-102$}

\section{Focus Area: Vitrification}

PNNL conducted rheological and physical properties testing on actual AZ-102 and C-104 melter feed samples prior to the addition of glass formers and secondary waste products. Analyses were repeated on the C-104 samples following the addition of simulated Sr/TRU secondary waste. Analyses were repeated again following addition of glass formers to both AZ-102 and C-104 samples. Samples from both feeds 
were tested at the target solids concentrations of 5, 15, and $25 \mathrm{wt} \%$. This data on actual waste is required to validate and qualify results obtained with simulants.

This report describes the experimental approach and results of the testing.

\section{PNNL-13452 (WTP-RPT-006) - Vitrification and Product Testing of C-104 and AZ-102 Pretreated Sludge Mixed with Flowsheet Quantities of Secondary Wastes}

\section{Focus Area: Vitrification}

PNNL was contracted to produce and test a vitrified IHLW waste form from two archived samples of Envelope D HLW. The primary objective for vitrifying the HLW samples was to generate glass products for subsequent product testing. The scope of the Vitrification and Product Testing has been divided into eight work elements: 1) Glass Fabrication, 2) Chemical Composition, 3) Radiochemical Composition, 4) Crystalline and Non-crystalline Phase Determination, 5) Release Rate (PCT), 6) Toxicity Characteristic Leaching Procedure (TCLP), 7) Total volatile organic and semi-volatile organic analyses (VOA and SVOA), and 8) WAPS, regulatory, and de-listing testing. The work presented in this report is from only the following five work elements: 1) Glass Fabrication, 2) Chemical Composition, 3) Radiochemical Composition, 4) Crystalline and Non-crystalline Phase Determination, and 5) Release Rate (PCT). These work elements will help demonstrate WTP ability to satisfy the product requirements concerning, chemical and radionuclide reporting, waste loading, identification and quantification of crystalline and non-crystalline phases, and waste form leachability.

\section{PNNL-13364 (WTP-RPT-007) - Inorganic and Radiochemical Analysis of 241-C-104 Tank Waste}

\section{Focus Area: Characterization}

PNNL received $2.3 \mathrm{~kg}$ of Hanford tank waste material from Hanford waste Tank 241-C-104 distributed over 14 sample jars. The contents of all jars were mixed to provide a single composite. The composite was homogenized, and representative subsamples were collected and then separated into supernatant and wet solids fractions. The individual fractions were analyzed for organic, radiochemical, and inorganic composition in support of regulatory activities for the WTP. This report presents the inorganic and radiochemical results. The inorganic and radiochemical analysis results obtained from the as-received materials were used to provide initial characterization information for subsequent process testing and to provide data to support permit application activities. Organic analyte results are reported in WTP-RPT-008.

\section{PNNL-15042 (WTP-RPT-008, Rev. 1) - Organic Analysis of C-104 Tank Waste}

\section{Focus Area: Characterization}

Fourteen jars of waste material from Hanford waste Tank C-104 were received by PNNL. The contents of all jars were mixed to provide a single composite. Each composite was homogenized and representative subsamples extracted for organic, radiochemical, and inorganic regulatory analyses.

The representative subsamples were analyzed for inorganic, radiochemical, and organic analyses for analytes of interest. This report describes the organic analyses and presents the results. The inorganic and radiochemical results are reported in WTP-RPT-007, PNNL-13364 (formerly BNFL-RPT-043). 


\section{PNNL-13354 (WTP-RPT-009 Rev 1) - Inorganic, Radioisotopic, and Organic Analysis of 241-AP-101}

Tank Waste

\section{Focus Area: Characterization}

PNNL received five samples from Hanford waste Tank 241-AP-101, taken at five different depths within the tank. No visible solids or organic layer were observed in the individual samples. Individual sample densities were measured, then the five samples were mixed together to provide a single composite. The composite was homogenized and representative subsamples taken for inorganic, radioisotopic, and organic analysis. All analyses were performed on triplicate subsamples of the composite material.

This report presents the physical observations from AP-101 and individual density measurements from the various tank depths sampled. Precipitate production was evaluated at $10^{\circ} \mathrm{C}$ for seven days on a composite subsample. Also presented are the inorganic, radioisotopic, and organic analytical results for the triplicate AP-101 composite samples. Analyte results are compared to Envelope A limits, where applicable. Data limitations are also described. Quality control, detection limits, and other quality control indicators are discussed relevant to the reporting method. The results of the analyses are used to assess the waste composition relative to the contract limits defined for Envelope A waste.

\section{PNNL-16832 (WTP-RPT-148) - Storage and Aging Effects on Spherical Resorcinol-Formaldehyde Resin Ion Exchange Performance}

\section{Focus Area: Pretreatment}

BNI is evaluating the alternate Cs ion exchange resin, spherical resorcinol-formaldehyde (RF), for use in the WTP. Previous test activities with spherical RF indicate that it has adequate capacity, selectivity, and kinetics to perform in the plant according to the flowsheet needs. It appears to have better elution and hydraulic properties than the existing alternatives: ground-gel RF and SuperLig ${ }^{\circledR} 644$ (SL-644). As of 2007, the spherical RF performance testing had been conducted on freshly manufactured resin (within $\sim 2$ months of manufacture).

The ion exchange resins will be subjected to a storage interval defined as the time from resin manufacture to its use at the WTP. Changes in the resin properties during storage could reduce the capacity of the resin to remove Cs from low-activity waste solutions. Active sites on organic SL-644 resin have been shown to degrade during storage. Additional testing was needed to study the effects of storage conditions and aging on spherical RF ion exchange performance. Variables that could have a significant impact on ion exchange resins during storage include storage temperature, medium, and time.

PNWD was contracted to test the effects of various storage conditions on spherical RF resin. Data obtained from the testing will be used by the WTP operations staff to provide direction for suitable storage conditions and manage the spherical RF resin stock. Storage test conditions included wet and dry resin configurations under nitrogen at three temperatures. Details of the testing are presented in this report. 


\section{PNNL-16611 (WTP-RPT-158) - Assessment of the HV-C2 Stack Sampling Probe Location}

\section{Focus Area: Vitrification}

This report documents a series of tests conducted to assess how the proposed air-monitoring system for the HV-C2 Stack will meet the applicable regulatory criteria regarding the placement of the air-sampling probe. Pacific Northwest National Laboratory conducted the tests on a scale model of the stack as it is currently designed. The objective was to determine the suitability of the probe location before the stack design is finalized. The standard governing the performance of the tests, test methods, and acceptance criteria is ANSI/HPS N13.1-1999, Sampling and Monitoring Releases of Airborne Radioactive Substances from the Stacks and Ducts of Nuclear Facilities.

Based on these tests, the location of the air-sampling probe in the current HV-C2 stack design with dampers meets the requirements of the ANSI/HPS N13.1-1999 standard.

\section{PNNL-16857 (WTP-RPT-154) - Estimate of Hanford Waste Rheology and Settling Behavior}

\section{Focus Area: Pretreatment}

This report addresses the data analyses performed by the Rheology Working Group and Risk Assessment Working Group. This group was composed of staff from PNNL, BNI, CH2M HILL, DOE Office of River Protection, and Yasuo Onishi Consulting, LLC staff. The charter of the working group is the following:

- To define the range of relevant waste properties that might be retrieved and handled at the Hanford Tank Farm.

- To develop relationships that describe the solids settling and rheological behavior ranges for Hanford wastes.

This report presents the data sources considered and the development of the best-estimate data sets for rheological properties. The relationship of the available data sets with regard to the insoluble solid inventory at Hanford is discussed. Quantifiable uncertainties in the data are elucidated. Liquid viscosity, sedimentation, and rheological models are also presented. Conclusions and recommendations are presented based on the models and data available.

\section{PNNL-17170 (WTP-RPT-156) - Results of Large-Scale Testing on Effects of Anti-Foam Agent on Gas Retention and Release}

\section{Focus Area: Pretreatment}

This report describes a test program conducted at PNNL and Savannah River National Laboratory (SRNL) to evaluate holdup and release of gas bubbles generated in waste simulants with an anti-foam agent (AFA). Previous testing in small-scale bubble columns and mixing vessels indicated that adding AFA increased bulk gas retention by more than a factor of 10 . This raised the concern that, if gas retention in the Hanford Waste Treatment and Immobilization Plant (WTP) process vessels was increased by a similar factor, flammable gas safety limits might be exceeded during reduced vessel mixing after a design basis power loss event (DBE). This would require modifications to the WTP (additional air compressors to support more frequent pulse jet mixer and sparger operation), revisions in the flammable gas safety basis, or qualification of an acceptable alternative AFA. 
This test program was undertaken to determine whether AFA has as strong an effect in a large-scale prototypic mixing system as it did in the small-scale tests, and, if it does, to help provide a technical basis for modifying the design and operating strategies to mitigate potential adverse effects. In addition to the large-scale gas retention and release testing, the program included a survey of the mechanisms by which AFA can affect gas retention, large-scale tests to quantify the mitigating effect of mass transfer of dissolved gases to sparged air bubbles, small-scale tests to evaluate the effect of simulant composition on gas retention, small-scale tests to find alternative AFAs, and development of improved models to predict gas retention and release in full-scale WTP process vessels.

This report provides literature summaries, test data results, and gas retention and release model results as specified in the PNNL tasks (SRNL task outcomes are not included). The report describes quality assurance requirements (Section 2) and simulants used in the AFA test series (Section 3). Section 4 describes the effects of gas physical properties on bubble behavior, and Section 5 describes the 1/4-scale test objectives, test stand, and results. Gas retention and release model input parameters and results are presented in Section 6, while Section 7 describes the bounding simulant test results. Section 8 provides overall test results for the 1/4-scale test stand. Cited references are listed in Section 9, and the appendixes contain supporting information.

\section{PNNL-17368 (WTP-RPT-157) - Characterization and Leach Testing for REDOX Sludge and S-Saltcake Actual Waste Sample Composites}

\section{Focus Area: Pretreatment}

A testing program evaluating actual tank waste was subdivided into logical increments. The bulk water-insoluble solid wastes that are anticipated to be delivered to the WTP were identified according to type such that the actual waste testing could be targeted to the relevant categories. Eight broad waste groupings were defined. The actual waste-testing program included homogenizing the samples by group, characterizing the solids and aqueous phases, and performing parametric leaching tests.

This is one in a series of reports that define the characterization, parametric leaching, and filtration testing of actual Hanford tank wastes in support of the WTP pretreatment process development and demonstration. Two of the eight defined waste groups - reduction-oxidation (REDOX) sludge (Group 5) and S-saltcake (Group 6) - are the subjects of this report. The Group 5 waste was anticipated to be high in boehmite, whereas the Group 6 waste was anticipated to contain a significant fraction of water-insoluble chromium. Thus, the focus of the Group 5 testing was on determining the behavior of $\mathrm{Al}$ dissolution during caustic leaching; the focus of the Group 6 testing was on the oxidative removal of Cr. The waste-type definition, archived sample conditions, homogenization activities, characterization (physical, chemical, radioisotope, and crystal habit), and caustic leach behavior (Group 5) and oxidative leach behavior (Group 6) as functions of time, temperature, and hydroxide concentration are discussed in this report.

\section{PNNL-16948 (WTP-RPT-160) - Technical Basis for Scaling Relationships for the Pretreatment Engineering Platform}

\section{Focus Area: Pretreatment}

As part of PNNL's work to resolve technical issues identified for the WTP pretreatment facility, the Pretreatment Engineering Platform (PEP) was designed and constructed as part of a plan to respond to 
issue M12, "Undemonstrated Leaching Processes," raised by the WTP External Flowsheet Review Team (EFRT). The PEP replicates the WTP leaching process using prototypic equipment and control strategies. The approach for scaling PEP performance data to predict WTP performance is critical to the successful resolution of the EFRT issue. This report describes the recommended PEP scaling approach.

\section{PNNL-16794 (WTP-RPT-164) - Process Development for Permanganate Addition During Oxidative Leaching of Hanford Tank Sludge Simulants}

\section{Focus Area: Pretreatment}

Previous BNI-sponsored studies have targeted optimizing the use of sodium permanganate for the selective oxidation of chromium from washed Hanford tank sludges. The recommendation from this previous work was that contact with sodium permanganate in a minimally caustic solution provided maximum $\mathrm{Cr}$ dissolution while minimizing concomitant $\mathrm{Pu}$ dissolution. At the request of BNI, PNNL researchers performed further work on oxidative alkaline leaching. Although the work had several goals, the primary focus of this study was to develop the information needed to propose a method to determine the target $\left[\mathrm{MnO}_{4}{ }^{-}\right]:[\mathrm{Cr}(\mathrm{III})]$ ratio to be used for oxidative alkaline leaching of high $\mathrm{Cr}(\mathrm{III})$ Hanford tank sludges.

The work described in this report was a scoping study that proceeded in several steps:

1. Develop a high Cr-containing Hanford sludge simulant.

2. Develop a defensible basis for determining the minimum oxidant dosage in the oxidation of poorly alkaline soluble $\mathrm{Cr}(\mathrm{III})$ to a more highly alkaline soluble $\mathrm{Cr}(\mathrm{VI})$ using these Hanford tank sludge simulants.

3. Determine the solubility and speciation of $\mathrm{Cr}$ and the solubility of other WTP-specified safety related components.

WTP operations staff will use the data obtained from the testing to develop procedures for permanganate dosing of Hanford tank sludge solids during oxidative leaching.

\section{PNNL-16844 (WTP-RPT-165) - Plutonium Speciation in Support of Oxidative-Leaching Demonstration Test}

\section{Focus Area: Pretreatment}

BNI is evaluating the plutonium speciation in caustic solutions that reasonably represent the process streams from the oxidative-leaching demonstration test. PNNL was contracted to develop a spectrophotometric method to measure plutonium speciation at submicromolar $\left(<10^{-6} \mathrm{M}\right)$ concentrations in alkaline solutions in the presence of chromate and carbonate. Data obtained from the testing will be used to identify the oxidation state of $\mathrm{Pu}(\mathrm{IV}), \mathrm{Pu}(\mathrm{V})$, and $\mathrm{Pu}(\mathrm{VI})$ species, which potentially could exist in caustic leachates.

This report documents PNNL's work to

- Determine the usable spectral range of 5-meter-long Liquid Wave Guide Capillary Cell (LWCC) in alkaline $\mathrm{H}_{2} \mathrm{O}$ and $\mathrm{D}_{2} \mathrm{O}$ media in the presence of chromate. 
- Demonstrate the applicability of LWCC-based optical absorbance spectroscopy for enhanced detection of various oxidation states of plutonium in alkaline media in the visible and near-infrared range of the spectrum.

- Establish spectral signatures of Pu(IV, V, and VI) in weakly to moderately caustic solutions ( $0.1 \mathrm{M}$ to $1 \mathrm{M}$ hydroxide) at low micromolar concentrations of $\mathrm{Pu}$. Determine detection limits of $\mathrm{Pu}$ for the respective oxidation states under these conditions.

- Evaluate the effect of carbonate on the spectral characteristics of $\mathrm{Pu}(\mathrm{IV}, \mathrm{V}$, and VI) in alkaline media and estimate the extent of solubility enhancement of $\mathrm{Pu}(\mathrm{IV})$ in the presence of carbonate at $0.25 \mathrm{M}$ of $\mathrm{NaOD}$.

- Study redox stability of $\mathrm{Pu}(\mathrm{IV})$ and $\mathrm{Pu}(\mathrm{V})$ in the presence of chromate and permanganate in alkaline medium and examine redox-state perturbation upon acidification of initially alkaline solutions.

- Study $\mathrm{Pu}$ leaching from the $\mathrm{Fe}(\mathrm{OH})_{3} / \mathrm{Cr}(\mathrm{OH})_{3} / \mathrm{Pu}(\mathrm{OH})_{4}$ sludge simulant with homogeneously co-precipitated $\mathrm{Pu}$ as a function of time, $\mathrm{Mn}(\mathrm{VII})$-to- $\mathrm{Cr}(\mathrm{III})$ ratio, and hydroxide concentration.

\section{PNNL-17257 (WTP-RPT-173) - Mechanism of Phosphorus Removal from Hanford Tank Sludge by Caustic Leaching}

\section{Focus Area: Pretreatment}

This report describes the test activities associated with two experiments conducted to explore the mechanism by which phosphorus is removed from Hanford tank sludge by caustic leaching. In the first experiment, a series of phosphate salts previously determined to exist in Hanford tank sludge was treated with $3 \mathrm{M} \mathrm{NaOH}$ under conditions prototypic of the actual leaching process to be performed in the WTP. The leachate solution was sampled at selected time intervals and analyzed for the specific metal ion involved ( $\mathrm{Al}, \mathrm{Bi}, \mathrm{Ca}$, or $\mathrm{Cr}$ ) and for $\mathrm{P}$ (total and as phosphate). The solids remaining after completion of the caustic leaching step were analyzed to determine the reaction product.

In the second experiment, the dependence of $\mathrm{P}$ removal from bismuth phosphate was examined as a function of the hydroxide ion concentration. It was anticipated that a plot of $\log$ [phosphate] versus $\log [$ hydroxide] would provide insight into the phosphorus-removal mechanism.

\section{PNNL-17758 (WTP-RPT-180) - Preparation and Characterization of Chemical Plugs Based on Selected Hanford Waste Simulants}

\section{Focus Area: Pretreatment}

This report presents the results of preparation and characterization of chemical plugs based on selected Hanford Site waste simulants. Included are the results of chemical plug bench testing conducted in support of the M1/M6 Flow Loop Chemical Plugging/Unplugging Test. These results support the proposed plug simulants for the chemical plugging/unplugging tests. Based on the available simulant data, a set of simulants was identified that would likely result in chemical plugs. The three types of chemical plugs that were generated and tested in this task consisted of:

- aluminum hydroxide

- sodium aluminosilicate

- $\quad$ sodium aluminum phosphate.

This report documents PNNL's work and analysis as follows: 
- photographing the chemical plugs in the pipes before extrusion to compare the morphology of aged gels with that of fresh gels

- $\quad$ setting up an extrusion apparatus and extruding the chemical plugs

- documenting the qualitative observations on the efforts to remove the chemical plug materials from the pipe sections

- performing x-ray diffraction analysis of extruded gel samples to detect any crystallization of gel during storage

- disposing of the extruded gel as a waste.

\section{PNNL-17231 Rev 1 (WTP-RPT-150 Rev 1) - Pulse Jet Mixer Overblow Testing for Assessment of Loadings During Multiple Overblows}

\section{Focus Area: Pretreatment}

Many of the vessels in the WTP pretreatment facility will contain pulse jet mixers (PJMs) that will provide some or all of the mixing in the vessels. This technology was selected for use in so-called "black cell" regions of the WTP, where maintenance capability will not be available for the operating life of the WTP. PJM technology was selected for use in these regions because it has no moving mechanical parts that require maintenance. The vessels with the most concentrated slurries will also be mixed with air spargers and/or steady jets in addition to the mixing provided by the PJMs.

This report contains the results of single and multiple PJM overblow tests conducted in a large, $\sim 13$-ft-diameter $\times 15$-ft-tall tank in the high bay of a PNNL test facility. These single and multiple PJM overblow tests were conducted using water and a clay simulant to bound the lower and upper rheological properties of the waste streams anticipated to be processed in the WTP. Hydrodynamic pressures were measured at a number of locations in the test vessel using an array of nine pressure sensors and four hydrophones. These measurements were made under normal and limiting vessel operating conditions (i.e., maximum PJM fluid emptying velocity, maximum and minimum vessel contents for PJM operation, and maximum and minimum rheological properties). Test data collected from the PJM overblow tests were provided to BNI for assessing hydrostatic, dynamic, and acoustic pressure loadings on in-tank structures during 1) single overblows, 2) multiple overlapping overblows of two to four PJMs, and 3) simultaneous overblows of pairs of PJMs.

\section{PNNL-17992 (WTP-RPT-166) - Characterization, Leaching, and Filtration Testing for Bismuth Phosphate Sludge (Group 1) and Bismuth Phosphate Saltcake (Group 2) Actual Waste Sample Composites}

\section{Focus Area: Pretreatment}

This report is one in a series that defines the characterization, parametric leaching, and filtration testing of actual Hanford tank wastes in support of the WTP pretreatment process development and demonstration. A testing program developed to evaluate actual tank waste was subdivided into logical increments. The bulk water-insoluble solid wastes that are anticipated to be delivered to the WTP were identified according to type such that the actual waste testing could be targeted to the relevant categories. Eight broad waste groupings were defined. Samples available were identified and obtained for testing. The actual waste-testing program included homogenizing the samples by group, characterizing the solids and aqueous phases, and performing parametric leaching tests. 
Two of the eight defined groups - bismuth phosphate sludge (Group 1) and bismuth phosphate saltcake (Group 2) - are the subjects of this report. The Group 1 waste was anticipated to be high in phosphorus and was implicitly assumed to be present as BiPO4 (however, results presented here indicate that the phosphate in Group 1 is actually present as amorphous iron(III) phosphate). The Group 2 waste was also anticipated to be high in phosphorus, but because of the relatively low bismuth content and higher aluminum content, it was anticipated that the Group 2 waste would contain a mixture of gibbsite, sodium phosphate, and aluminum phosphate. Thus, the focus of the Group 1 testing was on determining the behavior of P removal during caustic leaching, and the focus of the Group 2 testing was on the removal of both $\mathrm{P}$ and Al. This report discusses the waste-type definition, archived sample conditions, homogenization activities, characterization (physical, chemical, radioisotope, and crystal habit), and caustic leaching behavior as functions of time, temperature, and hydroxide concentration.

\section{PNNL-18054 (WTP-RPT-167) - Characterization and Leach Testing for PUREX Cladding Waste Sludge (Group 3) and REDOX Cladding Waste Sludge (Group 4) Actual Waste Sample Composites}

\section{Focus Area: Pretreatment}

This report is one in a series that defines the characterization, parametric leaching, and filtration testing of actual Hanford tank wastes in support of the WTP pretreatment process development and demonstration. A testing program developed to evaluate actual tank waste was subdivided into logical increments. The bulk water-insoluble solid wastes anticipated to be delivered to the WTP were identified according to type such that the actual waste testing could be targeted to the relevant categories. Eight broad waste groupings were defined. Samples available were identified and obtained for testing. The actual waste testing program included homogenizing the samples by group, characterizing the solids and aqueous phases, and performing parametric leaching tests.

Two of the eight defined groups - plutonium-uranium extraction (PUREX) cladding waste sludge (Group 3 , or CWP) and reduction-oxidation (REDOX) cladding waste sludge (Group 4, or CWR) - are the subjects of this report. Both the Group 3 and 4 waste composites were anticipated to be high in gibbsite, requiring caustic leaching. Characterization of the composite Group 3 and Group 4 waste samples confirmed them to be high in gibbsite. The focus of the Group 3 and 4 testing was on determining the behavior of gibbsite during caustic leaching. The waste-type definition, archived sample conditions, homogenization activities, characterization (physical, chemical, radioisotope, and crystal habit), and caustic leaching behavior as functions of time, temperature, and hydroxide concentration, are discussed in this report.

\section{PNNL-18117 (WTP-RPT-168) - Characterization of Filtration Scale-Up Performance}

\section{Focus Area: Pretreatment}

The scale-up performance of sintered stainless steel crossflow filter elements planned for use at the Pretreatment Engineering Platform (PEP) and at WTP were characterized by PNNL. This test report details the results of experimental activities related only to filter scale-up characterization. These tests were performed under the Simulant Testing Program supporting Phase 1 of the demonstration of the pretreatment leaching processes at the PEP.

Scale-up characterization tests employ HLW simulants. The experimental activities examined specific processes from two broad areas of simulant behavior: 1) leaching performance of the boehmite simulant 
as a function of suspending phase chemistry and 2) filtration performance of the blended simulant with respect to filter scale-up and fouling. Bench-scale experiments supporting scale-up testing employed both 2 -foot and 8-foot filters composed of a single stainless steel filter tube 0.5 inch in inner diameter. WTP operations will employ bundles of either 8-foot or 10-foot filter elements, and each bundle will be composed of ten filter tubes of inner diameter 0.5 inch.

This test report is concerned with the results of the filtration performance with respect to scale-up. Test results for boehmite dissolution kinetics and filter fouling are reported elsewhere. The primary goal of scale-up testing was to examine how filter length influenced permeate flux rates. To accomplish this, the existing Cells Unit Filter system, which employs a 2-ft-long, 0.5-in. (inner) diameter sintered stainless steel filter element, was redesigned to accommodate an 8 -ft. sintered stainless steel filter element of the same diameter. Testing was then performed to evaluate the filtration performance of waste simulant slurries. Scale-up testing consisted of two separate series of filtration tests: 1) scale-up axial velocity (AV)/transmembrane pressure (TMP) matrix tests, and 2) scale-up temperature tests. The AV/TMP matrix tests examined filtration performance of two different waste simulant slurries in the 8-ft. Cells Unit Filter system. Waste simulant slurry formulations for the 8-ft. scale-up test was selected to match simulant slurries for which filtration performance had been characterized on the 2-ft crossflow ultrafiltration (CUF) system. For the scale-up temperature tests, the filtration performance at three test temperatures (i.e., $25^{\circ} \mathrm{C}, 35^{\circ} \mathrm{C}$, and $45^{\circ} \mathrm{C}$ ) was determined to evaluate if filter flux versus temperature correlations developed using the 2 -ft filters were also valid for the 8 -ft filters.

\section{PNNL-18119 (WTP-RPT-169) - Characterization, Leaching, and Filtration Testing for Tributyl Phosphate (TBP, Group 7) Actual Waste Sample Composites}

\section{Focus Area: Pretreatment}

This report is one in a series that defines the characterization, parametric leaching, and filtration testing of actual Hanford tank wastes in support of the WTP pretreatment process development and demonstration. A testing program developed to evaluate actual tank waste was subdivided into logical increments. The bulk water-insoluble solid wastes anticipated to be delivered to the WTP were identified according to type such that the actual waste testing could be targeted to the relevant categories. Eight broad waste groupings were defined. Samples available were identified and obtained for testing. The actual waste-testing program included homogenizing the samples by group, characterizing the solids and aqueous phases, and performing parametric leaching tests.

The tributyl phosphate sludge (TBP, Group 7) is the subject of this report. The Group 7 waste was anticipated to be high in phosphorus as well as aluminum in the form of gibbsite. Both are believed to exist in sufficient quantities in the Group 7 waste to address leaching behavior. Thus, the focus of the Group 7 testing was on the removal of both P and Al. The waste-type definition, archived sample conditions, homogenization activities, characterization (physical, chemical, radioisotope, and crystal habit), and caustic leaching behavior as functions of time, temperature, and hydroxide concentration, are discussed in this report. 


\section{PNNL-18120 (WTP-RPT-170) - Characterization, Leaching, and Filtration Testing of Ferrocyanide}

Tank Sludge (Group 8) Actual Waste Composite

\section{Focus Area: Pretreatment}

This is the final report in a series of eight reports summarizing the characterization, leach, and filtration testing of a wide variety of Hanford tank waste sludges. The information generated from this series is intended to supplement the WTP project understanding of actual waste behaviors associated with tank waste sludge processing through the pretreatment portion of the WTP. The work described in this report presents information on a high-iron waste form, specifically the ferrocyanide tank waste sludge. Iron hydroxide has been shown to pose technical challenges during filtration processing; the ferrocyanide tank waste sludge represented a good source of the high-iron matrix to test the filtration processing. Specifically discussed in this report are:

- $\quad$ selection and compositing of tank waste sludge samples

- chemical and physical characterization of the composited tank waste feed (solids and supernatant)

- solids crossflow ultrafiltration testing

- caustic leaching for Al removal

- solids crossflow filtration

- stepwise solids washing using decreasing concentrations of sodium hydroxide with filtration

- chemical and physical characterization of the product solids

- chemical composition of the leaching solution and solids washing solutions.

The effectiveness of each pretreatment process step was evaluated by following mass balances of key components (such as $\mathrm{B}, \mathrm{Cd}, \mathrm{Cr}, \mathrm{Pu}, \mathrm{Ni}, \mathrm{Mn}$, and $\mathrm{Fe}$ ), demonstrating component (Al, $\mathrm{P}, \mathrm{Cr}, \mathrm{Cs}$ ) removal, demonstrating filterability by evaluating filter-flux rates under various processing conditions (transmembrane pressure, crossflow velocities, and $\mathrm{wt} \%$ undissolved solids), filter fouling, and identifying potential issues for WTP.

\section{PNNL-18007 (WTP-RPT-171) - Laboratory Demonstration of the Pretreatment Process with Caustic and Oxidative Leaching Using Actual Hanford Tank Waste}

\section{Focus Area: Pretreatment}

This report describes the bench-scale pretreatment processing of actual tank waste materials through the entire nominal WTP pretreatment flowsheet in an effort to demonstrate the efficacy of the defined leaching processes on actual Hanford tank waste sludge and the potential impacts on downstream pretreatment processing. The test material was a combination of reduction oxidation (REDOX) tank waste composited materials containing aluminum primarily in the form of boehmite and dissolved S-saltcake containing Cr(III)-rich entrained solids. The pretreatment processing steps tested included:

- caustic leaching for Al removal

- solids crossflow filtration through the cells unit filter (CUF)

- stepwise solids washing using decreasing concentrations of sodium hydroxide with filtration through the CUF

- oxidative leaching using sodium permanganate for removing $\mathrm{C}$

- solids filtration with the CUF

- follow-on solids washing and filtration through the CUF

- ion exchange processing for Cs removal 
- evaporation processing of waste stream recycle for volume reduction

- combination of the evaporated product with dissolved saltcake.

The effectiveness of each process step was evaluated by following the mass balance of key components (such as $\mathrm{Al}, \mathrm{B}, \mathrm{Cd}, \mathrm{Cr}, \mathrm{Pu}, \mathrm{Ni}, \mathrm{Mn}$, and $\mathrm{Fe}$ ), demonstrating component (Al, Cr, Cs) removal, demonstrating filterability by evaluating filter flux rates under various processing conditions (transmembrane pressure, crossflow velocities, wt $\%$ undissolved solids, and PSD) and filter fouling, and identifying potential issues for the WTP.

\section{PNNL-17965 (WTP-RPT-172) - Filtration and Leach Testing for REDOX Sludge and S-Saltcake Actual Waste Sample Composites}

\section{Focus Area: Pretreatment}

This report is one in a series that defines the characterization, parametric leaching, and filtration testing of actual Hanford tank wastes in support of the WTP pretreatment process development and demonstration. A testing program developed to evaluate actual tank waste was subdivided into logical increments. The bulk water-insoluble solid wastes anticipated to be delivered to the WTP were identified according to type such that the actual waste testing could be targeted to the relevant categories. Eight broad waste groupings were defined. Samples available were identified and obtained for testing. The actual waste-testing program included:

- $\quad$ homogenizing the archive samples by group as defined in the test plan

- characterizing the homogenized sample groups

- performing parametric leaching testing on each group for compounds of interest

- performing bench-top filtration/leaching tests in the hot cell for each group to simulate filtration and leaching activities if they occurred in the UFP2 vessel of the WTP pretreatment facility.

This report focuses on filtration/leaching tests performed on two of the eight waste composite samples and follow-on parametric tests to support aluminum leaching results from those tests.

The sample groups examined in this report were the reduction-oxidation (REDOX) sludge (Group 5) and S-saltcake (Group 6). The Group 5 waste was anticipated to be high in boehmite, requiring caustic leaching, whereas the Group 6 waste was anticipated to contain a significant fraction of water-insoluble chromium that required oxidative leaching. Project report WTP-RPT-157 describes the homogenization, characterization, and parametric leaching activities before bench-top filtration/leaching testing of these two waste groups. Characterization and parametric data in that report were used to plan two filtration/leaching tests — one test with only Group 5 material and another test that blended Group 5 and Group 6.

\section{PNNL-17639 (WTP-RPT-175) - Deposition Velocities of Newtonian and Non-Newtonian Slurries in Pipelines}

\section{Focus Area: Pretreatment}

The External Flowsheet Review Team (EFRT) expressed concern about the potential for WTP pipe plugging. To evaluate the potential for plugging, PNNL performed critical-velocity tests on several physical simulants to determine if the design approach is conservative. Critical velocity is defined as the 
point at which particles begin to deposit to form a moving bed of particles on the bottom of a straight horizontal pipe during slurry transport operations. The critical velocity depends on the physical properties of the particles, fluid, and system geometry.

This report gives the results from critical-velocity testing and provides an indication of slurry stability as a function of fluid rheological properties and transport conditions that are typical of what the plant will see. The experimental results are compared to the WTP design guide on slurry-transport velocity in an effort to confirm minimum waste-velocity and flushing-velocity requirements as established by calculations and critical-velocity correlations in the design guide.

\section{PNNL-18013 (WTP-RPT-176) - Development and Characterization of Gibbsite Component Simulant}

\section{Focus Area: Pretreatment}

Simulants for boehmite, gibbsite, and filtration are to be developed so they can be used in subsequent bench and integrated testing of the leaching/filtration processes for the WTP. These simulants will then be used to demonstrate the leaching process and to help refine processing conditions that may impact safety basis considerations.

The overall objective of this work was to develop a gibbsite (monoclinic $\mathrm{Al}(\mathrm{OH}) 3$ ) simulant that appropriately mimics the performance of the actual waste gibbsite for use in subsequent testing and to provide a technical performance basis for the use of this simulant. The specific objective of this work was to develop and characterize a gibbsite component simulant for testing of aluminum leaching and provide a basis for the selected simulant. Once the gibbsite simulant was chosen, it was fully tested and characterized.

\section{PNNL-17707 (WTP-RPT-177) - An Approach to Understanding Cohesive Slurry Settling, Mobilization, and Hydrogen Gas Retention in Pulsed Jet Mixed Vessels}

\section{Focus Area: Pretreatment}

Numerous process vessels will hold waste at various stages in the WTP. Some of these vessels have mixing-system requirements to maintain conditions where the accumulation of hydrogen gas stays below acceptable limits, and the mixing within the vessels is sufficient to release hydrogen gas under normal conditions and during off-normal events.

Some of the WTP process streams are slurries of solid particles suspended in Newtonian fluids that behave as non-Newtonian slurries, such as Bingham yield-stress fluids. When these slurries are contained in the process vessels, the particles can settle and become progressively more concentrated toward the bottom of the vessels, depending on the effectiveness of the mixing system. One limiting behavior is a settled layer beneath a particle-free liquid layer. The settled layer, or any region with sufficiently high solids concentration, will exhibit non-Newtonian rheology where it is possible for the settled slurry to behave as a soft solid with a yield stress.

In this report, these slurries are described as settling cohesive slurries. The slurry rheology will also depend on the particle characteristics and their interactions in addition to the solids concentration. If a liquid region of the vessel exists with sufficiently few particles, this region will be Newtonian. As has been observed historically within the Hanford waste tanks, the non-Newtonian region with sufficient settled solids will retain hydrogen gas bubbles unless the mixing system can mobilize the settled solids 
and release the hydrogen gas. Potential inadequate mixing of these vessels was defined as a technical issue and referred to as M3 - Inadequate Design of Mixing Systems—Pulse Jet Mixers (PJMs).

This report defines an approach to understanding cohesive slurry settling, mobilization, and hydrogen gas retention in pulsed jet mixed vessels. An overall approach to the hydrogen gas issue is presented, which illustrates the relationship between waste properties and PJM performance. This approach underscores the importance of quantifying how waste becomes inhomogeneous when mixing stops, the rate that solids settle, and the physical and rheological properties of the stratified waste. Previous work for the Hanford tank farms and the WTP project is being evaluated to determine where sufficient information exists and where needed information is uncertain or absent. A model of PJM performance for mobilizing settling layers is presented, and the performance limits are compared with the estimated strength of settling and stratified layers. The use of the settling and PJM performance models is demonstrated to evaluate how well PJMs mobilize slurries during and after off-normal events with settled or stratified layers and how the settling behavior of a slurry affects the capability of mixing systems to remobilize waste.

\section{PNNL-17973 (WTP-RPT-178) - A Qualitative Investigation of Deposition Velocities of a Non-Newtonian Slurry in Complex Pipeline Geometries}

\section{Focus Area: Pretreatment}

The External Flowsheet Review Team (EFRT) has identified the issues relating to the WTP pipe plugging. To evaluate the potential for plugging, PNNL performed testing to determine critical velocities and velocities for avoiding deposition (VFAD) for the complex WTP piping layout. Critical velocity is defined as the point at which a moving bed of particles begins to form on the pipe bottom during slurry-transport operations, whereas VFAD is defined as the velocity at which no particle deposition occurs.

The report describes the measurement of pressure drops across the fittings of the test pipeline taken with differential pressure transducers, from which the critical velocities and VFADs were determined. A WTP prototype flush system was installed and tested upon the completion of the pressure-drop measurements. Data are provided also for the overflow relief system representing a WTP complex piping geometry with a non-Newtonian slurry. A waste simulant composed of alumina (nominally $50 \mu \mathrm{m}$ in diameter) suspended in a kaolin clay slurry was used for this testing. The target composition of the simulant was $10 \mathrm{vol} \%$ alumina in a suspending medium with a yield stress of $3 \mathrm{~Pa}$.

The results were compared to those reported for which testing was performed for a straight horizontal pipe. The results of the flush test are compared to a WTP design guide in an effort to inspect flushing-velocity requirements.

\section{PNNL-18267 (WTP-RPT-179) - PJM Controller Testing with Prototypic PJM Nozzle Configuration}

\section{Focus Area: Pretreatment}

Many of the vessels in the WTP pretreatment facility will contain pulse jet mixers (PJM) that will provide some or all of the mixing in the vessels. Pulse jet mixers are susceptible to overblows that can generate large hydrodynamic forces, forces that can damage mixing vessels or their internal parts. The probability of an overblow increases if a PJM does not fill completely. The purpose of the testing performed for this 
report was to determine how reliable and repeatable the primary and safety (or backup) PJM control systems are at detecting drive overblows and charge vessel full conditions.

Testing was performed on the ABB 800xA1 and Triconex2 control systems. The objectives of the PJM control system tests were to generate experimental data using a prototypic PJM configuration to

- Establish reliability of the ABB and Triconex control systems to detect overblows.

- Establish ability of the Triconex system to control the PJMs in normal operation.

- Verify the ability to detect charge vessel full using the 4-inch nozzles.

- Determine optimal controller scan rate for overblow detection using the WTP flush line algorithm.

- Collect data for time-to-overblow, given the waste density-gravity-height (rho-g-h) characteristics for each waste type.

- Determine how long it takes for the PJM to refill at high levels of water and clay after an $80 \%-85 \%$ stroke with no suction (gravity re-fill).

\section{PNNL-18048 (WTP-RPT-181) - Filtration and Leach Testing for PUREX Cladding Sludge and REDOX Cladding Sludge Actual Waste Sample Composites}

\section{Focus Area: Pretreatment}

This report is one in a series that defines the characterization, parametric leaching, and filtration testing of actual Hanford tank wastes in support of the WTP pretreatment process development and demonstration. A testing program developed to evaluate actual tank waste was subdivided into logical increments. The bulk water-insoluble solid wastes anticipated to be delivered to the WTP were identified according to type such that the actual waste testing could be targeted to the relevant categories. Eight broad waste groupings were defined. Samples available were identified and obtained for testing. The actual waste-testing program included homogenizing the samples by group, characterizing the solids and aqueous phases, and performing parametric leaching tests.

- homogenizing the archive samples by group as defined in the test plan

- characterizing the homogenized sample groups

- performing parametric leaching testing on each group for compounds of interest

- performing bench-top filtration/leaching tests in the hot cell for each group to simulate filtration and leaching activities if they occurred in the UFP2 vessel of the WTP pretreatment facility.

The report focuses on a filtration/leaching test performed using two of the eight waste composite samples. The sample groups examined were the plutonium-uranium extraction (PUREX) cladding waste sludge (Group 3, or CWP) and reduction-oxidation (REDOX) cladding waste sludge (Group 4, or CWR). Both the Group 3 and 4 waste composites were anticipated to be high in gibbsite, thus requiring caustic leaching.

This test focused on filtration testing of the waste and caustic leaching for aluminum, in the form of gibbsite, and its impact on filtration. The initial sample was diluted with a liquid simulant to simulate the receiving concentration of retrieved tank waste into the UFP2 vessel ( $<10 \mathrm{wt} \%$ undissolved solids).

Filtration testing was performed on the dilute waste sample and dewatered to a higher solids concentration. Filtration testing was then performed on the concentrated slurry. Afterwards, the slurry was caustic leached to remove aluminum present in the undissolved solid present in the waste. The leach was planned to simulate leaching conditions in the UFP2 vessel. During the leach, slurry supernate samples were collected to measure the dissolution rate of aluminum in the waste. After the slurry cooled 
down from the elevated leach temperature, the leach liquor was dewatered from the solids. The remaining slurry was rinsed and dewatered with caustic solutions to remove a majority of the dissolved aluminum from the leached slurry. The concentration of sodium hydroxide in the rinse solutions was high enough to maintain the solubility of the aluminum in the dewatered rinse solutions after dilution of the slurry supernate. Filtration tests were performed on the final slurry to compare to filtration performance before and after caustic leaching.

\section{PNNL-18098 (WTP-RPT-182) - Pulse Jet Mixing Tests With Noncohesive Solids}

\section{Focus Area: Pretreatment}

Results from pulse jet mixing (PJM) tests with noncohesive solids in Newtonian liquid are summarized in this report. The tests were conducted to support the design of mixing systems for the WTP. Tests were conducted at three geometric scales using noncohesive simulants, and the test data were used to develop models predicting two measures of mixing performance for full-scale WTP vessels. The models predict the cloud height (the height to which solids will be lifted by the PJM action) and the critical suspension velocity (the minimum velocity needed to ensure all solids are suspended off the floor, though not fully mixed). From the cloud height, the concentration of solids at the pump inlet can be estimated. The predicted critical suspension velocity for lifting all solids is not precisely the same as the mixing requirement for "disturbing" a sufficient volume of solids, but the values will be similar and closely related. These predictive models were successfully benchmarked against larger scale tests and compared well with results from computational fluid dynamics simulations.

The application of the models to assess mixing in WTP vessels is illustrated in examples for 13 distinct designs and selected operational conditions. The values selected for these examples are not final; thus the estimates of performance should not be interpreted as final conclusions of design adequacy or inadequacy. However, this work does reveal that several vessels may require adjustments to design, operating features, or waste feed properties to ensure confidence in operation. The models described in this report will prove to be valuable engineering tools to evaluate options as designs are finalized for the WTP.

\section{PNNL-18090 (WTP-RPT-183) - Development and Demonstration of Ultrafiltration Simulants}

\section{Focus Area: Pretreatment}

Simulants for boehmite, gibbsite, and filtration are to be developed that can be used in subsequent bench and integrated testing of the leaching/filtration processes for the WTP. These simulants will then be used to demonstrate the leaching process and to help refine processing conditions that may impact safety-basis considerations. This report documents the results of the filtration simulant development. Note that the development of the boehmite and gibbsite simulants is covered in separate reports (WTP-RPT-184 and WTP-RPT-176, respectively). This report also includes the results of the filter fouling with fines particles. 


\section{PNNL-18176, Rev. 1 (WTP-RPT-184 Rev 1) - Development and Characterization of Boehmite Component Simulant}

\section{Focus Area: Pretreatment}

Waste simulants for boehmite, gibbsite, and filtration are to be developed that can be used in subsequent bench and integrated testing of the leaching/filtration processes at the WTP. These simulants will then be used to demonstrate the leaching process and to help refine processing conditions that may impact safety basis considerations.

The overall objective of the work described in this report was to develop a boehmite (orthorhombic $\mathrm{AlOOH}$ ) simulant that appropriately mimics the performance of the actual waste boehmite for use in subsequent testing and to provide a technical performance basis for the use of this simulant. The overall objective of the work from the test plan described in this report was to determine the effect of aluminate and other substantial anions on the solubility of boehmite in caustic solution.

This report documents four tasks. The first task screened a set of available boehmite simulants and downselected one of these simulants for additional testing, based on existing actual waste data. This task is described in Section 2 of this report. The second task was to use the chosen boehmite simulant to assess the impact of process variables on boehmite leaching performance. This task is described in Sections 3 and 4. The next task was to assess the performance of the boehmite simulant when blended with the remainder of the simulant components under prototypic processing conditions. The task is described in Sections 5 and 6 . The final task was to use more recent actual waste boehmite leaching data and to reevaluate the selection of the boehmite component. This task also evaluated some additional boehmite sources that had been identified; its description is in Section 7.

PNNL-18498, Rev. 1 (WTP-RPT-185, Rev. 1) - EFRT M-12 Issue Resolution: Comparison of Filter Performance at PEP and CUF Scale

\section{Focus Area: Pretreatment}

PNNL evaluated the filtration performance of a non-radioactive Hanford waste slurry simulant in both a bench-scale test apparatus (the Cells Unit Filter [CUF]) and the Pretreatment Engineering Platform (PEP). The filter flux results from each test scale were compared to evaluate filter scale-up and to provide a basis for determining filter scale-up issues.

This report describes the results of scale-up testing at the PEP. Comparative filtration tests included two separate low-solids filter conditioning tests and a single high-solids dewatering test conducted in the PEP on a bench-scale filtration system designated for non-radioactive simulant materials (i.e., the cold CUF at the PNNL Applied Process Engineering Laboratory). The low-solids conditioning tests were conducted with an unmodified low-solids simulant slurry feed; the high-solids dewatering test was conducted using a high-solids concentration leached and washed simulant slurry. The results of these tests are compared to support the development of a scale factor for use in the WTP. 


\section{PNNL-18502, Rev. 1 (WTP-RPT-186, Rev. 1) - EFRT M-12 Issue Resolution: Caustic-Leach Rate}

Constants from PEP and Laboratory-Scale Tests

\section{Focus Area: Pretreatment}

The work described in this report addresses caustic leaching under WTP conditions, based on tests performed with a Hanford waste simulant. Because gibbsite leaching kinetics are rapid (gibbsite is expected to be dissolved by the time the final leach temperature is reached), boehmite leach kinetics are the main focus of the caustic-leach tests. Two laboratory-scale caustic-leach tests were performed for each of the PEP runs. For each PEP run, unleached slurry was taken from the PEP caustic-leach vessel for one batch and used as feed for both of the corresponding laboratory-scale tests.

The report summarizes the results from both scales that are related to caustic-leach chemistry to support development of a scale-up factor for the submodels to be used in the G2 model, which predicts WTP operating performance. The scale-up factor takes the form of an adjustment factor for the rate constant in the boehmite leach kinetic equation in the G2 model. These factors provide scale-up from laboratory-scale to PEP-scale and therefore, effectively, to the PTF-scale, because the PEP caustic leach is considered to be prototypic of PTF leach.

\section{PNNL-18499, Rev. 1 (WTP-RPT-187, Rev. 1) - EFRT M-12 Issue Resolution: Solids Washing}

\section{Focus Area: Pretreatment}

This report documents PNNL research and development activities to resolve technical issues identified for the Pretreatment Facility (PTF). The Pretreatment Engineering Platform (PEP) was designed, constructed, and operated as part of a plan to respond to issue M12, "Undemonstrated Leaching Processes," of the External Flowsheet Review Team (EFRT) issue response plan. The PEP is a 1/4.5-scale test platform designed to simulate the WTP pretreatment caustic leaching, oxidative leaching, ultrafiltration solids concentration, and slurry washing processes. The PEP replicates the WTP leaching processes using prototypic equipment and control strategies. The PEP also includes non-prototypic ancillary equipment to support the core processing.

Two operating scenarios are currently being evaluated for the ultrafiltration process (UFP) and leaching operations. The first scenario has caustic leaching performed in the UFP-2 ultrafiltration feed vessels. The second scenario has caustic leaching conducted in the UFP-1 ultrafiltration feed-preparation vessels.

In both scenarios, 19-M sodium hydroxide solution ( $\mathrm{NaOH}$, caustic) is added to the waste slurry in the vessels to leach solid aluminum compounds (e.g., gibbsite, boehmite). Caustic addition is followed by a heating step that uses direct injection of steam to accelerate the leach process. Following the caustic leach, the vessel contents are cooled using vessel cooling jackets and/or external heat exchangers. The main difference between the two scenarios is that for leaching in UFP1, the 19-M NaOH is added to un-concentrated waste slurry ( 3 to $8 \mathrm{wt} \%$ solids), while for leaching in UFP2, the slurry is concentrated to nominally $20 \mathrm{wt} \%$ solids using crossflow ultrafiltration before caustic is added.

The PEP testing program included the following tests with the simulated Hanford tank waste:

- Shakedown/Functional testing: tested process operations (e.g., slurry transfers, steam heating of the vessels and the accumulation of condensate, filter back-pulsing and flushing), process controls (e.g., transmembrane pressure and axial flow velocity in the filter loop), and certain test functions (e.g., in-line slurry sampling accuracy and precision). 
- Integrated Test A: demonstrated integrated processing when caustic leaching $\left(98^{\circ} \mathrm{C}\right)$ is performed in UFP-VSL-00001A/B with the $\mathrm{Cr}$ simulant component added after the post-caustic-leach washing step.

- Integrated Test B: demonstrated integrated processing when the caustic leaching $\left(98^{\circ} \mathrm{C}\right)$ is performed in UFP-VSL-00002A with the Cr simulant component added after the post-caustic-leach washing step.

This report discusses the two different solids washing steps carried out during slurry processing, the first taking place after caustic leaching and the second after oxidative leaching. Results for the solids washing steps from Integrated Tests A and B are included in this report.

\section{PNNL-18500, Rev. 1 (WTP-RPT-188, Rev. 1) - EFRT M-12 Issue Resolution: Comparison of PEP and Bench-Scale Oxidative Leaching Results}

\section{Focus Area: Pretreatment}

This report documents PNNL research and development activities to resolve technical issues identified for the Pretreatment Facility (PTF). The Pretreatment Engineering Platform (PEP) was designed, constructed, and operated as part of a plan to respond to issue M12, "Undemonstrated Leaching Processes," of the External Flowsheet Review Team (EFRT) issue response plan. The PEP is a 1/4.5-scale test platform designed to simulate the WTP pretreatment caustic leaching, oxidative leaching, ultrafiltration solids concentration, and slurry washing processes. The PEP replicates the WTP leaching processes using prototypic equipment and control strategies. The PEP also includes non-prototypic ancillary equipment to support the core processing.

Two operating scenarios are currently being evaluated for the ultrafiltration process (UFP) and leaching operations. The first scenario has caustic leaching performed in the UFP-2 ultrafiltration feed vessels. The second scenario has caustic leaching conducted in the UFP-1 ultrafiltration feed-preparation vessels.

In both scenarios, 19-M sodium hydroxide solution ( $\mathrm{NaOH}$, caustic) is added to the waste slurry in the vessels to leach solid aluminum compounds (e.g., gibbsite, boehmite). Caustic addition is followed by a heating step that uses direct injection of steam to accelerate the leach process. Following the caustic leach, the vessel contents are cooled using vessel cooling jackets and/or external heat exchangers. The main difference between the two scenarios is that for leaching in UFP1, the 19-M NaOH is added to unconcentrated waste slurry ( 3 to $8 \mathrm{wt} \%$ solids), while for leaching in UFP2, the slurry is concentrated to nominally $20 \mathrm{wt} \%$ solids using crossflow ultrafiltration before caustic is added.

For wastes that have significantly high chromium content, the caustic leaching and slurry dewatering is followed by adding sodium permanganate to UFP-VSL-T02A, and the slurry is subjected to oxidative leaching at nominally ambient temperature. The purpose of the oxidative leaching is to selectively oxidize the poorly alkaline-soluble $\mathrm{Cr}$ (III) believed to be the insoluble form in Hanford tank sludge to the much more alkaline-soluble $\mathrm{Cr}(\mathrm{VI})$, e.g., chromate.

The PEP testing program included the following tests with simulated Hanford tank waste:

- Shakedown/Functional testing: tested process operations (e.g., slurry transfers, steam heating of the vessels and the accumulation of condensate, filter back-pulsing and flushing), process controls (e.g., trans-membrane pressure and axial flow velocity in the filter loop), and certain test functions (e.g., in-line slurry sampling accuracy and precision). 
- Integrated Test A: demonstrated integrated processing when caustic leaching $\left(98^{\circ} \mathrm{C}\right)$ is performed in UFP-VSL-00001A/B (PEP equivalent: UFP-VSL-T01A\&B) with the Cr simulant component added after the post-caustic-leach washing step.

- Integrated Test B: demonstrated integrated processing when the caustic leaching $\left(98^{\circ} \mathrm{C}\right)$ was performed in UFP-VSL-00002A (PEP equivalent: UFP-VSL-T02A) with the Cr simulant component added after the post-caustic-leach washing step.

- Integrated Test D: demonstrated integrated processing when the caustic leaching is performed at a lower temperature $\left(85^{\circ} \mathrm{C}\right)$ in UFP-VSL-00002A (PEP equivalent: UFP-VSL-T02A) and with the Cr simulant component added to the initial batch of simulant.

The work described in this report examines the test results related to the efficiency of the oxidative leaching process to support process modeling based on tests performed with a Hanford waste simulant. The tests were completed both at the laboratory-bench scale and in the PEP. This report summarizes the results from both scales that are related to oxidative leaching chemistry to support the development of a scale factor for the submodels to be used in the G2 model, which predicts WTP operating performance. The PEP test data included in this report are limited to those from Integrated Tests A (T01 A/B caustic leaching) and B (T02A caustic leaching). Whether caustic leaching is carried out in UFP-VSL-T01A/B (Test A) or UFP-VSL-T02A (also referred to as UFP-2) (Test B), all oxidative leaching processes occur in vessel UFP-2.

The Results section documents two methods used to calculate leach factors: one method was based on comparison between the initial and final mass of $\mathrm{Cr}$ in the residual solids, and a second method compares the amount of $\mathrm{Cr}$ dissolved in the leachate with the total mass of $\mathrm{Cr}$ present in the initial solids.

\section{PNNL-18316 (WTP-RPT-189) - Deposition Velocities of Non-Newtonian Slurries in Pipelines: Complex Simulant Testing}

\section{Focus Area: Pretreatment}

One of the concerns expressed by the External Flowsheet Review Team (EFRT) is about the potential for pipe plugging at the WTP. To evaluate the potential for plugging, PNWD performed deposition-velocity tests on several physical simulants to determine whether the design approach is conservative. Deposition velocity is defined as the velocity below which particles begin to deposit to form a moving bed of particles on the bottom of a straight horizontal pipe during slurry-transport operations. The deposition velocity depends on the system geometry and the physical properties of the particles and fluid.

This report documents the testing with two types of simulant. The first consists of glass beads with a nominal particle size of $150 \mu \mathrm{m}$ in a kaolin/water slurry. The initial simulant was prepared at a target yield stress of approximately $30 \mathrm{~Pa}$. The yield stress was then reduced, stepwise, via dilution or rheological modifiers, ultimately to a level of $<1 \mathrm{~Pa}$. At each yield-stress step, deposition-velocity testing was performed. Testing over this range of yield-stress bounds the expected rheological operating window of the WTP and allows the results to be compared to stability-map predictions for this system.

The second simulant was a precipitated hydroxide that simulates HLW pretreated sludge from Hanford waste Tank AZ-101. Testing was performed in a manner similar to that for the first simulant over a wide range of yield stresses; however, an additional test of net-positive suction-head required $\left(\mathrm{NPSH}_{\mathrm{R}}\right)$ was performed at each yield stress condition. Unlike the previous simulant, the sizes and densities of the particles that can deposit in the piping are a result of the simulant precipitation process; there is expected to be a complex mixture of particles of various sizes and densities that make it difficult to predict a 
stability map. The objective of the testing was to observe whether behavior consistent with the stability-map concept occurs in complex simulants with mixtures of different sizes and densities.

\section{PNNL-18597, Rev. 1 (WTP-RPT-200, Rev. 1) - PEP Support: Laboratory Scale Leaching and Permeate Stability Tests}

\section{Focus Area: Pretreatment}

This report documents results from a variety of activities related to caustic leaching, oxidative leaching, and permeate precipitation behavior of waste as well as chromium leaching:

- model input boehmite leaching tests

- Pretreatment Engineering Platform (PEP) support leaching tests

- PEP parallel leaching tests

- precipitation study results

- chromium caustic and oxidative leaching tests.

Leaching test activities using the PEP simulant provided input to a boehmite dissolution model and determined the effect of temperature on mass loss during caustic leaching, the reaction rate constant for the boehmite dissolution, and the effect of aeration in enhancing the chromium dissolution during caustic leaching. Other tests were performed in parallel with the PEP tests to support the development of scaling factors for caustic and oxidative leaching. Another study determined if precipitate formed in the wash solution after the caustic leach in the PEP. Finally, the leaching characteristics of different chromium compounds under different conditions were examined to determine the best one to use in further testing.

This report addresses several testing objectives. The experimental methods used in this testing are described in Section 3. The first testing objective provided input to a boehmite dissolution model and is described in Section 4. The model is described in more detail in Appendix A. The objectives of the next tests were to determine the effect of temperature on the solids mass loss during caustic leaching, the reaction rate constant for the boehmite dissolution, and the effect of aeration in enhancing the chromium dissolution during caustic leaching using the PEP simulant. This is described in Section 5. Section 6 describes the tests that were performed in parallel with the PEP tests to support the development of scaling factors for caustic and oxidative leaching. A study was performed to determine if precipitate formed in the wash solution after the caustic leach in the PEP and is described in Section 7. The final task was to examine the leaching characteristics of different chromium compounds under different conditions to determine the best one to use in further testing. This task is described in Section 8 .

\section{PNNL-18673 (WTP-RPT-203) - Bench-Scale Filtration Testing in Support of the Pretreatment Engineering Platform (PEP)}

\section{Focus Area: Pretreatment}

The cold Cells Unit Filter (CUF) and Pretreatment Engineering Platform test systems are designed to simulate WTP waste pretreatment operations. Pretreatment activities involve separating HLW from the LAW liquid stream by crossflow filtration in the pretreatment facility (PTF). The waste solids intended for the HLW stream will undergo caustic and oxidative leaching processes to dissolve and wash out materials that would otherwise limit the HLW loading in the immobilized waste glass. The concentrated 
HLW solids are sequentially caustic leached and oxidative leached during pretreatment. After each leaching step, the HLW solids are concentrated and undergo a wash operation using crossflow filtration.

The work described in this report presents filter flux results using a Hanford tank waste simulant for testing performed in support of PEP operations. The tests were made at the bench-scale on a cold (i.e., designated for nonradioactive simulant test materials) CUF. Each test was connected to operations at the PEP. The complete suite of testing performed can be summarized into the following categories:

- Low-Solids Conditioning and Dewatering Tests \#1 and \#2 - 36-hr low-solids concentration continuous/backpulsed recycle filtration operation followed by slurry dewatering using pre-leach simulant slurry

- High-Solids Dewatering Tests \#1 and \#2 - dewatering operations to achieve high-solids slurries using leached, washed solids

- Post-Caustic-Leach Dewatering and Oxalate Washing Test - investigation of the effect of oxalate super-saturation on permeate flux using slurry from a PEP caustic-leach batch

- Filter Cleaning and Clean Water Flux Testing - data obtained from fouling and cleaning the CUF, both routine and non-routine, including

o PEP process water fouling and cleaning tests

o oxalic acid cleaning after simulant use.

Of these tests, three were intended to provide a basis of comparison to assess scaling effects that exist between PEP engineering-scale filtration operations and CUF bench-scale filtration operations. These tests were:

- Low-Solids Conditioning Test \#1

- Low-Solids Conditioning Test \#2

- High-Solids Dewatering Test \#2.

The low-solids conditioning and dewatering tests were conducted with an unmodified low-solids simulant slurry feed, whereas the high-solids dewatering tests were conducted with a leached and washed simulant slurry. The results are reported herein as information, and no systematic attempt to compare them to analogous testing at PEP has been made.

\section{PNNL-18823 (WTP-RPT-190) - PEP Run Report for Simulant Shakedown/Functional Testing}

\section{Focus Area: Pretreatment}

The Pretreatment Engineering Platform (PEP) was designed, constructed, and operated to simulate the WTP pretreatment caustic leaching, oxidative leaching, ultrafiltration solids concentration, and slurry washing processes to be conducted in the Pretreatment Facility. The PEP, a 1/4.5-scale test platform, replicates the WTP leaching processes using prototypic equipment and control strategies. The PEP also includes nonprototypic ancillary equipment to support the core processing.

Two process flowsheets are currently being evaluated for the ultrafiltration process (UFP) and leaching operations. The baseline flowsheet has caustic leaching conducted in the UFP-1 ultrafiltration feed preparation vessels (i.e., vessels UFP-VSL-T01A and B in the PEP; vessels UFP-VSL-00001A and B [UFP-1] in the WTP PTF). The alternative scenario has caustic leaching performed in the UFP-2 ultrafiltration feed vessels (i.e., vessel UFP-VSL-T02A in the PEP and vessels UFP-VSL-00002A and B [UFP-2] in the WTP PTF). 
With both flowsheets, 19-M sodium hydroxide solution ( $\mathrm{NaOH}$, caustic) is added to the waste slurry to leach solid aluminum compounds (e.g., gibbsite, boehmite). Caustic addition is followed by a heating step that uses direct injection of steam to accelerate the leaching process. Following the caustic-leach, the vessel contents are cooled using vessel cooling jackets and/or external heat exchangers. The main difference between the two scenarios is that for leaching in UFP-1, the 19-M NaOH is added to unconcentrated waste slurry (3- to 8-wt\% solids), while for leaching in UFP-2, the slurry is concentrated to nominally 20 -wt $\%$ solids using crossflow ultrafiltration before adding caustic. After cooling, the leached slurry is concentrated and washed with an aqueous solution of $0.01-\mathrm{M} \mathrm{NaOH}$ (referred to as inhibited water) to remove soluble salts. If the resulting waste solids remain high in chromium, sodium permanganate reagent is added, and the slurry is circulated to oxidize and dissolve the chromium solids. Following the oxidative leaching of chromium-containing solids, the slurry is washed to remove the dissolved chromium and concentrated.

The PEP testing program, conducted using a waste simulant, included shakedown/functional testing, which tested process operations (e.g., slurry transfers, steam heating of the vessels and the accumulation of condensate, filter backpulsing , and flushing), process controls (e.g., transmembrane pressure and axial flow velocity in the filter loop), and certain test functions (e.g., in-line slurry sampling accuracy and precision).

The work described in this report includes a narrative of the shakedown/functional test and the data obtained during the test. The PEP data will be used by WTP along with laboratory-scale data and appropriate application of scaling to improve the WTP plant models used to predict plant operating performance.

\section{PNNL-18755 (WTP-RPT-191) - PEP Run Report for Integrated Test A; Caustic Leaching in UFP-VSL-T01A, Oxidative Leaching in UFP-VSL-T02A}

\section{Focus Area: Pretreatment}

The Pretreatment Engineering Platform (PEP) was designed, constructed, and operated to simulate the WTP pretreatment caustic leaching, oxidative leaching, ultrafiltration solids concentration, and slurry washing processes to be conducted in the Pretreatment Facility. The PEP, a 1/4.5-scale test platform, replicates the WTP leaching processes using prototypic equipment and control strategies. The PEP also includes nonprototypic ancillary equipment to support the core processing.

Two process flowsheets are currently being evaluated for the ultrafiltration process (UFP) and leaching operations. The baseline flowsheet has caustic leaching conducted in the UFP-1 ultrafiltration feed preparation vessels (i.e., vessels UFP-VSL-T01A and B in the PEP; vessels UFP-VSL-00001A and B [UFP-1] in the WTP PTF). The alternative scenario has caustic leaching performed in the UFP-2 ultrafiltration feed vessels (i.e., vessel UFP-VSL-T02A in the PEP and vessels UFP-VSL-00002A and B [UFP-2] in the WTP PTF).

With both flowsheets, 19-M sodium hydroxide solution $(\mathrm{NaOH}$, caustic) is added to the waste slurry to leach solid aluminum compounds (e.g., gibbsite, boehmite). Caustic addition is followed by a heating step that uses direct injection of steam to accelerate the leaching process. Following the caustic leach, the vessel contents are cooled using vessel cooling jackets and/or external heat exchangers. The main difference between the two scenarios is that for leaching in UFP-1, the $19-\mathrm{M} \mathrm{NaOH}$ is added to unconcentrated waste slurry ( 3 to 8 -wt\% solids), while for leaching in UFP-2, the slurry is concentrated to nominally 20 -wt $\%$ solids using crossflow ultrafiltration before adding caustic. After cooling, the leached 
slurry is concentrated and washed with an aqueous solution of $0.01-\mathrm{M} \mathrm{NaOH}$ (referred to as inhibited water) to remove soluble salts. If the resulting waste solids remain high in chromium, sodium permanganate reagent is added, and the slurry is circulated to oxidize and dissolve the chromium solids. Following the oxidative leaching of chromium-containing solids, the slurry is washed to remove the dissolved chromium and concentrated.

The PEP testing program, conducted with a waste simulant, included Integrated Test A. This test demonstrated integrated processing when caustic leaching $\left(98^{\circ} \mathrm{C}\right)$ is performed in UFP-VSL-00001A/B with the chromium simulant component added after the post-caustic-leach washing step.

The work described in this report includes a narrative of the conduct of Integrated Test A and the data obtained during the test. This report summarizes test operations and difficulties encountered during Integrated Test A. For test summary operations for the other tests, refer to WTP-RPT-190 for Shakedown/Functional Testing, WTP-RPT-192 for Integrated Test B, and WTP-RPT-193 for Integrated Test D.

This report includes only very limited data analysis. Supporting data files have been supplied on transportable hard drives because of the large amount of data.

\section{PNNL-18723 (WTP-RPT-192) - Pretreatment Engineering Platform (PEP) Integrated Test B Run Report-Caustic and Oxidative Leaching in UFP-VSL-T02A}

\section{Focus Area: Pretreatment}

The Pretreatment Engineering Platform (PEP) was designed, constructed, and operated to simulate the WTP pretreatment caustic leaching, oxidative leaching, ultrafiltration solids concentration, and slurry washing processes to be conducted in the Pretreatment Facility. The PEP, a 1/4.5-scale test platform, replicates the WTP leaching processes using prototypic equipment and control strategies. The PEP also includes nonprototypic ancillary equipment to support the core processing.

Two process flowsheets are currently being evaluated for the ultrafiltration process (UFP) and leaching operations. The baseline flowsheet has caustic leaching conducted in the UFP-1 ultrafiltration feed preparation vessels (i.e., vessels UFP-VSL-T01A and B in the PEP; vessels UFP-VSL-00001A and B [UFP-1] in the WTP PTF). The alternative scenario has caustic leaching performed in the UFP-2 ultrafiltration feed vessels (i.e., vessel UFP-VSL-T02A in the PEP and vessels UFP-VSL-00002A and B [UFP-2] in the WTP PTF).

With both flowsheets, 19-M sodium hydroxide solution ( $\mathrm{NaOH}$, caustic) is added to the waste slurry to leach solid aluminum compounds (e.g., gibbsite, boehmite). Caustic addition is followed by a heating step that uses direct injection of steam to accelerate the leaching process. Following the caustic leach, the vessel contents are cooled using vessel cooling jackets and/or external heat exchangers. The main difference between the two scenarios is that for leaching in UFP-1, the $19-\mathrm{M} \mathrm{NaOH}$ is added to unconcentrated waste slurry ( 3 to 8 -wt $\%$ solids), while for leaching in UFP-2, the slurry is concentrated to nominally 20 -wt $\%$ solids using crossflow ultrafiltration before adding caustic. After cooling, the leached slurry is concentrated and washed with an aqueous solution of $0.01-\mathrm{M} \mathrm{NaOH}$ (referred to as inhibited water) to remove soluble salts. If the resulting waste solids remain high in chromium, sodium permanganate reagent is added, and the slurry is circulated to oxidize and dissolve the chromium solids. Following the oxidative leaching of chromium-containing solids, the slurry is washed to remove the dissolved chromium and concentrated. 
The PEP testing program, conducted with a waste simulant, included Integrated Test B. Integrated Test B Demonstrated integrated processing when the caustic leaching $\left(98^{\circ} \mathrm{C}\right)$ is performed in UFP-VSL-00002A with the chromium simulant component added after the post-caustic-leach washing step.

This report focuses on Integrated Test B and summarizes test conduct and results; it includes only very limited data analysis. It is one in a series of reports that summarize Phase 1 results from testing in the PEP housed by PNNL.

\section{PNNL-18741 (WTP-RPT-193) - PEP Integrated Test D Run Report-Caustic and Oxidative Leaching in UFP-VSL-T02A}

\section{Focus Area: Pretreatment}

The Pretreatment Engineering Platform (PEP) was designed, constructed, and operated to simulate the WTP pretreatment caustic leaching, oxidative leaching, ultrafiltration solids concentration, and slurry washing processes to be conducted in the Pretreatment Facility. The PEP, a 1/4.5-scale test platform, replicates the WTP leaching processes using prototypic equipment and control strategies. The PEP also includes nonprototypic ancillary equipment to support the core processing.

Two process flowsheets are currently being evaluated for the ultrafiltration process (UFP) and leaching operations. The baseline flowsheet has caustic leaching conducted in the UFP-1 ultrafiltration feed preparation vessels (i.e., vessels UFP-VSL-T01A and B in the PEP; vessels UFP-VSL-00001A and B [UFP-1] in the WTP PTF). The alternative scenario has caustic leaching performed in the UFP-2 ultrafiltration feed vessels (i.e., vessel UFP-VSL-T02A in the PEP and vessels UFP-VSL-00002A and B [UFP-2] in the WTP PTF).

With both flowsheets, 19-M sodium hydroxide solution $(\mathrm{NaOH}$, caustic) is added to the waste slurry to leach solid aluminum compounds (e.g., gibbsite, boehmite). Caustic addition is followed by a heating step that uses direct injection of steam to accelerate the leaching process. Following the caustic leach, the vessel contents are cooled using vessel cooling jackets and/or external heat exchangers. The main difference between the two scenarios is that for leaching in UFP-1, the $19-\mathrm{M} \mathrm{NaOH}$ is added to unconcentrated waste slurry ( 3 to 8 -wt $\%$ solids), while for leaching in UFP-2, the slurry is concentrated to nominally 20 -wt $\%$ solids using crossflow ultrafiltration before adding caustic. After cooling, the leached slurry is concentrated and washed with an aqueous solution of $0.01-\mathrm{M} \mathrm{NaOH}$ (referred to as inhibited water) to remove soluble salts. If the resulting waste solids remain high in chromium, sodium permanganate reagent is added, and the slurry is circulated to oxidize and dissolve the chromium solids. Following the oxidative leaching of chromium-containing solids, the slurry is washed to remove the dissolved chromium and concentrated.

The PEP testing program, conducted with a waste simulant, included Integrated Test D. Integrated Test $\mathrm{D}$ demonstrated integrated processing when the caustic leaching is performed at a lower temperature $\left(85^{\circ} \mathrm{C}\right)$ in UFP-VSL-00002A and with the chromium simulant component added to the initial batch of simulant.

This report focuses on Integrated Test B and summarizes test conduct and results; it includes only very limited data analysis. It is one in a series of reports that summarize Phase 1 results from testing in the PEP housed by PNNL. 


\section{PNNL-18894 (WTP-RPT-197) - Pretreatment Engineering Platform Phase 1 Final Test Report}

\section{Focus Area: Pretreatment}

In 2005, the DOE Office of River Protection (ORP) and the WTP prime contractor BNI commissioned an External Flowsheet Review Team (EFRT) to critically review the WTP flowsheets. A major issue identified by the EFRT was that the pretreatment leaching and filtration processes had not been demonstrated at a meaningful scale. Testing had been limited to laboratory scale (bench scale). Testing at the engineering scale was considered necessary to confirm the process design and provide improved projections of system capacity.

A multi-part issue response plan was prepared to address this issue. The most prominent part of the issue response plan was engineering-scale testing of the leaching and filtration system in the Pretreatment Engineering Platform (PEP). The PEP is a 1/4.5-scale facility designed, constructed, and operated to test the integrated leaching and ultrafiltration processes being deployed in the WTP. The PEP replicates the WTP leaching processes using prototypic equipment and control strategies. The PEP also includes nonprototypic ancillary equipment to support the systems used to leach and filter slurries. The testing approach used a nonradioactive aqueous slurry simulant to demonstrate the unit operations of caustic and oxidative leaching, ultrafiltration solids concentration, and solids washing.

Two process flowsheets are currently being evaluated for the ultrafiltration process (UFP) and leaching operations. The baseline flowsheet has caustic leaching conducted in the UFP-1 ultrafiltration feed preparation vessels (i.e., vessels UFP-VSL-T01A and B in the PEP; vessels UFP-VSL-00001A and B [UFP-1] in the WTP Pretreatment Facility [PTF]). The alternative scenario has caustic leaching performed in the UFP-2 ultrafiltration feed vessels (i.e., vessel UFP-VSL-T02A in the PEP and vessels UFP-VSL-00002A and B [UFP-2] in the WTP PTF).

With both flowsheets, 19-M sodium hydroxide solution ( $\mathrm{NaOH}$, caustic) is added to the waste slurry to leach solid aluminum compounds (e.g., gibbsite, boehmite). Caustic addition is followed by a heating step that uses direct injection of steam to accelerate the leaching process. Following the caustic-leach, the vessel contents are cooled using vessel cooling jackets and/or external heat exchangers. The main difference between the two scenarios is that for leaching in UFP-1, the $19-\mathrm{M} \mathrm{NaOH}$ is added to unconcentrated waste slurry (3- to 8-wt\% solids), while for leaching in UFP-2, the slurry is concentrated to nominally 20 -wt $\%$ solids using crossflow ultrafiltration before adding caustic. After cooling, the leached slurry is concentrated and washed with an aqueous solution of $0.01-\mathrm{M} \mathrm{NaOH}$ (referred to as inhibited water) to remove soluble salts. If the resulting waste solids remain high in chromium, sodium permanganate reagent is added, and the slurry is circulated to oxidize and dissolve the chromium solids. Following the oxidative leaching of chromium-containing solids, the slurry is washed to remove the dissolved chromium and concentrated.

The PEP testing program included the following tests with simulated Hanford tank waste:

- Shakedown/Functional testing: tested process operations (e.g., slurry transfers, steam heating of the vessels and the accumulation of condensate, filter backpulsing and flushing), process controls (e.g., transmembrane pressure and axial flow velocity in the filter-loop), and certain test functions (e.g., in-line slurry sampling accuracy and precision).

- Integrated Test A: demonstrated integrated processing when caustic leaching $\left(98^{\circ} \mathrm{C}\right)$ is performed in UFP-VSL-00001A/B with the Cr simulant component added after the post-caustic-leach washing step. 
- Integrated Test B: demonstrated integrated processing when the caustic leaching $\left(98^{\circ} \mathrm{C}\right)$ is performed in UFP-VSL-00002A with the Cr simulant component added after the post-caustic-leach washing step.

- Integrated Test D: demonstrated integrated processing when the caustic leaching is performed at a lower temperature $\left(85^{\circ} \mathrm{C}\right)$ in UFP-VSL-00002A and with the $\mathrm{Cr}$ simulant component added to the initial batch of simulant.

This report summarizes the critical information gained during the Shakedown and Functional Testing, Integrated Test A, Integrated Test B, and Integrated Test D. Laboratory-scale filtration and caustic and oxidative leaching tests are also summarized. The objectives, success criteria, and research and technology conditions defined in the test plan are discussed in the tables in this summary. A summary of conclusions from the overall PEP testing program is provided in Section 14.

\section{PNNL-18701 (WTP-RPT-201) - Simulated Waste for Leaching and Filtration Studies-Laboratory Preparation Procedure}

\section{Focus Area: Pretreatment}

This report discusses the simulant preparation procedure for producing multi-component simulants for leaching and filtration studies, including development and comparison activities. A fundamental premise is that this approach would allow blending of the different components to simulate a wide variety of feeds to be treated in the WTP. For example, a given feed from the planned feed vector could be selected, and the appropriate components would then be blended to achieve a representation of that particular feed. Using the blending of component simulants allows the representation of a much broader spectrum of potential feeds to the Pretreatment Engineering Platform (PEP).

The overall objective of the work described in this report was to develop, validate, and prepare a simulant preparation procedure. Use of actual waste in PNNL's PEP is not possible due to safety, cost, and volume considerations. Therefore, a simulant that was simple and chemically benign enough to assemble needed to be developed for use in the PEP testing. This simulant would be capable of covering a wide range of waste compositions and could be disposed of at a reasonable cost yet still be a realistic test material for PEP evaluation.

The simulant that was developed and is discussed in this report consists of a simplified version of actual waste sludge, which includes elements found in most wastes with additions of aluminum compounds, chromium oxide, phosphate, and sulfate as needed to match a given waste type. Hence, this waste simulant contains some of each of the waste components (i.e., aluminum compounds) that WTP is planning to remove from the high-level waste stream. As such, the simulant can be readily shimmed to target compositions needed for PEP testing while maintaining similar chemical and physical properties to the actual waste to be treated in the plant.

This report addresses a portion of the work required to demonstrate the caustic leaching and oxidative leaching processes at greater than bench-scale size. Filtration and leaching simulants were developed that can be used in the laboratory and in the integrated demonstration testing. This report provides important data needed to prepare a blended simulant to meet those performance targets. 


\section{PNNL-18678 (WTP-RPT-204) - Scale-Up, Production, and Procurement of PEP Simulants}

\section{Focus Area: Pretreatment}

The Pretreatment Engineering Platform (PEP) is a 1/4.5-scale test platform designed to simulate the WTP pretreatment caustic leaching, oxidative leaching, ultrafiltration solids concentration, and slurry washing processes. The PEP replicates the WTP leaching processes using prototypic equipment and control strategies. The PEP also includes non-prototypic ancillary equipment to support the core processing.

To accomplish the required testing at the PEP, PNNL subcontracted NOAH Technologies Corporation of San Antonio, Texas (NOAH) through a competitive bidding process to prepare and deliver simulated feed (PEP Simulant) and the chromium simulant component (chromium oxyhydroxide) for use at the PEP. To minimize project cost and schedule risk, PNNL, in close collaboration with WTP staff, made sure that the prepared simulant met project requirements by contracting NOAH to prepare increasingly larger batches of the PEP Simulant (scale-up).

The first two PEP Simulant batch preparations (15-gal and 250-gal) were prepared to confirm that the recipes developed in the laboratory could be used to produce the large amounts of PEP Simulant needed in the PEP. Secondarily, these scale-up preparations provided the preparer with valuable experience implementing the recipes. This report summarizes the work carried out to provide an acceptable quality simulant feed and simulant components for use in the PEP through scale-up from laboratory scale to 1200- to 3500-gal batches and the lessons learned along the way.

\section{PNNL-18876 (WTP-RPT-205) - Laboratory Tests on Post-Filtration Precipitation in the WTP Pretreatment Process}

\section{Focus Area: Pretreatment}

Significant post-filtration precipitation was observed in the post-caustic leachate and wash solutions while the leaching and ultrafiltration processes were demonstrated in the Pretreatment Engineering Platform (PEP). Precipitation in these streams could lead to precipitates accumulating in filtrate receipt vessels and in the feed to ion exchange columns. Post-filtration precipitation in the feed to the ion-exchange column, if it occurs, will severely impact the operability of the unit and the pretreatment process. Therefore, a laboratory study was carried out to develop an understanding of the phenomenon of post-filtration precipitation and the help in identifying the pathways to mitigate it.

This report summarizes the results from the laboratory studies to support this objective. The test objective was divided into several tasks to develop an understanding of the post-filtration-precipitation phenomenon. The post-filtration precipitate mineralogy, precipitate phase compositions, and solution saturation compositions in the post-caustic leachate and wash solution samples from Integrated Test A are described in Section 3. The rate at which the anions approach equilibrium solution composition upon cooling in the post-caustic-leach slurry is discussed in Section 4 of this report. Section 5 identifies and characterizes the precipitates formed in the post-caustic leachate solution through controlled laboratory experiments. Section 6 describes the potential to redissolve the post-filtration precipitate in Integrated Tests A, B, and D in the PEP through dilution with water. Determination of solution supersaturation in the post-caustic-leach filtrate during the dewatering and washing period based on the samples collected during Integrated Test B in the PEP is described in Section 7. The effects of blending during the post-caustic-leach dewatering and wash periods in Integrated Test B in the PEP are discussed in Section 8 . 
PNNL-19015 (WTP-RPT-206) - Effect of Antifoam Agent on Oxidative Leaching of Hanford Tank Sludge Simulant

\section{Focus Area: Pretreatment}

Oxidative leaching of simulant tank waste using permanganate as the oxidant in $0.25 \mathrm{M} \mathrm{NaOH}$ solutions reduces the chromium content of the sludge. An antifoam agent (AFA) is added to the waste treatment process to reduce foaming. The AFA, Dow Corning Q2-3183A, is a surface-active polymer that consists of polypropylene glycol, polydimethylsiloxane, octylphenoxy polyethoxy ethanol, treated silica, and polyether polyol. Some of the WTP) waste slurries contain high concentrations of undissolved solids that would exhibit undesirable behavior without AFA addition.

The work described in this report involved testing a $\mathrm{Cr}$ (III)-containing simulant for conversion from $\mathrm{Cr}$ (III) to $\mathrm{Cr}$ (VI) by contact with alkaline solutions containing permanganate in the presence of AFA. The ultimate goal of this work was to determine if the amount of permanganate required to oxidize $\mathrm{Cr}$ (III) needs to be adjusted for the presence of AFA because some of the permanganate may be consumed by oxidizing the organic material in the AFA. 



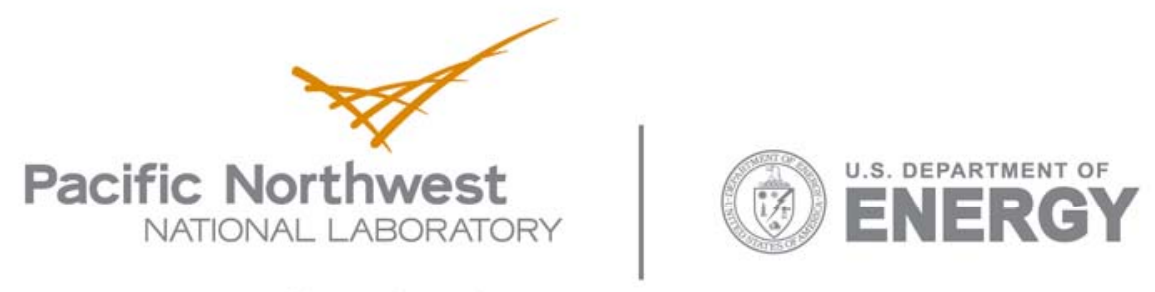

902 Battelle Boulevard

P.O. Box 999

Richland, WA 99352

1-888-375-PNNL (7665)

www.pnl.gov 